\title{
Molecular mechanisms of the cytokine-dependent induction of the heme oxygenase-1 gene: in vivo and in vitro studies
}

\author{
Dissertation \\ zur Erlangung des Doktorgrades \\ der Mathematisch-Naturwissenschaftlichen Fakultäten \\ der Georg-August-Universität zu Göttingen
}

vorgelegt von

Kyrylo Tron

aus Zhytomyr, Ukraine

Göttingen 2004 
D7

Referent:

Prof. Dr. Rüdiger Hardeland

Korreferent:

Prof. Dr. Kurt von Figura

Tag der mündlichen Prüfung: $\quad 30.06 .2004$ 


\section{Contents}

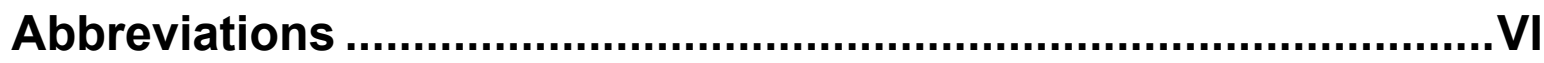

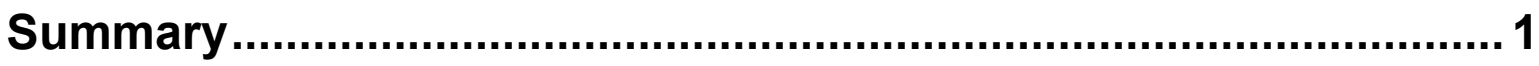

1. Introduction ........................................................................ 3

1.1 Heme: an essential catalyst of biological oxidation processes .............. 3

1.2 Heme oxygenases (HO), key enzymes for heme catabolism................... 3

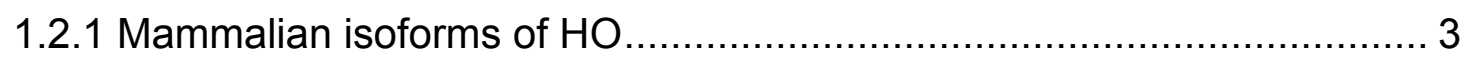

1.2.2 The oxidative cleavage of heme by HO-1 ….................................. 4

1.2.3 HO-1, the "inducible" isozyme among the HO family ............................ 6

1.3 The biological significance of the $\mathrm{HO}$ system ..................................... 7

1.3.1 Carbon monoxide (CO), a second messenger gas ............................. 7

1.3.2 Biliverdin and bilirubin as potent antioxidants .................................... 9

1.3.3 "Free" iron: a regulator of mRNAs expression................................... 10

1.4 Acute phase response (APR) and its mediators................................... 11

1.4.1 APR: a systemic reaction of an organism to maintain its integrity ......... 11

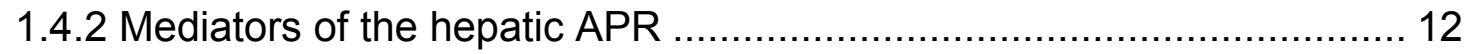

1.4.3 Acute phase proteins and their regulation ....................................... 13

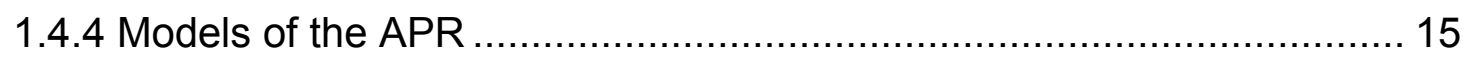

Animal models of the APR ........................................................... 15

In vitro models of the APR ......................................................... 15

1.5 Aim of the study ............................................................................. 16

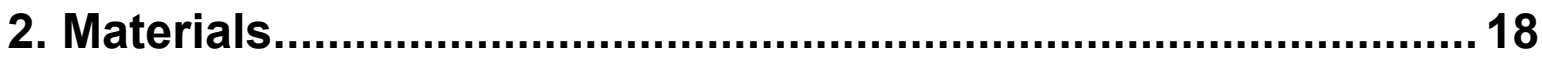

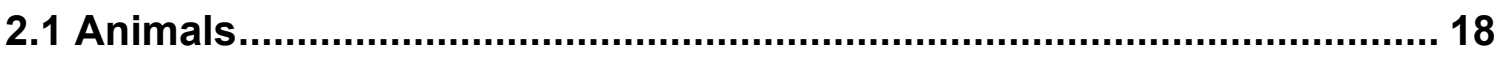

2.2 Bacterial strain, vectors and plasmid constructs ................................ 18

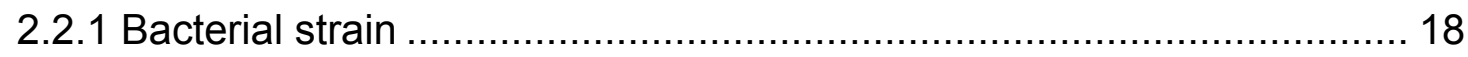

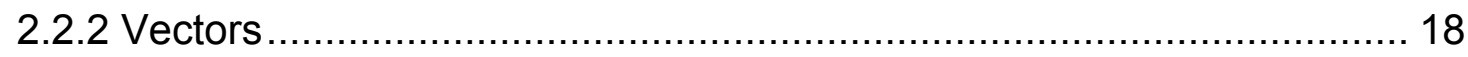

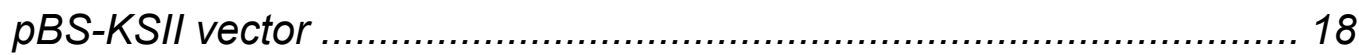

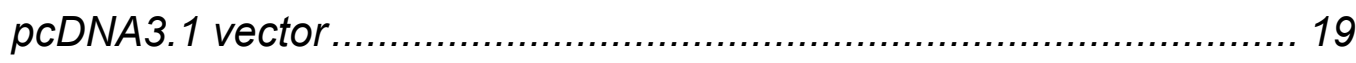

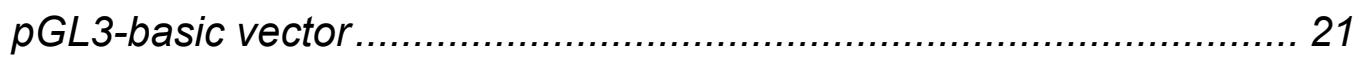

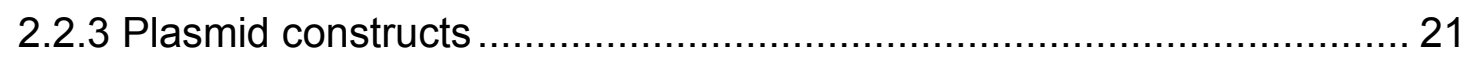

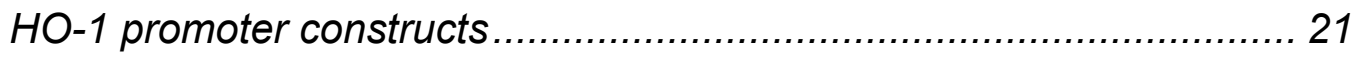

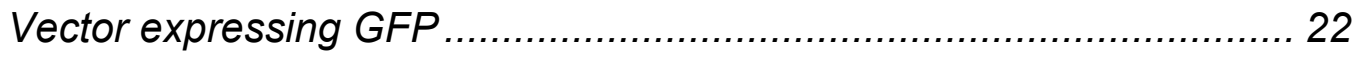

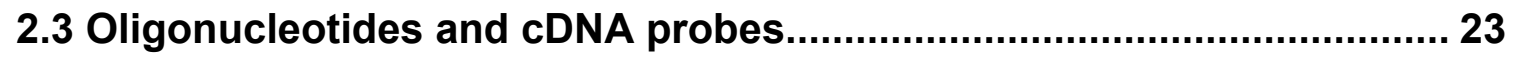




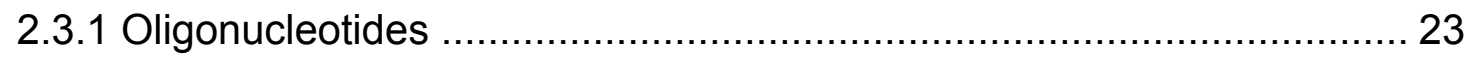

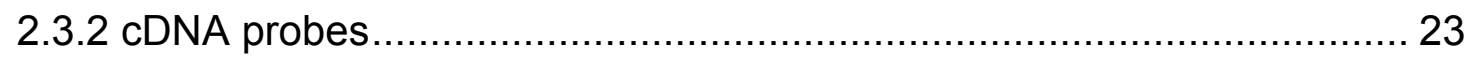

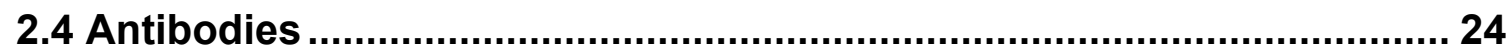

2.5 Proteins, enzymes and protein standards............................................ 25

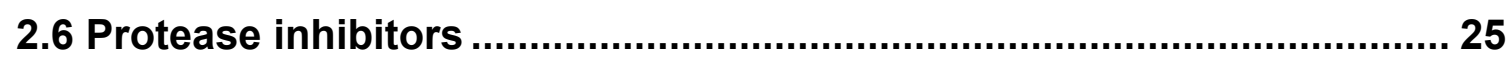

2.7 Detection, purification and synthesis systems (kits) ............................ 25

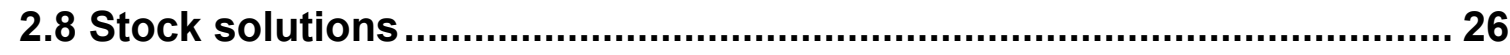

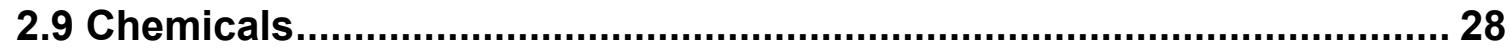

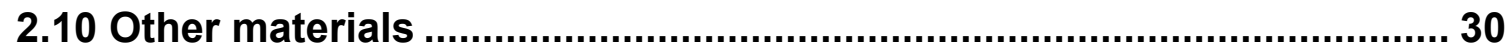

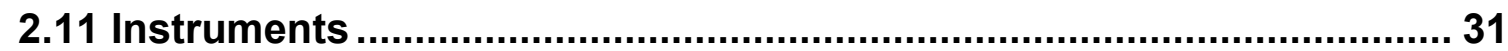

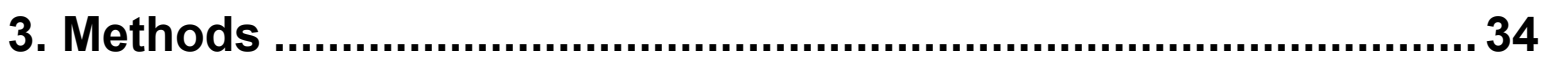

3.1 Methods of cell biology ......................................................................... 34

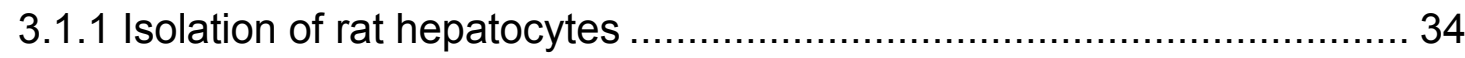

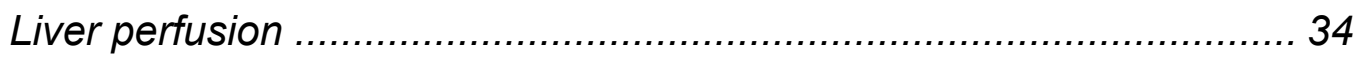

Preparation of the hepatocyte suspension ........................................ 34

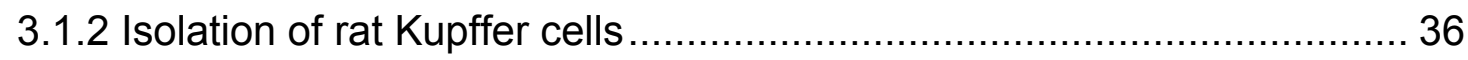

Liver perfusion and preparation of cell suspension ............................. 36

Separation of nonparenchymal liver cells........................................ 36

Purification of Kupffer cells by counterflow elutriation .......................... 37

3.1.3 Primary culture treatment and harvesting of rat liver cells................... 40

Primary culture of rat hepatocytes.................................................. 40

Culturing of Kupffer cells ............................................................... 41

3.2 Methods of molecular biology ........................................................ 42

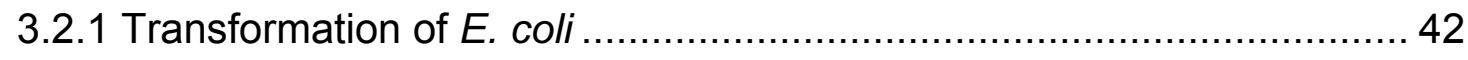

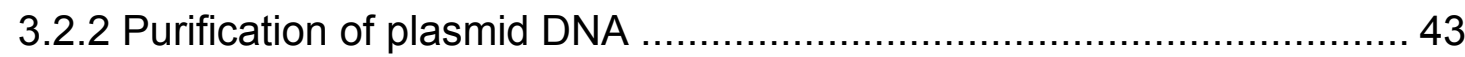

3.2.3 Amplification of DNA by polymerase chain reaction (PCR) ................ 45

3.2.4 Agarose gel electrophoresis of DNA ................................................. 48

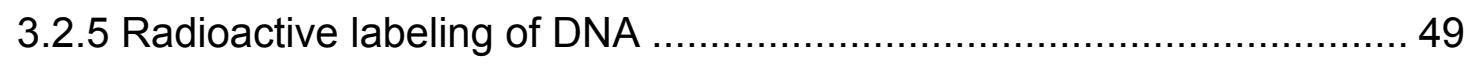

DNA labeling by nick translation method............................................. 49

DNA labeling by random priming reaction ..........................................50

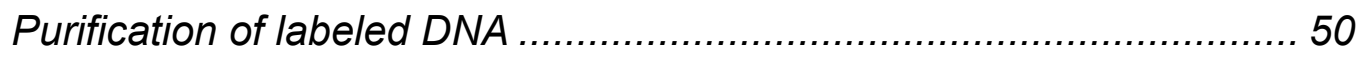

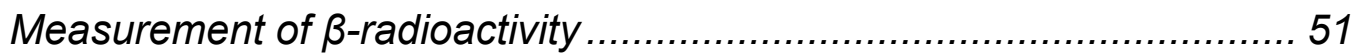

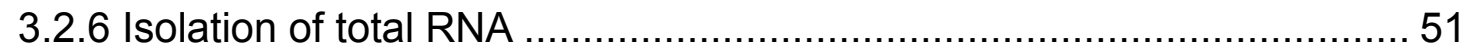

RNA isolation procedure using silicate columns ................................ 51 
Isolation of RNA by density-gradient ultracentrifugation................... 53

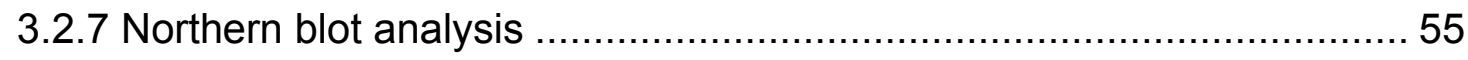

Preparation of RNA samples............................................... 55

Electrophoresis conditions ................................................ 56

Transfer of RNA to nylon membrane...................................... 56

Hybridization of RNA with radiolabeled cDNA probe....................... 57

3.2.8 Transient transfection of primary rat hepatocytes ..........................6 60

3.2.9 Detection of luciferase activity ............................................. 61

Preparation of cell lysates ......................................................... 61

Luciferase detection ................................................................ 62

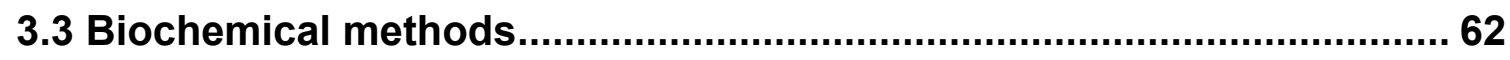

3.3.1 Protein extraction from liver tissue and cultured hepatocytes ...............62 62

Preparation of tissue homogenates......................................... 62

Preparation of cell lysates ................................................. 63

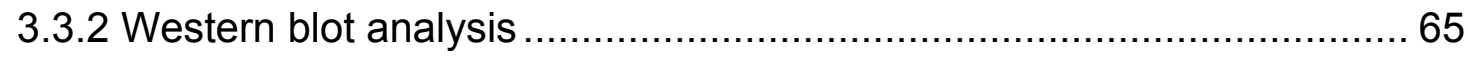

Sample preparation ........................................................ 65

Casting of SDS-polyacrylamide gel........................................... 65

SDS-polyacrylamide gel electrophoresis (SDS-PAGE) and

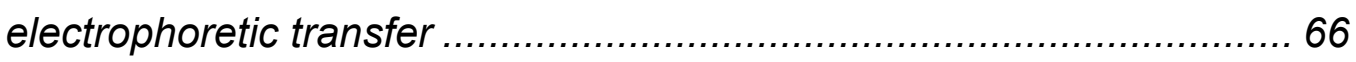

Staining the membrane with Ponceau S ....................................66 66

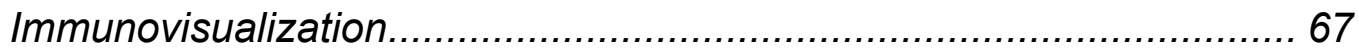

3.3.3 Enzyme-Linked Immunosorbent Assay (ELISA) .......................... 71

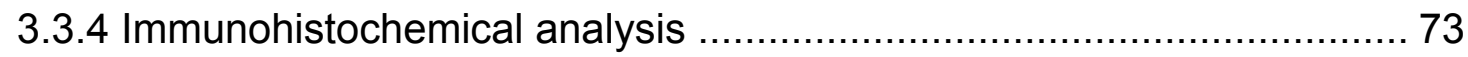

Preparation and fixation of tissue sections.................................. 73

Inhibition of endogenous peroxidases and blocking of nonspecific

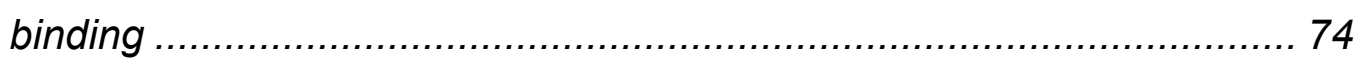

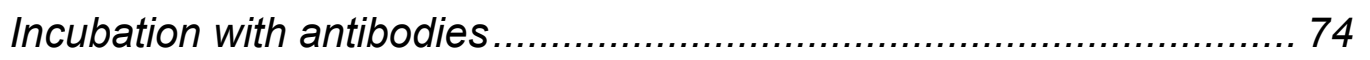

Visualization of immune complexes ...................................... 74

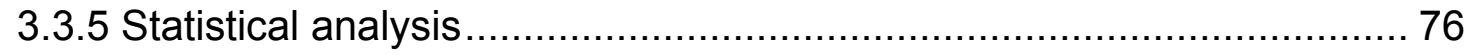

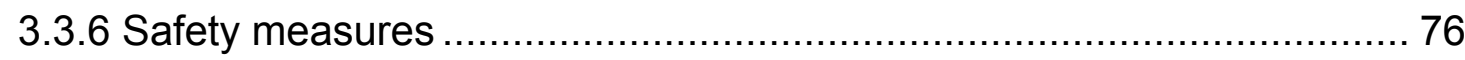

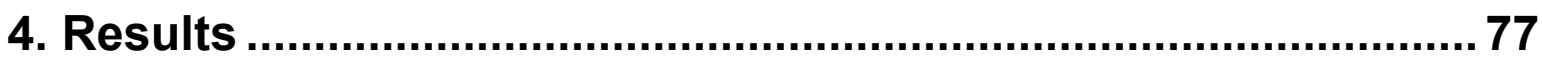

4.1 Studies in vivo: HO-1 expression in a turpentine oil (TO) model of the acute phase response (APR) in rats................................................ 77 
4.1.1 HO-1 expression in the liver and extrahepatic tissues during a turpentine oil (TO)-induced acute phase response (APR) in rats 77

Expression of hepatic HO-1 mRNA and protein during a turpentine oil (TO)-induced acute phase reaction

Expression of HO-1 mRNA in extrahepatic rat tissues during a turpentine oil (TO)-induced acute phase reaction

4.1.2 Distribution of $\mathrm{HO}-1$ within the liver and injured muscle during a turpentine oil (TO)-induced acute phase response (APR) in rats.

HO-1 distribution in the livers of untreated and turpentine oil (TO)treated rats.

HO-1 distribution in injured muscle during a turpentine oil (TO)induced acute phase reaction

4.1.3 Assessment of IL-6 mRNA expression in various tissues and serum levels of IL-6 during a turpentine oil (TO)-induced acute phase response (APR) in rats 85

Expression of IL-6 mRNA occurred only in muscle during a turpentine oil (TO)-induced acute phase reaction

Serum IL-6 levels in rats during a turpentine oil (TO)-induced acute phase reaction.

\subsection{Studies in vitro: HO-1 expression in primary cultures of rat}

hepatocytes treated with proinflammatory cytokines

4.2.1 Regulation of HO-1 mRNA expression in primary rat hepatocytes

by proinflammatory cytokines 88

Dose-dependent induction of HO-1 mRNA expression in primary rat hepatocytes by proinflammatory cytokines

Time-dependent induction of HO-1 mRNA expression in primary rat hepatocytes by proinflammatory cytokines

4.2.2 Regulation of HO-1 mRNA and protein expression by IL-6 in primary rat hepatocytes 92

Dose-dependent induction of HO-1 mRNA and protein expression by IL-6 in primary rat hepatocytes.

Time-dependent induction of HO-1 mRNA and protein expression by $I L-6$ in primary rat hepatocytes. 
4.2.3 Regulation of transfected $\mathrm{HO}-1$ promoter luciferase gene constructs by IL- 6 in primary rat hepatocytes 96

Sequence analysis of the rat $\mathrm{HO}-1$ promoter.

Induction of the rat HO-1 promoter controlled luciferase

expression in primary rat hepatocytes by IL-6 treatment.

5. Discussion

5.1 Regulation of HO-1 expression in turpentine oil (TO) model of the acute phase response (APR) in rats.

5.2 Expression of IL- 6 after turpentine oil (TO) administration and its possible role in HO-1 induction in the liver

5.3 Cell type specificity of HO-1 induction and its possible role in turpentine oil (TO)-induced acute phase response (APR). 104

5.4 Cytokine-dependent regulation of HO-1 in cultured hepatocytes 106

5.5 Molecular mechanisms of HO-1 regulation under inflammatory conditions 108

5.6 Conclusions and future directions. 110

References 


\section{Abbreviations}

$A b$

AMP

AP-1

APP

APR

APS

ATP

BCA

bp

BR

BSA

BV

BV-R

C/EBP $\beta$

cAMP

cDNA

CDTA

cGMP

$\mathrm{Ci}$

CNTF

$\mathrm{CO}$

CRE

CRP

dd $\mathrm{H}_{2} \mathrm{O}$

DEPC

DMSO

dNTP

DTT

E. coli

E-box

EDTA

EGTA
Antibody

Adenosine monophosphate

Activating protein 1

Acute phase proteins

Acute phase response

Ammonium persulfate

Adenosine triphosphate

Bicinchoninic acid

Base pair

Bilirubin

Bovine serum albumin

Biliverdin

Biliverdin reductase

CCAAT/enhancer binding protein $\beta$

Cyclic adenosine-3',5'-monophosphate

Copy desoxyribonucleic acid

trans-1,2-Diaminocyclohexane -N, N, N', N'-tetraacetate

Cyclic guanosine monophosphate

Curie

Ciliary neurotrophic factor

Carbon monoxide

cAMP response element

C-reactive protein

Double distilled water

Diethylpyrocarbonate

Dimethylsulfoxide

Deoxyribonucleoside triphosphate

Dithiothreitol

Escherichia coli

Enhancer box element

Ethylendiaminetetraacetic acid

Ethylenglycol-bis-(2-aminoethylether)-N, N'-tetraacetate 


\begin{tabular}{|c|c|}
\hline ELISA & Enzyme-linked immunosorbent assay \\
\hline FCS & Fetal calf serum \\
\hline g & Gravity \\
\hline GAPDH & Glyceraldehyde-3-phosphate dehydrogenase \\
\hline GFP & Green fluorescent protein \\
\hline gp & Glycoprotein \\
\hline GRE & Glucocorticoid response element \\
\hline HEPES & 2-(4-2-hydroxyethyl)-piperazinyl-1-ethansulfonate \\
\hline $\mathrm{HO}$ & Heme oxygenase \\
\hline HPLC & High performance liquid chromatography \\
\hline HRP & Horseradish peroxidase \\
\hline HSE & Heat shock element \\
\hline hsp32 & $32 \mathrm{kDa}$ heat-shock protein \\
\hline $\lg G$ & Immunoglobulin G \\
\hline IL & Interleukin \\
\hline IL-6-RE & IL-6 response element \\
\hline Ins & Insulin \\
\hline IRP & Iron regulatory protein \\
\hline IKB & NFKB inhibitory subunit \\
\hline JAK & Janus kinase \\
\hline $\mathrm{kb}$ & Kilobase \\
\hline $\mathrm{kDa}$ & Kilodalton \\
\hline LB & Luria Bertani \\
\hline LIF & Leukemia inhibitory factor \\
\hline LPS & Lipopolysaccharide \\
\hline Luc & Luciferase \\
\hline$\alpha 2-M$ & a2-macroglobulin \\
\hline MAPK & Mitogen-activated protein kinase \\
\hline MOPS & 3-(N-Morpholino)-propanesulfonic acid \\
\hline $\mathrm{NAD}(\mathrm{P})^{+}$ & Nicotinamide adenine dinucleotide (phosphate) oxidized \\
\hline $\mathrm{NAD}(\mathrm{P}) \mathrm{H}$ & Nicotinamide adenine dinucleotide (phosphate) reduced \\
\hline NF-KB & Nuclear factor $\mathrm{kB}$ \\
\hline NO & Nitric oxide \\
\hline OD & Optical density \\
\hline
\end{tabular}




\begin{tabular}{|c|c|}
\hline OSM & Oncostatin M \\
\hline PBS & Phosphate buffered saline \\
\hline pBS & Plasmid Bluescript \\
\hline PCR & Polymerase chain reaction \\
\hline PGJ-2 & Prostaglandin $\mathrm{J}_{2}$ \\
\hline $\mathrm{pHO}$ & Heme oxygenase promoter \\
\hline PMSF & Phenylmethyl sulfonylfluoride \\
\hline RNase & Ribonuclease \\
\hline ROS & Reactive oxygen species \\
\hline rpm & Revolutions per minute \\
\hline RT & Room temperature \\
\hline RT-PCR & Reverse transcriptase-PCR \\
\hline SAA & Serum amyloid $A$ \\
\hline SBE & STAT binding element \\
\hline SDS & Sodium dodecylsulfate \\
\hline SDS-PAAG & SDS-polyacrylamide gel \\
\hline SDS-PAGE & SDS-polyacrylamide gel electrophoresis \\
\hline SEM & Standard error of the mean \\
\hline sGC & Soluble guanylate cyclase \\
\hline SSC & Standard saline citrate \\
\hline STAT & Signal transducer and activator of transcription \\
\hline TAE & Tris acetate EDTA buffer \\
\hline TEMED & $\mathrm{N}, \mathrm{N}, \mathrm{N}^{\prime}, \mathrm{N}^{\prime}$-tetramethylethylenediamine \\
\hline TNF- $\alpha$ & Tumor necrosis factor $\alpha$ \\
\hline TO & Turpentine oil \\
\hline Tris & Tris-(hydroxymethyl)-aminomethane \\
\hline UV & Ultraviolet \\
\hline WB & Western blot \\
\hline
\end{tabular}




\section{Summary}

Heme oxygenase-1 (HO-1) is the inducible and rate-limiting enzyme which catalyses the oxidative degradation of heme. This reaction yields carbon monoxide (CO), divalent iron $\left(\mathrm{Fe}^{2+}\right)$, and biliverdin. For these products, a broad range of antiinflammatory, anti-apoptotic and anti-proliferative activities has been discussed. In this regard HO-1 has been proposed to be involved in the acute phase response (APR), the defense reaction of the organism directed against any damaging or injuring agents. However, the mechanisms of the HO-1 regulation under inflammatory conditions are poorly understood. Especially, it remains unclear, whether the induction of HO-1 in vivo occurs as a response to the cytokines released by inflammatory cells. It is also a matter of debate which cell type(s) within the liver contribute(s) to $\mathrm{HO}-1$ up-regulation in the course of inflammation. Moreover, it is not known whether the induction of HO-1 during inflammation is a liver-specific, direct consequence of the APR or just a matter of accompanying oxidative stress and occurs in other organs to the similar extent. Furthermore, on the level of signal transduction, the pathways for cytokine-dependent HO-1 induction are not yet elucidated.

Therefore it was the aim of the present study, by the use of a turpentine oil model of the acute phase response in rats, to examine the HO-1 expression in the liver and in extrahepatic tissues and to evaluate the role of IL-6, the principle mediator of inflammation, in this process. Further, the investigation of spatial and cell typespecific induction of HO-1 within the liver and injured muscle was intended. In addition, it was also the purpose to study regulation of HO-1 expression by various proinflammatory cytokines using primary cultures of isolated rat hepatocytes and to perform a functional analysis of the rat $\mathrm{HO}-1$ promoter to define DNA elements involved in the cytokine-dependent $\mathrm{HO}-1$ gene regulation.

The present study has demonstrated that during turpentine oil-induced localized inflammation in rats, the expression of $\mathrm{HO}-1$ was strongly up-regulated at early time points in injured muscle, the initiating site of the acute phase reaction, and in the liver, the major source of serum acute phase proteins. In other internal organs investigated, only moderate changes were observed. As revealed by immunohistochemical analysis, in injured muscle the induction of HO-1 was 
attributed to macrophages, whereas in the liver, hepatocytes were the major source of the elevated $\mathrm{HO}-1$ levels during the acute phase response.

Among various tissues examined under inflammatory conditions by Northern blot, muscular tissue at the site of turpentine oil injection was found to be the only source of IL-6, the principle mediator of the acute phase response in rats. The upregulation of IL-6 mRNA levels was followed by elevated plasma levels of this cytokine, as measured by the rat IL-6-specific ELISA. The elevated plasma IL-6 concentrations correlated with hepatic $\mathrm{HO}-1$ induction in the course of inflammation, suggesting that IL-6 derived from injured muscle is most likely responsible for the HO-1 induction in the rat liver.

Studies in primary rat hepatocytes further underlined the pivotal role of IL-6 in hepatic HO-1 induction under inflammatory conditions. As demonstrated by Western and Northern blot analyses, among the proinflammatory cytokines (IL-6, IL-1 $\beta$, and TNF- $\alpha$ ) used for the treatment of primary cultured rat hepatocytes, IL-6 was the most potent inducer of HO-1 expression in time- and dose-dependent experiments. Sequence analysis of the rat HO-1 promoter revealed the presence of several putative binding sites for transcription factors of the STAT-family, the major transducers of IL- 6 signalling. Furthermore, the functional analysis of the rat HO-1 promoter by means of the luciferase reporter gene assay, using deletion and mutation approaches, identified one of the putative STAT binding sites, S3BE, as an active element of the IL-6-dependent HO-1 gene regulation, which does not require cooperation with $\mathrm{AP}-1$ binding site for its action.

Taken together, these data indicate that HO-1 might be referred to as an intracellular positive acute phase protein that plays an important role in cytoprotection of hepatocytes, which might become damaged during their clearance function. Moreover, at the site of local injury, up-regulation of HO-1 in macrophages can participate in the resolution of inflammation. 


\section{Introduction}

\subsection{Heme: an essential catalyst of biological oxidation processes}

Heme (Fe-protoporphyrin IX) is a ubiquitous molecule containing an active iron linked to the four nitrogen atoms of a tetrapyrrole macrocycle (Maines, 1997). Since the active iron in a reduced ferrous state has a high affinity for molecular oxygen and can donate electrons, the heme molecule promotes most biological oxidation processes and, thus, performs vital functions in aerobic metabolism (Ryter and Tyrrell, 2000).

Heme serves as a prosthetic moiety for various heme proteins involved in oxygen transport (hemoglobin) and storage (myoglobin), mitochondrial respiration (cytochromes), oxidative modification of xenobiotics (cytochrome P450 family), cellular antioxidant defenses (peroxidases, catalase, other enzyme systems), and signal transduction processes (nitric oxide synthase, soluble guanylate cyclase) (Ryter and Tyrrell, 2000; Dennery, 2000).

On the other hand, heme may catalyze the production of cytotoxic reactive oxygen species which, in turn, cause DNA damage, lipid peroxidation and protein denaturation resulting in cellular damage. Therefore, the cellular heme pool needs to be tightly controlled by heme synthesis (provided by $\delta$-aminolevulinate synthase) and degradation (carried out by heme oxygenase) (Immenschuh and Ramadori, 2000).

\subsection{Heme oxygenases (HO), key enzymes for heme catabolism}

Heme oxygenases $(\mathrm{HO})$ perform the oxidative cleavage of the heme molecule, an essential reaction in diverse physiological processes in various species. Thus expression and regulation of these enzymes might play an important role in maintaining cellular homeostasis (Otterbein and Choi, 2000).

\subsubsection{Mammalian isoforms of $\mathrm{HO}$}

Three isoforms of $\mathrm{HO}$ (HO-1, $\mathrm{HO}-2$, and $\mathrm{HO}-3$ ) have been described in mammals as the products of separate genes (Maines et al., 1986; Shibahara et al., 1993; McCoubrey, Jr. et al., 1997b). HO-1, also known as the major 32-kDa heat-shock protein (hsp32), is widely expressed in tissues and highly inducible in virtually all 
cell types by a variety of stimuli (Maines, 1997). Under physiological conditions, HO-1 expression is highest in the spleen, a major organ for destruction of senescent erythrocytes (Dennery, 2000). Constitutively synthesized HO-2, a 36$\mathrm{kDa}$ protein, is known to be abundant in brain, testis, and unstimulated liver of rodents and humans (Cruse and Maines, 1988). HO-2 is so far unresponsive to any of known HO-1 inducers and therefore functions mainly in normal heme metabolism (Shibahara et al., 1993; McCoubrey, Jr. and Maines, 1994; Maines, 1997). The recently discovered HO-3 isozyme (33 kDa in size) displays a high sequence homology with $\mathrm{HO}-2$ but it is nearly devoid of catalytic activity (McCoubrey, Jr. et al., 1997b). Besides the catalytic domain, both HO-2 and HO-3 contain two additional heme binding sites which might be relevant to the regulatory role of these isoforms in heme-dependent cellular processes (McCoubrey, Jr. et al., 1997a; McCoubrey, Jr. et al., 1997b). Although functions and regulation of HO3 are not completely understood, there is evidence that it may serve as heme binding/transporting protein (McCoubrey, Jr. et al., 1997b).

\subsubsection{The oxidative cleavage of heme by HO-1}

Heme oxygenase-1 (EC 1.14.99.3) catalyzes the initial and rate-limiting reaction in the catabolism of heme (iron-protoporphyrin IX) yielding equimolar amounts of biliverdin, carbon monoxide (CO), and free ferrous iron $\left(\mathrm{Fe}^{2+}\right)$ (Figure 1) (Tenhunen et al., 1968; Tenhunen et al., 1969). HO-1 is found in the endoplasmic reticulum in a complex with NADPH cytochrome P450 reductase and degrades heme in a multi-step, energy-requiring system (Yoshida and Kikuchi, 1979). This system utilizes molecular oxygen $\left(\mathrm{O}_{2}\right)$ and requires $\mathrm{NADPH}$ as a source of the reducing equivalents, which are transferred to $\mathrm{HO}-1$ by cytochrome $\mathrm{P} 450$ reductase and used for activation of $\mathrm{O}_{2}$ and reduction of heme iron from $\mathrm{Fe}^{3+}$ to $\mathrm{Fe}^{2+}$ and/or maintenance of iron in the $\mathrm{Fe}^{2+}$ state (Maines, 1997). The conversion reaction of one heme molecule requires the input of three $\mathrm{O}_{2}$ molecules and a total of seven electrons (Figure 1) (Wilks, 2002).

The cleavage of heme by $\mathrm{HO}-1$ is regiospecific and occurs at the a-meso-carbon to form biliverdin IXa as the sole enzymatic product (Tenhunen et al., 1969). This reaction consists of three mono-oxygenation cycles; in each of them the reduced iron binds molecular oxygen that accepts the second electron from NADPH. The first cycle forms a-meso-hydroxyheme, the second cycle eliminates the a-methene 
bridge carbon as $\mathrm{CO}$ producing $\alpha$-verdoheme, and the third cycle forms a ferribiliverdin IXa complex, $\mathrm{BV}-\mathrm{Fe}^{3+}$. An additional $\mathrm{NADPH}$ is consumed for reduction of the $\mathrm{BV}-\mathrm{Fe}^{3+}$ followed by dissociation of $\mathrm{Fe}^{2+}$ from biliverdin (Ryter and Tyrrell, 2000).

\section{HEME}
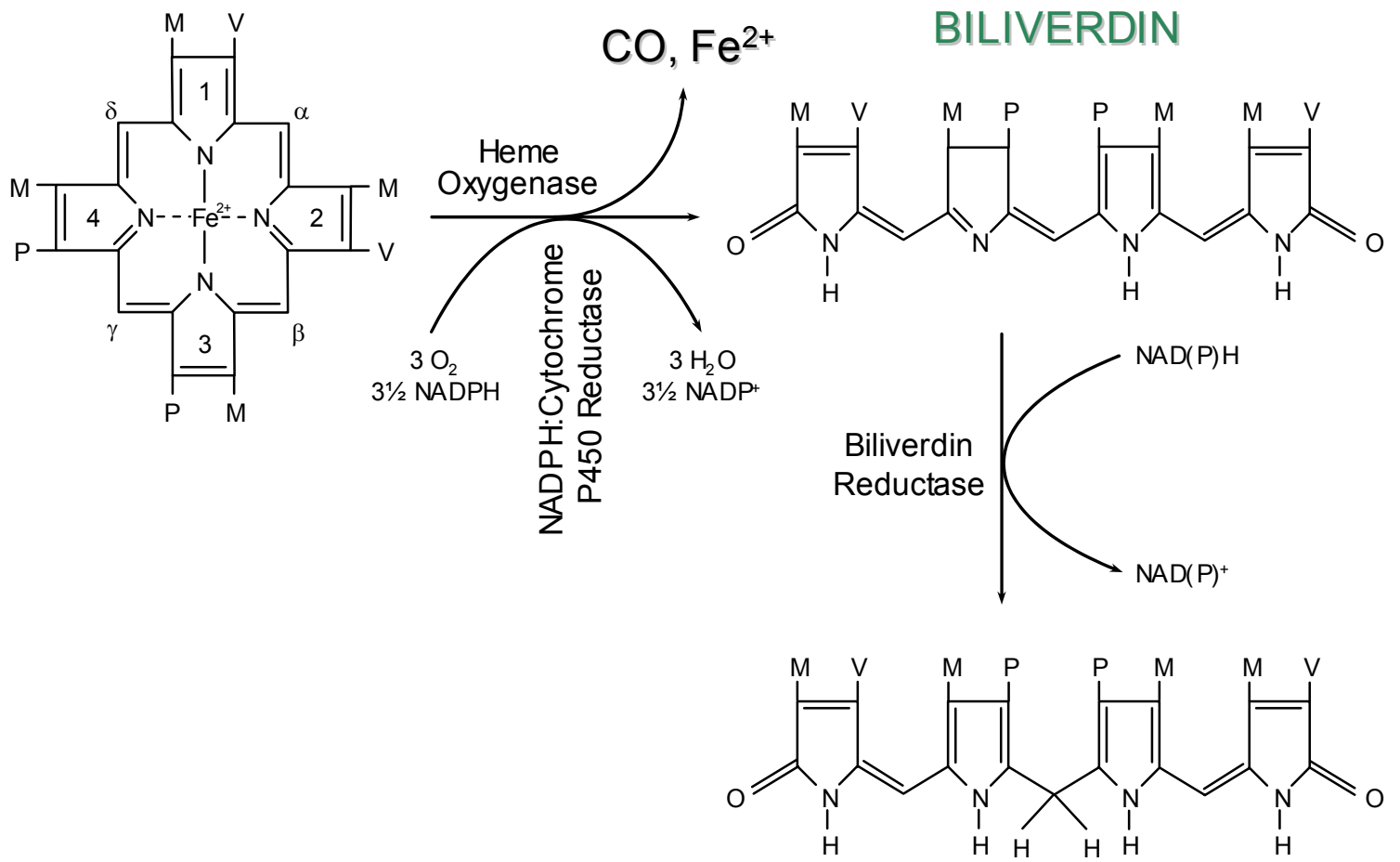

BILIRUBIN

Figure 1. Enzymatic conversion of heme to bilirubin. Oxidative cleavage of the ameso-carbon bridge of a b-type heme molecule by heme oxygenase yields equimolar quantities of biliverdin IX a and carbon monoxide (CO), while the central iron is released. Biliverdin is subsequently converted to bilirubin by biliverdin reductase. Abbreviations are as follows: $\mathrm{M}$, methyl; $\mathrm{V}$, vinyl; $\mathrm{P}$, propionate. The heme pyrrole rings are labeled 1-4 and the meso-carbons $\alpha-\gamma$.

In most mammalian species, biliverdin is subsequently reduced to bilirubin (BR) by the action of the cytoplasmic enzyme $\mathrm{NAD}(\mathrm{P}) \mathrm{H}$ biliverdin reductase (Figure 1), (Tenhunen et al., 1969) while the free iron is promptly sequestered into ferritin (Balla et al., 1992). The BR formed in the various tissues effluxes into the blood, where it forms a 1:1 complex with albumin. The circulating BR, in turn, is absorbed by the liver parenchyma, subsequently conjugated with sugars (mainly glucuronic acid) by uridine diphosphate-glucuronosyl transferase and then excreted into the bile (Ryter and Tyrrell, 2000). 


\subsubsection{HO-1, the "inducible" isozyme among the HO family}

HO-1 expression is induced not only in response to its substrate heme (Tenhunen et al., 1970), but also by various stress stimuli such as hydrogen peroxide $\left(\mathrm{H}_{2} \mathrm{O}_{2}\right)$, xenobiotics, nitric oxide, ultraviolet-A radiation, heavy metals, hypoxia, hyperoxia, heat shock, glutathione depletion, sodium arsenite, prostaglandins (Elbirt and Bonkovsky, 1999; Ryter and Choi, 2002), ischemia/reperfusion (Maines et al., 1993; Bauer et al., 1998), shear stress (Wagner et al., 1997; Pillar and Seitz, 1999), bacterial endotoxins (Rizzardini et al., 1994; Immenschuh et al., 1999), and proinflammatory cytokines (Cantoni et al., 1991; Mitani et al., 1992; Rizzardini et al., 1998; Oguro et al., 2002).

Despite the great variety of HO-1 inducers, most, if not all, of them exert their effects on HO-1 gene expression at the transcriptional level (Elbirt and Bonkovsky, 1999; Bauer and Bauer, 2002). However, the broad spectrum and chemical diversity of HO-1 inducers argues against the possibility that all agents utilize a single transcription activation pathway. Indeed, various transcriptional enhancer elements have been identified within the $5^{\prime}$-flanking region of the mouse, rat, human and chicken HO-1 genes (Choi and Alam, 1996; Elbirt and Bonkovsky, 1999). In most cases, these motifs are equivalent to or a variation of recognition sites for known DNA-binding proteins, including those for activator protein-1 (AP-1) and nuclear factor $\mathrm{KB}(\mathrm{NF}-\mathrm{KB})$ as well as hypoxia response, cadmium response, heat-shock response, and metal response elements (Bauer and Bauer, 2002).

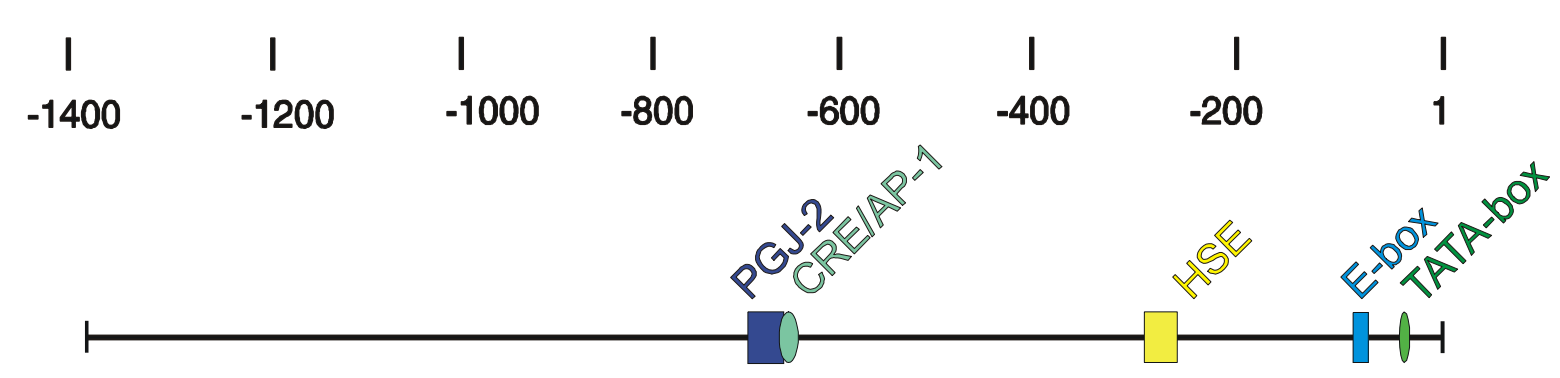

Figure 2. Scheme of the rat HO-1 gene promoter. The known functional response elements are indicated as: TATA-box element; E-box, enhancer box element; HSE, heat shock response element; CRE/AP-1, cAMP response element / activator protein-1 binding site; PGJ-2, prostaglandin $\mathrm{J}_{2}$ response element. The promoter length is indexed on top by negative numbers in bp, starting from the transcription initiation site.

Among mammalian HO-1 genes, the most detailed description is given to the mouse one. The majority of functional inducer-responsive sequences identified to 
date were found in the promoter, proximal enhancer and two distal enhancers within $12 \mathrm{~kb}$ of the $5^{\prime}$-flanking region of the mouse HO-1 gene (Choi and Alam, 1996). Being located 4 and $10 \mathrm{~kb}$ upstream from the transcription initiation site, the distal enhancers exhibit a potent cooperation with the HO-1 promoter in mediating HO-1 gene transcription in response to various stimuli (Alam et al., 1994; Camhi et al., 1995; Lee et al., 2000).

Although the gene coding for rat HO-1 has been cloned as early as 1987 by Müller and colleagues (Muller et al., 1987), the rat HO-1 gene promoter region is poorly investigated (Figure 2). Only a few functional inducer-responsive sequences were identified within $1387 \mathrm{bp}$ of the $5^{\prime}$-flanking region of the rat HO-1 gene. Among them are: enhancer box (Kietzmann et al., 2003), heat shock response element (Okinaga and Shibahara, 1993), activator protein-1 binding site (Immenschuh et al., 1998), and prostaglandin $J_{2}$ response element (Koizumi et al., 1995).

\subsection{The biological significance of the HO system}

The potential toxicity of heme points to a critical role for heme degradation in cellular metabolism. This function is provided by the $\mathrm{HO}$ system, which thus participates in cellular defense. An increasing number of evidences reveals the protective role of $\mathrm{HOs}$, particularly $\mathrm{HO}-1$ due to its inducibility, by virtue of antiinflammatory, anti-apoptotic and anti-proliferative activities of the products released by the heme breakdown reaction (Figure 3) (Otterbein et al., 2003; Wunder and Potter, 2003; Alcaraz et al., 2003).

\subsubsection{Carbon monoxide (CO), a second messenger gas}

Carbon monoxide (CO) was known for a long time as poisonous gas, lethal at high enough doses, and metabolic waste compound. Indeed, due to its strong affinity for hemoglobin and myoglobin, $\mathrm{CO}$ is able to prevent oxygen delivery to the tissues and organs, creating hypoxia (Otterbein and Choi, 2000). However, recent studies have shown that physiological concentrations of $\mathrm{CO}$ generated from $\mathrm{HO}$ activity can regulate vasomotor tone as well as neurotransmission (Verma et al., 1993; Maines, 1997; Suematsu and Ishimura, 2000).

Currently it is known that $\mathrm{CO}$ is an endogenous monoxide that, similar to nitric oxide (NO), activates soluble guanylate cyclase (SGC) by binding to the heme moiety of this enzyme, thereby functioning as a second messenger gas 
(Christodoulides et al., 1995). Despite CO being a 50-100 times less potent activator of SGC than NO, it appears to provide the major control of the sinusoidal vascular tone in the liver (Wunder and Potter, 2003). This might be due to the fact that in contrast to NO, which is extremely labile and in reaction with superoxide forms peroxynitrite (a potent cytotoxic oxidant), $\mathrm{CO}$ is a stable gas and does not form radicals (Motterlini et al., 2002; Hartsfield, 2002). Therefore, CO can accumulate in the cell to levels that are presumably much higher than those of NO (Otterbein and Choi, 2000). The SGC activity leads to the generation of cyclic guanosine monophosphate (cGMP) which, in turn, mediates various physiological functions, e. g., smooth muscle relaxation (Wang et al., 1997).

In addition, CO may influence vascular resistance independently of cGMP via activation of calcium-dependent potassium channels, leading to smooth muscle cells relaxation (Wang et al., 1997), or by inhibiting the cytochrome P450-mediated production of endothelin-1, a vasoactive compound known to cause contraction of the hepatic stellate cells, thereby increasing sinusoidal resistance in the liver (Wunder and Potter, 2003).

As to the liver, $\mathrm{CO}$ is involved in the regulation of hepatobiliary function through altering the bile acid-dependent bile flow and the contractility of the bile canaliculus. Moreover, HO-1-derived $\mathrm{CO}$ has been shown to protect hepatic microcirculation under stress conditions (Suematsu and Ishimura, 2000).

CO may also possess potent anti-inflammatory effects such as the ability to prevent platelet aggregation by activation of $\mathrm{SGC}$ and subsequent generation of cGMP (Brune and Ullrich, 1987). Furthermore, CO has been shown to suppress the proinflammatory cytokine production and to promote increased interleukin (IL)10 expression by macrophages both in vitro and in vivo through a pathway involving the mitogen-activated protein (MAP) kinases (Otterbein et al., 2000). Moreover, CO mediates the anti-inflammatory effects of IL-10 via a MAP kinasedependent pathway (Lee and Chau, 2002). It was also reported that CO prevented apoptosis in several cell types, including endothelial cells, fibroblasts and hepatocytes, utilizing cGMP and/or MAP kinase signalling systems, depending on the cell type (Otterbein et al., 2003).

Thus, $\mathrm{CO}$ is one of the most important from HO-1 downstream mediators with a broad range of physiological functions (Figure 3). 


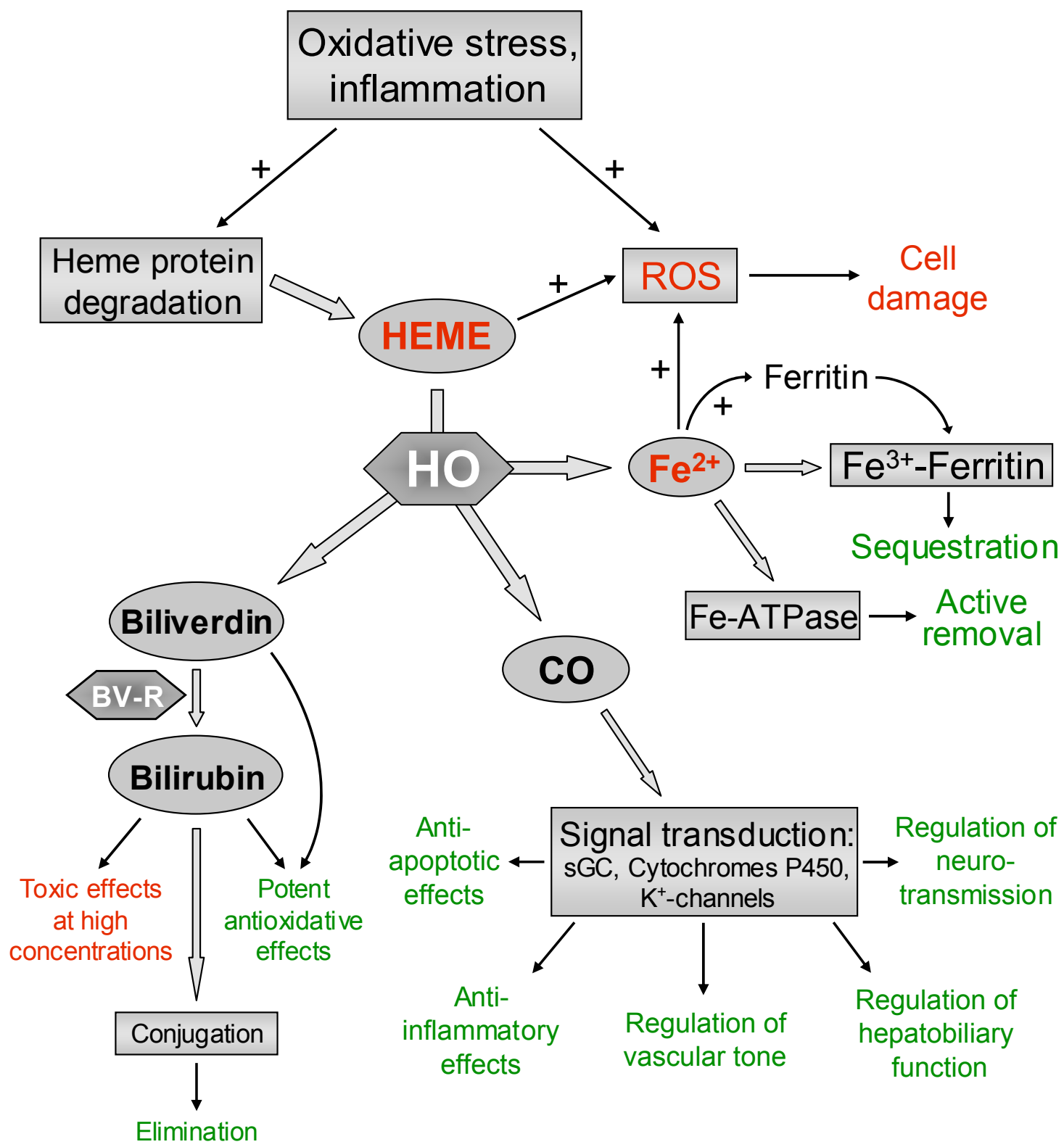

Figure 3. Significance of the heme oxygenase reaction for cellular homeostasis. Under inflammatory or oxidative stress conditions, heme, a potent oxidant released from heme containing proteins, becomes available for enzymatic degradation. The degradation of heme by heme oxygenase $(\mathrm{HO})$ results in the release of several by-products like carbon monoxide $(\mathrm{CO})$, divalent iron $\left(\mathrm{Fe}^{2+}\right)$, and biliverdin with a broad range of biological activities. Biliverdin is subsequently converted into bilirubin by the action of cytosolic biliverdin reductase (BV-R). Beneficial consequences of heme oxygenase activity are shown in green color. Potentially deleterious effects and compounds are indicated in red. ROS, reactive oxygen species; SGC, soluble guanylate cyclase; "+" indicates activation.

\subsubsection{Biliverdin and bilirubin as potent antioxidants}

Cytoplasmic $\mathrm{NAD}(\mathrm{P}) \mathrm{H}$ biliverdin reductase reduces the water soluble biliverdin (BV) to the hydrophobic bilirubin IXa (BR) (Tenhunen et al., 1968). Dissociation of $\mathrm{BR}$ from serum albumin, which serves as a principle transporter of unconjugated 
$\mathrm{BR}$, represents a rate-limiting step in absorption of BR by hepatocytes (Zucker et al., 1999). Once absorbed, BR undergoes phase-Il glucuronidation, forming watersoluble mono- and di-glucuronides which are eliminated by bile and faeces (Figure 3) (Wunder and Potter, 2003). The excess accumulation of unconjugated $\mathrm{BR}$ in plasma is known to induce neurotoxicity and can cause hemolysis (Ryter and Tyrrell, 2000). In contrast, BR at nannomolar concentrations protects neuronal cultures against oxidative stress injury (Dore et al., 1999). Administration of BV to mice prolonged survival of cardiac allografts and islets transplanted into allogeneic recipients (Otterbein et al., 2003). Administrated to rats, BV appeared to modulate lipopolysaccharide-induced P- and E-selectin expression in the vascular system, acting as an anti-inflammatory agent (Otterbein and Choi, 2000). BR was reported to provide a protective effect on the transplanted liver grafts via inhibition of lipid peroxidation in hepatocytes (Kato et al., 2003).

BR and BV are thought to exert their protective (including anti-inflammatory and anti-apoptotic) effects largely because of their antioxidant properties (Otterbein et al., 2003). This hypothesis originates from observations of bile pigment antioxidant activity in vitro. It has been clearly shown for both BR and BV to prevent the oxidation of polyunsaturated fatty acids in multilamellar liposomes at least as effectively as a-tocopherol (Stocker et al., 1987). While BR functioned as a chain breaking antioxidant (peroxyl radical reductant), the BV acted as a peroxyl radical trap (Stocker et al., 1987). Exogenous free and albumin-bound BR has also been shown to inhibit plasma and low density lipoprotein lipid peroxidation after the depletion of endogenous circulating antioxidants (Neuzil and Stocker, 1994).

Although it is evident that BR has antioxidant effects in extracellular fluids in vivo and some in vitro model systems, it remains uncertain to what extent this metabolic waste product is significant as a chain breaking antioxidant at the cellular level (Ryter and Tyrrell, 2000).

\subsection{3 "Free" iron: a regulator of mRNAs expression}

Reduced iron $\left(\mathrm{Fe}^{2+}\right)$, released by $\mathrm{HO}-1$ from the core of the heme molecule, is a potent prooxidant, which exhibits its cytotoxic effect via production of reactive oxygen species by Fenton chemistry (Immenschuh and Ramadori, 2000). However, the potential catalysis of oxidative reactions by this compound is limited through its chelation by the iron-sequestering protein ferritin as well as via its 
active removal from the cell by the specific Fe-ATPase pump (Figure 3) (Ferris et al., 1999; Baranano et al., 2000).

Expression of ferritin was originally reported to be the mechanism by which $\mathrm{HO}-1$ conferred resistance to oxidative stress in endothelial cells (Balla et al., 1992). HO-1 induction by heme demonstrated ferritin-mediated protective effect in a model of hyperoxic lung injury (Taylor et al., 1998).

Ferritin is a heterooligomeric protein consisting of 24 subunits with a high capacity for iron sequestration ( 4500 $\mathrm{Fe}^{3+}$ ions per holoferritin). The ferroxidase activity intrinsic to ferritin maintains the iron as $\mathrm{Fe}^{3+}$ (Ryter and Tyrrell, 2000). The synthesis of ferritin is regulated by a post-transcriptional mechanism, which utilizes iron released from $\mathrm{HO}$ activity (Eisenstein and Munro, 1990). An iron regulatory protein (IRP) binds to and inhibits the translation of ferritin mRNA. Cytoplasmic iron, as it becomes available, binds to the IRP, releasing the Fe-IRP from ferritin mRNA and thus de-repressing its translation (Eisenstein and Munro, 1990). Similar regulatory mechanisms were found to control synthesis of other proteins involved in iron redistribution, such as transferrin receptor and $\delta$-aminolevulinate synthase (Hentze and Kuhn, 1996), divalent cation transporter-1 (Gunshin et al., 1997), and, probably, Fe-ATPase (Baranano et al., 2000).

Thus, the cytoprotective action of ferritin under the stress conditions is triggered by $\mathrm{HO}-1$ induction with subsequent release of "regulatory" iron from heme.

\subsection{Acute phase response (APR) and its mediators}

The acute phase reaction comprises a variety of systemic changes in response to tissue injury and infection.

\subsubsection{APR: a systemic reaction of an organism to maintain its integrity}

The acute phase response (APR) is the defense reaction of the organism directed to restrict the area of damage and to eliminate, or at least isolate, the damaging agent. Every agent, which leads to loss of tissue integrity, induces a local reaction, known as inflammation (Ramadori and Christ, 1999).

Different injury agents (e.g., bacterial or viral infections, trauma or extensive surgery, thermal injury, intoxication, etc.) can induce more or less similar signs and symptoms of the APR, such as fever, neurological and hormonal alterations, loss of appetite, muscular pain, leucocytosis, hypoferremia, hyperglycemia, and 
increased protein metabolism in muscles with consequent transfer of amino acids to the liver to maintain synthesis of acute phase proteins (Ramadori and Christ, 1999). The purposes of these systemic and metabolic changes are to control the defense mechanisms, to maintain vital functions in the course of inflammation, and, finally, to restore homeostasis (Moshage, 1997).

\subsubsection{Mediators of the hepatic APR}

Cells of the inflammatory infiltrate produce and/or induce the production of cytokines, the main soluble factors responsible for the onset, progression and resolution of the APR, whereas the liver is the primary target organ of the host defense reaction (Streetz et al., 2001). The cytokines of the APR can be classified according to similarities in transduction of their signals via specific receptors into two major groups (Table 1).

Table 1. Cytokines of the acute phase response

\begin{tabular}{llll}
\hline \hline IL-1-type & Role in the APR & IL-6-type & \\
cytokines & & cytokines & Role in the APR \\
\hline IL-1 $\alpha$ & Modulation & IL-6 & Induction \\
IL-1 $\beta$ & Induction & CNTF & Modulation \\
TNF- $\alpha$ & Induction & OSM & Modulation \\
TNF- $\beta$ & Modulation & LIF & Modulation \\
& & Cardiotropin 1 & Modulation \\
& & IL-11 & Modulation \\
\hline \hline
\end{tabular}

CNTF, ciliary neurotrophic factor; IL, interleukin; LIF, leukemia inhibitory factor; OSM, oncostatin M; TNF, tumor necrosis factor.

Interleukin (IL)-6 itself from the group of IL-6-type cytokines and IL-1 $\beta$ together with tumor necrosis factor (TNF)- $\alpha$ from the IL-1-type cytokine group are considered to be the major mediators of the APR. At the inflammatory sites, IL-6 is produced by macrophages, endothelial cells, and fibroblasts (Ramadori and Christ, 1999). The release of mature IL-1 $\beta$ by macrophages seems to take place only during or after cell death (Perregaux and Gabel, 1998). TNF- $\alpha$ is synthesized mainly by mononuclear phagocytes recruited at the sites of damage and by tissue macrophages (Ramadori and Christ, 1999). While IL-6, IL-1 $\beta$, and TNF- $\alpha$ are the 
inducers of acute phase protein gene expression, other cytokines (Table 1) were shown to modulate this expression (Moshage, 1997).

\subsubsection{Acute phase proteins and their regulation}

Various plasma proteins synthesized by the liver parenchymal cells exhibit quantitative changes after onset of the APR. Proteins with a transient increase in synthesis and plasma concentration are called positive acute phase proteins (APP), e.g., a2-macroglobulin in rats, C-reactive protein (CRP) and serum amyloid A (SAA) in humans. Proteins whose synthesis decreases under inflammatory conditions are referred to as negative APP, e.g., albumin, transferrin, a-1 lipoprotein (Ramadori and Christ, 1999). The APPs could be also divided into two classes according to their ability to be regulated by certain cytokines acting via their specific signalling pathways (Figure 4).

IL-6-type cytokines use the common receptor $\beta$-subunit (gp130) for signal transduction which in some cases requires an $\alpha$-receptor subunit (IL-6, IL-11, CNTF) but in other does not (OSM, LIF) (Heinrich et al., 1998). After ligand binding, dimerization of two $\beta$-subunits leads to the activation of the receptorassociated Janus kinases (JAKs), which, in turn, phosphorylate transcription factors from the signal transducer and activator of transcription (STAT) family, namely STAT1, 3, and 5 (Heinrich et al., 2003). After homo- or heterodimerization, activated STATs are translocated to the nucleus, where they bind to target sequences in the promoters of type II APP genes, stimulating synthesis of corresponding proteins (Figure 4). Among STAT factors, STAT3 is considered to play a pivotal role in the regulation of the APR, since STAT3 binding sites were shown in the promoters of various APP genes induced by IL-6 (Streetz et al., 2001).

Activation of TNF/IL-1 receptors after interaction with their ligands initiates the conversion of membrane sphingomyelin to ceramide via sphingomyelinase (Kolesnick and Golde, 1994). Subsequently, ceramide-activated protein kinases connect to several signalling pathways which lead to activation and translocation of transcription factors, such as activating protein (AP)-1 and nuclear factor (NF)-KB (Moshage, 1997). NF-KB is activated and translocated to the nucleus after phosphorylation and degradation of inhibitory subunit IKB (Streetz et al., 2001). Many type I APP genes contain NF-KB and AP-1 response elements in their promoter regions (Figure 4) (Kolesnick and Golde, 1994). 

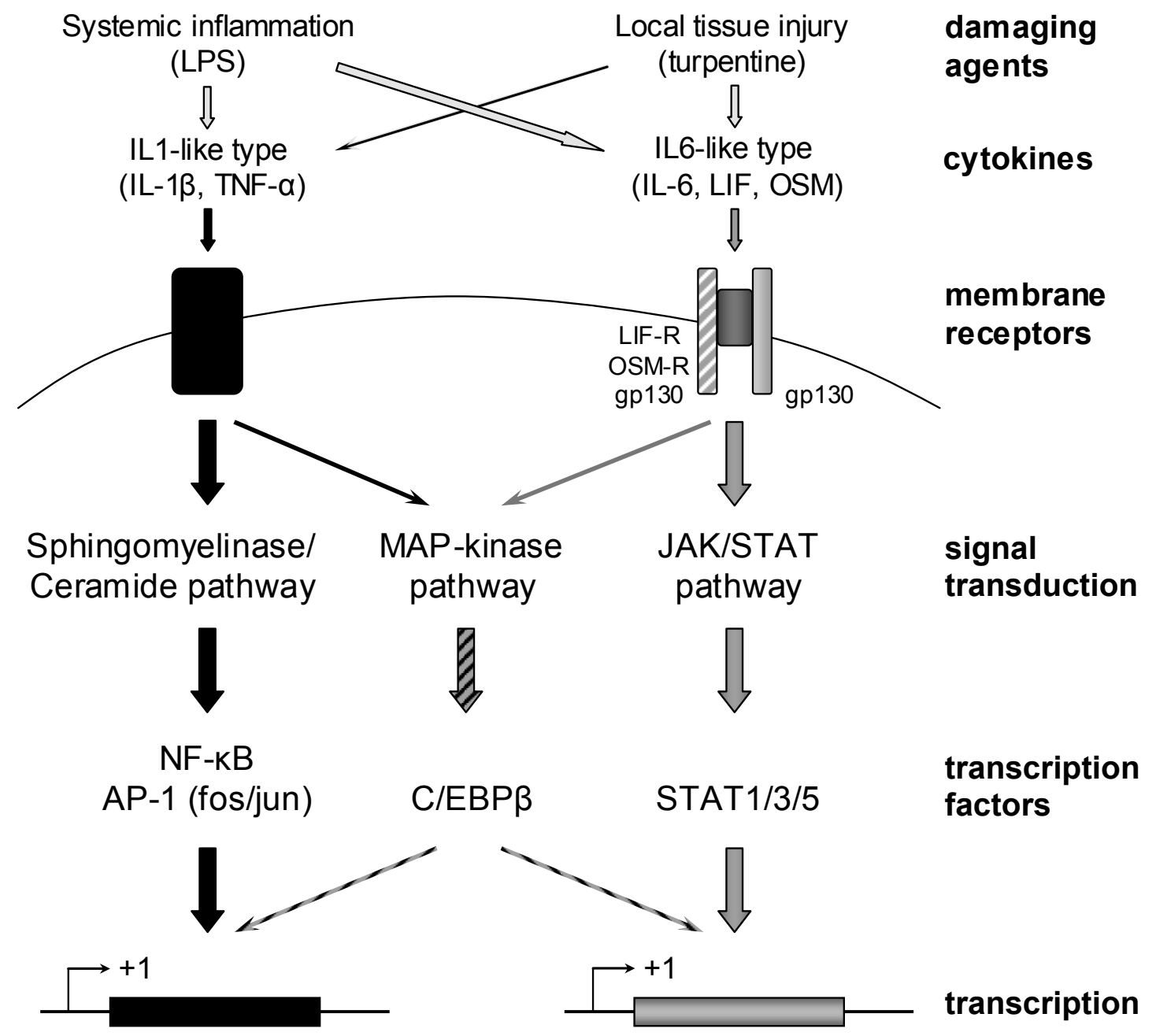

Type I Acute Phase Protein Genes

Type II Acute Phase Protein Genes

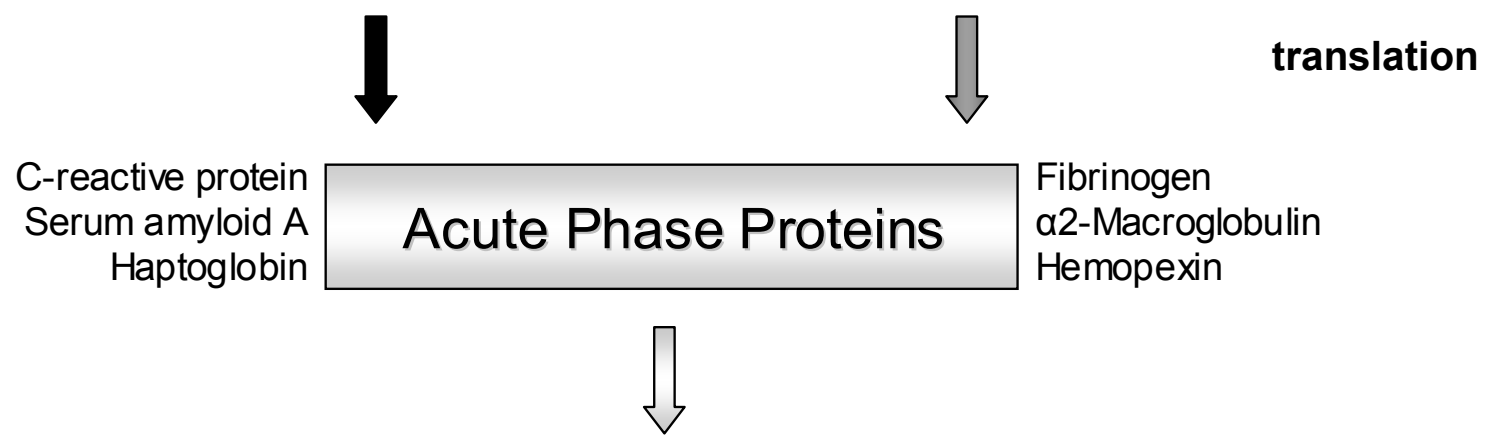

Restoration of Homeostasis

Figure 4. Induction of the acute phase response. Damaging agents cause local or systemic inflammation, resulting in increased expression of cytokines. Binding of the ligands to cytokine receptors initiate signalling events, leading to activation of several transcription factors. These factors bind to their response elements in the promoter regions of acute phase genes. Transcription of acute phase genes is induced and acute phase proteins are secreted. In the extracellular environment, acute phase proteins function to restore homeostasis. 
An overlapping signalling involving both cytokines families is provided by the mitogen activated protein (MAP) kinase pathway activating the transcription factors of the CCAAT/enhancer binding protein $\beta$ (C/EBP $\beta)$ family, which may recognize target sequences in the promoters of type I and II APPs (Figure 4) (Ramadori and Armbrust, 2001).

\subsubsection{Models of the APR}

\section{Animal models of the APR}

To study APR in vivo, two types of animal models are generally used (Ramadori and Christ, 1999). In the first model, APR is induced in rodents by intraperitoneal or intravenous administration of the bacterial lipopolysaccharide (LPS). It is characterized by systemic inflammation and rapid circulatory increase of all three major proinflammatory cytokines: IL-6, IL-1 $\beta$ and TNF- $\alpha$ (Ulich et al., 1990; Ulich et al., 1991; Luster et al., 1994). In the second model, induction of a sterile abscess in rats by subcutaneous or intramuscular injection of turpentine oil (TO) causes a local inflammation with a subsequent systemic APR (Fey and Fuller, 1987). This model is characterized by local increase in IL-1 $\beta$ and TNF- $\alpha$, and circulatory increase in IL-6 (Luheshi et al., 1997).

In vitro models of the APR

Once it became obvious that the liver is a primary target organ for the APR, the individual liver cell types were introduced in culture to investigate a hierarchy of the events triggering the full APR in the liver. Besides the ability to respond to the cytokine action, different cell types within the liver are also able to express IL-1 $\beta$, TNF- $\alpha$, IL-6, and other modulatory cytokines of the hepatic APR (Ramadori and Christ, 1999). However, despite limited evidence on the production of cytokines by hepatic sinusoidal endothelial cells (Feder et al., 1993) and hepatic stellate cells (Ramadori and Armbrust, 2001), Kupffer cells are by far the most active intrahepatic "amplifiers" of the systemic APR in the liver by liberating a second wave of proinflammatory cytokines, promoting autocrine stimulation and paracrine hepatocyte stimulation (Decker, 1990).

Hepatocytes express a great variety of receptors for cytokines, growth factors, and prostaglandins and represent therefore the major target for a multiple set of mediators involved in both systemic and local host defense reactions. Hepatocytes 
are also known to express and secrete the cytokines of the APR, which might further stimulate adjacent hepatocytes and neighboring Kupffer cells (Rowell et al., 1997).

\subsection{Aim of the study}

Despite single reports appeared over the last one and a half decade of years suggesting the involvement of $\mathrm{HO}-1$ in the acute phase response, the mechanisms of the HO-1 regulation under inflammatory conditions are poorly understood. Although hepatic HO-1 induction has been shown in different models of the APR (Cantoni et al., 1991; Rizzardini et al., 1998; Bauer et al., 1998; Lyoumi et al., 1998a), it remains unclear whether induction of HO-1 in vivo occurs as a response to the cytokines released by inflammatory cells. It is also not clear which cell type(s) within the liver is/are the main contributor(s) to $\mathrm{HO}-1$ up-regulation during inflammation. Moreover, it is even not known whether the induction of $\mathrm{HO}-1$ during inflammation is a liver-specific, direct consequence of the APR or just a matter of accompanying oxidative stress and occurs also in other organs to the similar extent. Even though it has been shown that $\mathrm{HO}-1$ was up-regulated by proinflammatory cytokines in different cell types (Mitani et al., 1992; Choi and Alam, 1996; Terry et al., 1998), the role of individual cytokines in the elevation of $\mathrm{HO}-1$ expression in vivo is still a matter of debates (Oguro et al., 2002; Song et al., 2003b). Furthermore, the signal transduction pathways of the cytokine-dependent $\mathrm{HO}-1$ induction are not known in detail. Therefore, the aim of the present study was:

1. using a turpentine oil model of the acute phase response in rats:

a) to study $\mathrm{HO}-1$ expression in the liver and extrahepatic tissues under inflammatory conditions;

b) to investigate spatial and cell type-specific induction of $\mathrm{HO}-1$ within the liver (and other organs) during acute phase reaction;

c) to evaluate the role of interleukin-6, the principle mediator of inflammation, in the $\mathrm{HO}-1$ induction in vivo;

2. using primary cultures of isolated rat hepatocytes:

a) to study regulation of $\mathrm{HO}-1$ expression by various proinflammatory cytokines in a dose- and time-dependent experiments; 
b) to perform a functional analysis of the rat $\mathrm{HO}-1$ promoter by means of luciferase reporter gene assay in order to define the molecular mechanisms of the cytokine-dependent $\mathrm{HO}-1$ gene regulation. 


\section{Materials}

\subsection{Animals}

Male Wistar rats (about $200 \mathrm{~g}$ body weight) were purchased from HarlanWinkelmann (Borchen, Germany) and kept under standard conditions with 12-hour light/dark cycles and access to fresh water and food pellets ad libitum at room temperature of $19-23^{\circ} \mathrm{C}$. The rats consumed 12-15 g food (rat diet "ssniff", Spezialitäten $\mathrm{GmbH}$, Soest, Germany) and 12-25 $\mathrm{ml}$ water per day and had a 30-40 g gain of weight per week.

Animals were used for the experiments not earlier than 6 days after arrival. The preparation of hepatocytes was performed during the first $3 \mathrm{~h}$ of the light phase. Rats were anesthetized by intraperitoneal injection of pentobarbital $(400 \mathrm{mg} / \mathrm{kg}$ body weight). For in vivo investigations, an acute phase reaction was induced by intramuscular injection with $5 \mathrm{ml} / \mathrm{kg}$ body weight turpentine oil (TO) into the right and left hind limb of ether-anesthetized rats; control animals received no injection. Animals were sacrificed at time points, ranging from 30 minutes to 48 hours after TO administration under pentobarbital anesthesia. Different organs and muscle tissue from the hind limb were excised, rinsed with physiological sodium saline, snap-frozen in liquid nitrogen and stored at $-80^{\circ} \mathrm{C}$ until use.

All animals received humane care in accordance with the institution's guidelines, the German Convention for Protection of Animals and the National Institutes' of Health guidelines.

\subsection{Bacterial strain, vectors and plasmid constructs}

\subsubsection{Bacterial strain}

E. coli DH5a strain [genotype: supE44, thi-1, recA1, relA1, hsdR17(rK-mK+), thi-1, $\Delta$ lacU169(Ф80 lacZ $\Delta \mathrm{M} 15)$, endA1, gyrA (Nal')] (Stratagene /Heidelberg, Germany) was used for plasmid transformation.

\subsubsection{Vectors}

pBS-KSII vector

For the amplification of the specific cDNA fragments used for Northern blot analysis, the plasmid vector pBluescript (pBS-KS II) (Stratagene, Heidelberg) was 
used. The vector, derived from the vector pUC19, consists of $2961 \mathrm{bp}$. It contains T3 and T7 RNA polymerase promoters, necessary for the in vitro transcription, a multiple cloning site (polylinker), containing the sites for different restriction endonucleases, and primer sequences (universal and reverse primers) necessary for DNA sequencing (Figure 5). Moreover, the multiple cloning site, where a cDNA of interest could be cloned, is flanked by the sequences for T3 and T7 standard primers, which were used in the current work for the PCR-amplification of the cDNAs of interest.

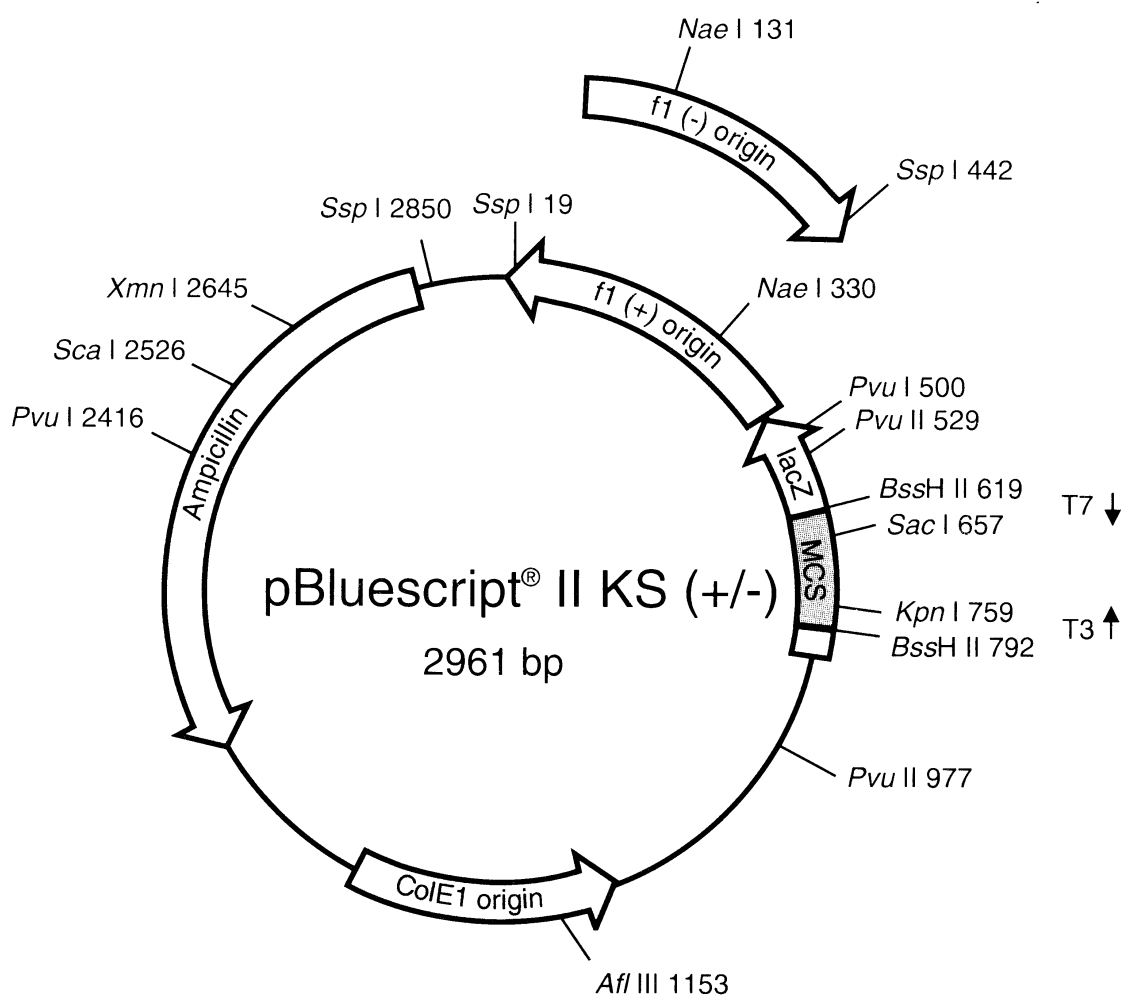

Figure 5. Structure of the pBluescript vector (pBS-KSII). The vector contains the origin of replication ColE1 ori, the ampicillin resistance gene for antibiotic selection, and the LacZ gene coding for $\beta$-galactosidase, which provides the possibility for blue/white color selection of recombinant clones. The multiple cloning site is flanked by T3 and T7 promoters and by the sequences for T3 and T7 primers, KS and SK primers, universal (M13) and reverse sequencing primers.

pcDNA3.1 vector

To assess the transfection efficiency of primary rat hepatocytes, a reporter vector pcDNA3.1 (Invitrogen/Karlsruhe, Germany), containing the GFP gene cloned between EcoR I and Xho I restriction endonuclease sequences of the plasmid multiple cloning site (polylinker), was used. The vector consists of 5428 bp and contains human cytomegalovirus (CMV) promoter followed by the polylinker in 
forward orientation $(+)$ with $\mathrm{T7}$ promoter and the sites for different restriction endonucleases (Figure 6). The CMV promoter permits efficient, high-level expression of the recombinant protein of interest CDNA cloned in the polylinker. Bovine growth hormone $(B G H)$ polyadenylation signal is needed for efficient transcription termination and polyadenylation of the respective mRNA. T7 promoter/priming site allows for in vitro transcription in the sense orientation and sequencing through the insert. pUC origin permits high-copy number replication and growth in $E$. coli, and ampicillin resistance gene ( $\beta$-lactamase) allows selection of vector in E. coli.

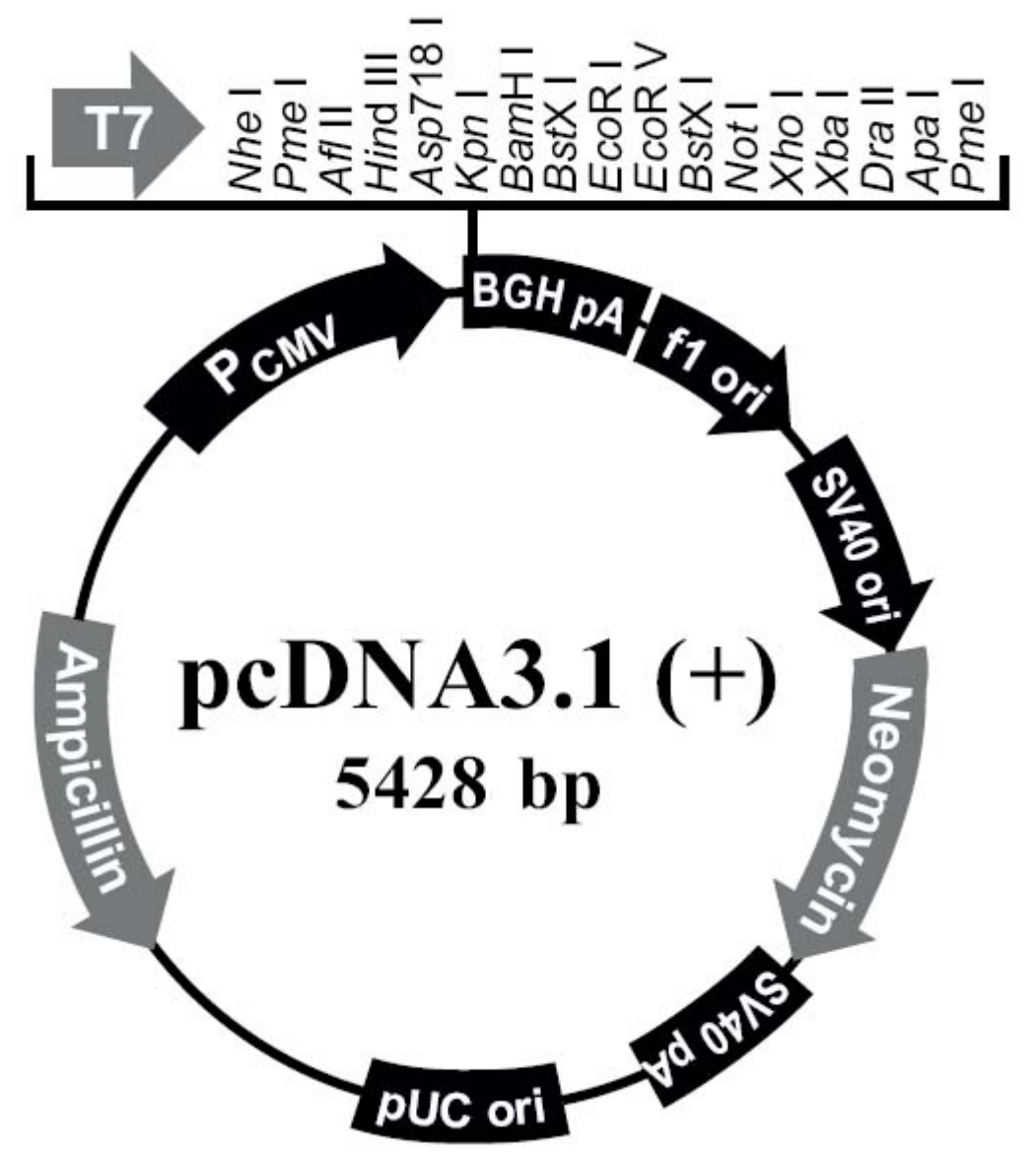

Figure 6. Structure of the pcDNA3.1 (+) vector. The multiple cloning site (polylinker) is flanked by the sequences for T7 forward and BGH reverse priming sites. CMV promoter and $\mathrm{BGH}$ polyadenylation (polyA) sequences are located directly before and after the polylinker, respectively. The SV40 early promoter with origin and SV40 early polyA signal are flanking the neomycin resistance gene. The plasmid also contains the ampicillin resistance gene ( $\beta$-lactamase) and two other origins of replication, pUC ori and $f 1$ ori. The gene of interest and the neomycin gene are transcribed clockwise whereas ampicillin gene is transcribed counterclockwise. 
pGL3-basic vector

For the luciferase reporter gene assay, primary rat hepatocytes were transfected with constructs, containing various rat HO-1 promoter sequences in front of the luciferase (Luc) gene, based on the pGL3-basic vector (Promega /Mannheim, Germany). The vector consists of $4818 \mathrm{bp}$. The HO-1 promoter sequences were cloned in the multiple cloning site (polylinker) of pGL3-basic. The polylinker is flanked by the primer sequences GL2, RV4 and RV3, which are necessary for DNA sequencing. The vector contains the firefly luciferase gene (Luc+) as a reporter gene to estimate the promoter activity, and two polyadenylation signals. The vector pGL3 basic also contains the gene responsible for ampicillin resistance and two origins of replication ColE1 ori and $f 1$ ori, the second of which is necessary for the production of single-stranded DNA (ssDNA) (Figure 7).

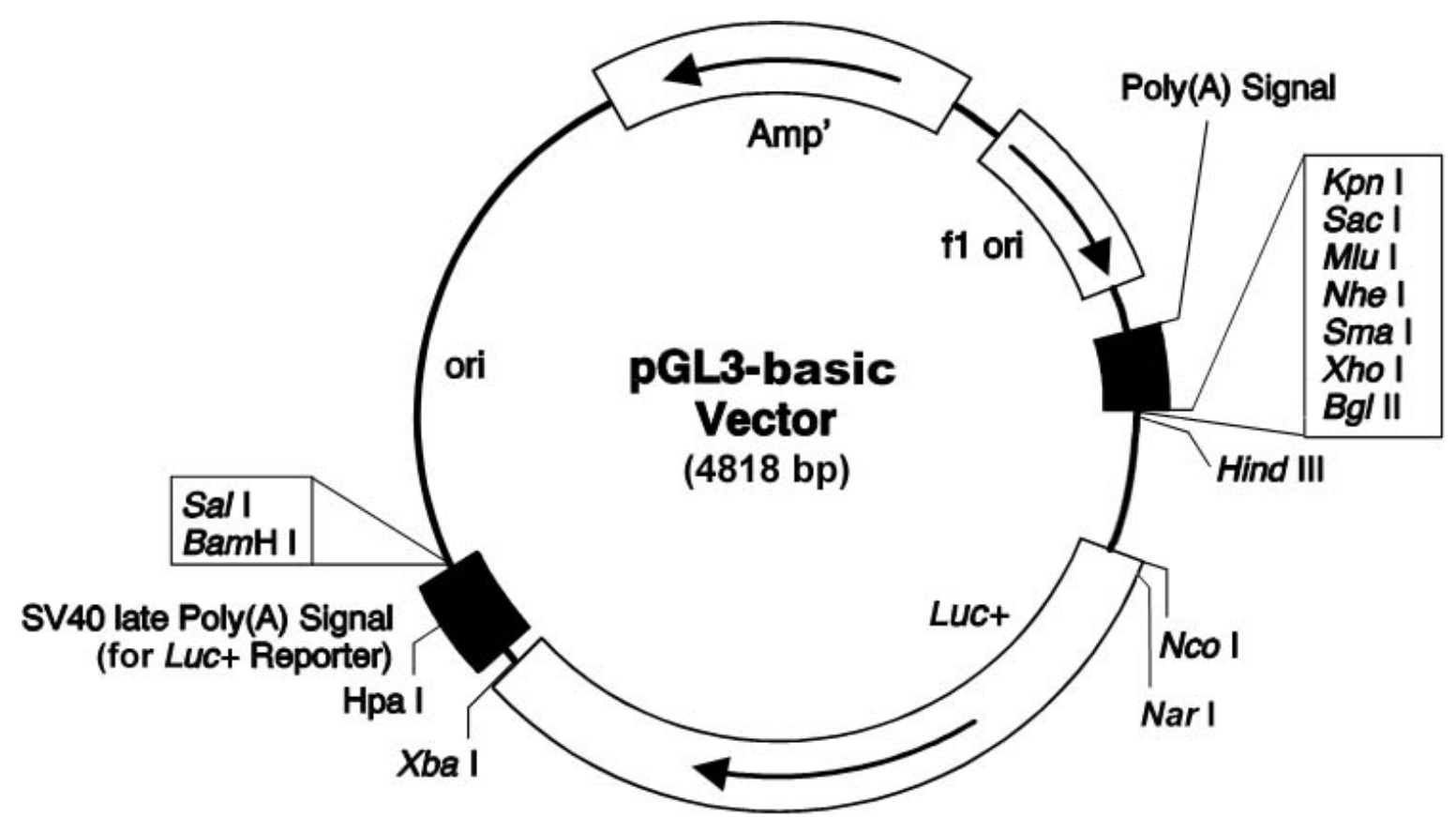

Figure 7. Structure of the pGL3-basic vector. The multiple cloning site (41 bp) is followed by the firefly luciferase gene (Luc+, $1649 \mathrm{bp}$ ) and the SV40 late polyA signal (221 bp). Another, upstream polyA signal (153 bp), is located directly before the multiple cloning site. The plasmid also contains the ampicillin resistance gene ( $\beta$-lactamase; Amp'; $857 \mathrm{bp}$ ) and two origins of replication, ColE1 ori and f1 ori (454 bp). The Luc+ gene is transcribed clockwise whereas Amp' is transcribed counterclockwise.

\subsubsection{Plasmid constructs}

HO-1 promoter constructs

To investigate regulation of the rat $\mathrm{HO}-1$ promoter, primary rat hepatocytes were transiently transfected with luciferase (Luc) gene constructs driven by wild-type 
1387,754 , and 347 bp of the rat $\mathrm{HO}-1$ promoter $(\mathrm{pHO}-1387, \mathrm{pHO}-754$, and $\mathrm{pHO}-$

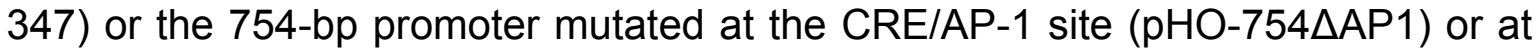
the STAT3 site (pHO-754 $\triangle \mathrm{S} 3 \mathrm{BE})$ (Figure 8).

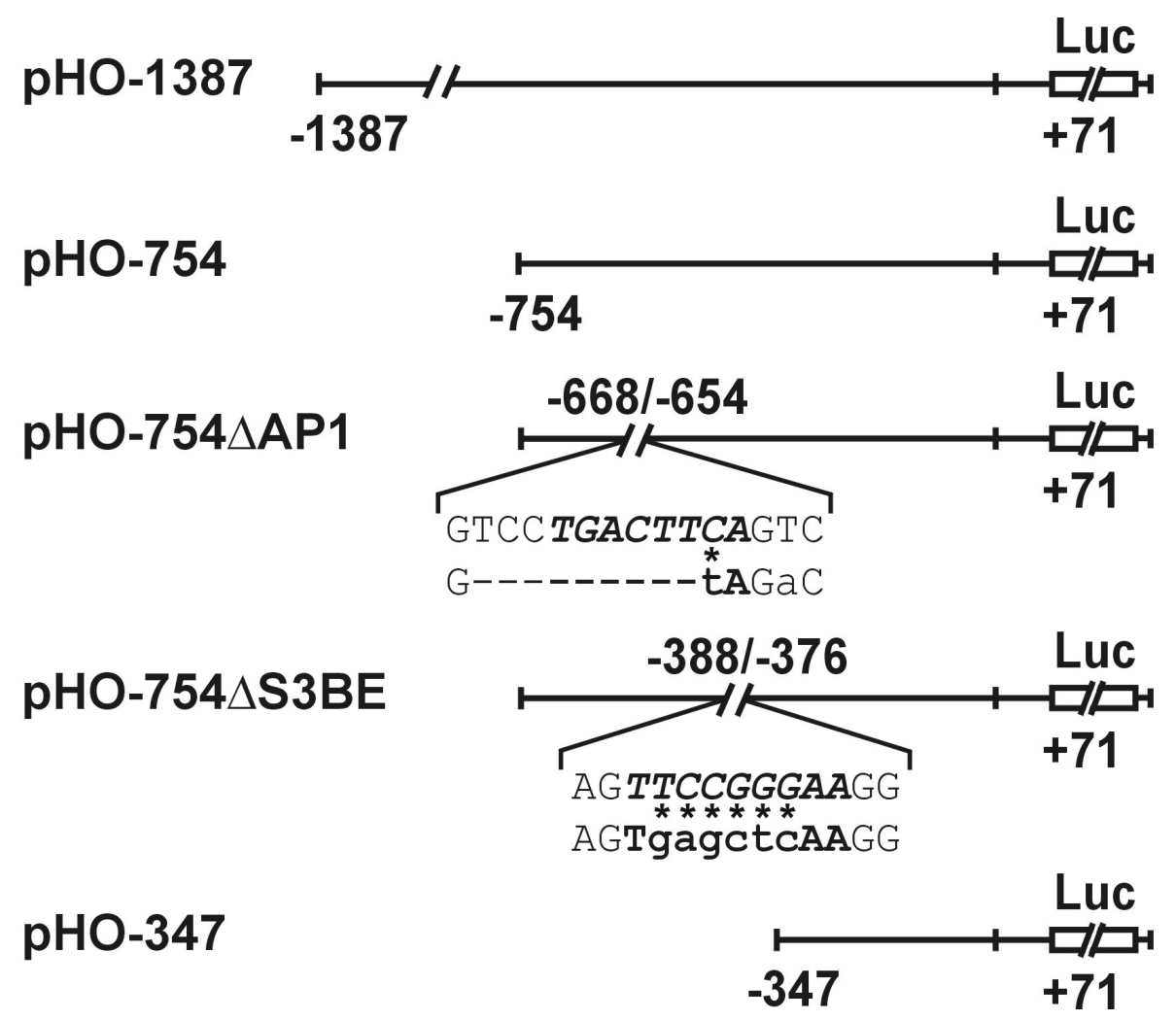

Figure 8. HO-1 promoter luciferase gene constructs. The denominations of the pGI3HO-1 Luc constructs are indicated on the left. In pHO-754 $\triangle$ AP 1 and pHO-754 $\Delta$ S3BE, the wild-type HO-1 promoter sequence is shown on the upper strand, and the mutated sequence is shown on the lower strand: deleted bases are indicated by "-", mutated bases are shown in lowercase letters and indicated by asterisks.

The HO-1 promoter luciferase gene constructs were generously provided by Dr. Thomas Kietzmann and Dr. Anatoly Samoylenko.

\section{Vector expressing GFP}

The bioluminescent jellyfish Aequorea victoria produces light when energy is transferred from $\mathrm{Ca}^{2+}$-activated photoprotein aequorin to green fluorescent protein (GFP) (Morin and Hastings, 1971). The cloning of the wild-type GFP gene (Prasher et al., 1992; Inouye and Tsuji, 1994) and its subsequent expression in heterologous systems (Chalfie et al., 1994; Inouye and Tsuji, 1994; Wang and Hazelrigg, 1994) established GFP as a novel genetic reporter system. When expressed in either eukaryotic or prokaryotic cells and illuminated by blue or UV light, GFP yields a bright green fluorescence. Light-stimulated GFP fluorescence is species-independent and does not require any cofactors, substrates, or additional 
gene products from A. victoria. Additionally, detection of GFP and its variants can be performed in living cells and tissues as well as fixed samples.

In the current study, a plasmid construct pcDNA3.1-GFP was used to assess the transfection efficiency of primary rat hepatocytes. In this vector, the GFP gene is cloned between EcoR I and Xho I restriction endonucleases sequences of the plasmid multiple cloning site. The pcDNA3.1-GFP construct was kindly provided by Dr. Thomas Armbrust.

\subsection{Oligonucleotides and cDNA probes}

\subsubsection{Oligonucleotides}

For PCR-amplification of the cDNAs cloned in pBS-KSII vector, standard T3 and T7 primers were used:

\section{T3: 5'-AAT TAA CCC TCA CTA AAG GG-3'}

T7: 5'-GTA ATA CGA CTC ACT ATA GGG C-3'

Northern blot hybridization with the following $28 \mathrm{~S}$ rRNA-specific oligonucleotide probe was used to control equal loading of total RNA (Barbu and Dautry, 1989):

Oligonucleotide complementary to 28S rRNA:

5'-AAC GAT CAG AGT AGT GGT ATT TCA CC-3'

\subsection{2 cDNA probes}

Two of the cDNA probes used for Northern blot were amplified from respective clones (based on pBS-KSII vector) by polymerase chain reaction (PCR) using standard T3 and T7 primers:

- an 883 base pair (bp) EcoR I - Hind III insert of clone pBS-HO-1 coding for the rat HO-1 (Shibahara et al., 1985);

- a 901 bp Pst I - BamH I fragment of a rat IL-6 clone (Northemann et al., 1989).

In order to control development of the APR in the rat liver, a rat $\alpha 2$-macroglobulinspecific cDNA clone (Gehring et al., 1987) and a clone carrying a 700 bp fragment of mouse albumin cDNA (Kioussis et al., 1981) were used.

To validate quantitative Northern blot results, a clone carrying the rat glyceraldehyde-3-phosphate dehydrogenase (GAPDH) cDNA was used (Fort et al., 1985). 


\subsection{Antibodies}

Anti-Heme-Oxygenase-1 Ab (SPA-895)

For the detection of HO-1 using immunoblotting, rabbit polyclonal anti-serum raised against recombinant rat $\mathrm{HO}-1$ was used (Stressgen Biotechnologies Corp. Nictoria, BC, Canada). Species reactivity: SPA-895 detects HO-1 from human, mouse, rat, monkey, rabbit, hamster, guinea pig, sheep, and canine tissues.

\section{Anti-Heme-Oxygenase-1 Ab (OSA-111)}

For the detection of $\mathrm{HO}-1$ using immunohistochemical analysis, mouse monoclonal antibody (HO-1-2 clone) raised against rat $\mathrm{HO}-1$ was used (Stressgen Biotechnologies Corp. /Victoria, BC, Canada). Species reactivity: OSA-111 detects $\mathrm{HO}-1$ in mouse and rat.

\section{$\underline{\text { Anti- } \beta \text {-actin Ab }}$}

For the detection of $\beta$-actin, mouse monoclonal antibody (AC-15 clone) raised against $\mathrm{N}$-terminal peptide of $\beta$-actin was used (Sigma /Munich, Germany). This antibody recognizes $\beta$-isoform (nonmuscle) of actin in human, bovine, sheep, pig, rabbit, dog, mouse, rat, guinea pig, chicken, carp, and fruit fly tissues. The antibody does not cross react with skeletal and cardiac isoform (a-isoform) of actin.

\section{Anti-rat ED1 Ab (MCA341R)}

For the detection of rat tissue macrophages in immunohistochemical analysis, mouse monoclonal antibody raised against rat spleen cells was used (Serotec /Düsseldorf, Germany). This antibody recognizes a single chain glycoprotein of 90-100 kDa expressed by the majority of tissue macrophages in rat.

\section{Anti-rat ED2 Ab (MCA342R)}

For the detection of rat Kupfer cells in immunohistochemical analysis, mouse monoclonal antibody raised against rat spleen cell homogenate was used (Serotec /Düsseldorf, Germany). This antibody recognizes a membrane antigen on Kuppfer cells in rat. 
Secondary Ab (horse radish peroxidase conjugated):

rabbit anti-mouse affinity purified Ig, Dako /Copenhagen, Denmark;

donkey anti-rabbit whole Ig, Amersham Pharmacia Biotech /Freiburg, Germany.

\subsection{Proteins, enzymes and protein standards}

Bovine serum albumin (BSA)

Collagenase type I

Collagenase $\mathrm{H}$

DNase I

Glucose oxidase

Insulin, porcine

Pronase E

Rainbow $^{\mathrm{TM}}$ colored protein

molecular weight markers

Recombinant rat IL-6

Taq DNA polymerase
PAA /Linz, Austria

Biochrom /Berlin, Germany

Roche /Mannheim, Germany

Roche /Mannheim, Germany

Sigma /Munich, Germany

Sigma /Munich, Germany

Merck /Darmstadt, Germany

Amersham Pharmacia Biotech /

Freiburg, Germany

PeproTech Inc. /Rocky Hill, USA

Invitrogen /Karlsruhe, Germany

\subsection{Protease inhibitors}

Antipain

Benzamidine

Chymostatin

Leupeptin

Pepstatin A

PMSF
Sigma /Munich, Germany

Sigma /Munich, Germany

Sigma /Munich, Germany

Sigma /Munich, Germany

Sigma /Munich, Germany

Sigma /Munich, Germany

\subsection{Detection, purification and synthesis systems (kits)}

BCA Protein Assay, Pierce /Bonn, Germany

EndoFree $^{\mathrm{TM}}$ Plasmid Maxi Kit, Qiagen /Hilden, Germany

Liquid DAB+ Substrate Chromogen System, Dako /Copenhagen, Denmark Luciferase Assay Kit, Berthold/Pforzheim, Germany

Nick translation kit, Invitrogen /Karlsruhe, Germany 
NEBlot ${ }^{\circledR}$ Kit, New England Biolabs /Schwalbach, Germany

NucleoSpin ${ }^{\circledR}$ RNAIl kit, Macherey-Nagel /Düren, Germany

SuperSignal ${ }^{\circledR}$ West Pico Chemiluminescent Substrate, Pierce /Bonn, Germany

Quantikine ${ }^{\circledR}$ M rat IL-6 immunoassay kit, R\&D Systems /Wiesbaden, Germany

\subsection{Stock solutions}

All stock solutions were prepared either in double distilled water or (for experiments with RNA) in RNase-free water; the $\mathrm{pH}$ values of stock solutions are presented as the values at $25^{\circ} \mathrm{C}$.

APS 10\%

For $10 \mathrm{ml} \quad$ Final concentration

APS

$1 \mathrm{~g} \quad 10 \%$

$\mathrm{ddH}_{2} \mathrm{O}$

to $10 \mathrm{ml}$

The solution was dispensed into $100 \mu$ laliquots and stored at $-20^{\circ} \mathrm{C}$.

$\underline{\text { Citric acid } 0.25 \mathrm{M}}$

For $100 \mathrm{ml}$

Final concentration

Citric acid

$4.8 \mathrm{~g}$

$0.25 \mathrm{M}$

RNase-free $\mathrm{H}_{2} \mathrm{O}\left(\right.$ Ampuwa ${ }^{\circledR}$ )

to $100 \mathrm{ml}$

The solution was stored at room temperature.

EDTA $0.5 \mathrm{M}$

For $100 \mathrm{ml}$

Final concentration

EDTA (disodium salt)

$18.61 \mathrm{~g}$

$0.5 \mathrm{M}$

RNase-free $\mathrm{H}_{2} \mathrm{O}\left(\right.$ Ampuwa $^{\circledR}$ )

to $100 \mathrm{ml}$

$\mathrm{pH}$ was adjusted with $5 \mathrm{~N} \mathrm{NaOH}$ to 8.0. The solution was sterile filtered and stored at room temperature.

\section{PBS 10X}




$\begin{array}{lll}\mathrm{KCl} & 2 \mathrm{~g} & 27 \mathrm{mM} \\ \mathrm{Na}_{2} \mathrm{HPO}_{4} & 14.2 \mathrm{~g} & 100 \mathrm{mM} \\ \mathrm{KH}_{2} \mathrm{PO}_{4} & 2.45 \mathrm{~g} & 18 \mathrm{mM} \\ \mathrm{ddH}_{2} \mathrm{O} & \text { to } 1 \mathrm{I} & \end{array}$

$\mathrm{pH}$ was adjusted with $\mathrm{HCl}$ to 7.3 . The solution was sterile filtered and stored at room temperature.

SDS 20\%

$\begin{array}{lll} & \text { For } 100 \mathrm{ml} & \text { Final concentration } \\ \mathrm{SDS} & 20 \mathrm{~g} & 20 \% \\ \mathrm{ddH}_{2} \mathrm{O} & \text { to } 100 \mathrm{ml} & \end{array}$

In the case of precipitation of SDS, the solution was warmed until clear.

Sodium acetate $2 \mathrm{M}$

$\begin{array}{lll} & \text { For } 100 \mathrm{ml} & \text { Final concentration } \\ \text { Sodium acetate } & 16.408 \mathrm{~g} & 2 \mathrm{M} \\ \mathrm{RNase}-\mathrm{free} \mathrm{H}_{2} \mathrm{O}\left(\text { Ampuwa }^{\circledR}\right) & \text { to } 100 \mathrm{ml} & \\ \mathrm{pH} \text { was adjusted with acetic acid to } 5.4 \text {. The solution was stored at } 4^{\circ} \mathrm{C} .\end{array}$

\section{$\underline{\text { Sodium citrate } 0.25 \mathrm{M}}$}

$\begin{array}{lll} & \text { For } 100 \mathrm{ml} & \text { Final concentration } \\ \text { Sodium citrate } & 7.35 \mathrm{~g} & 0.25 \mathrm{M} \\ \mathrm{RNase}-\text { free } \mathrm{H}_{2} \mathrm{O}\left(\text { Ampuwa }^{\circledR}\right) & \text { to } 100 \mathrm{ml} & \\ \mathrm{pH} \text { was adjusted with } 0.25 \mathrm{M} \text { citric acid to } 7.0 \text {; the solution was stored at room } \\ \text { temperature. }\end{array}$

\section{$\underline{\text { Tris- } \mathrm{HCl} 2 \mathrm{M}}$}

$\begin{array}{lll} & \text { For } 1 \mathrm{l} & \text { Final concentration } \\ \text { Tris- } \mathrm{HCl} & 315.2 \mathrm{~g} & 2 \mathrm{M} \\ \mathrm{RNase}-\mathrm{free} \mathrm{H}_{2} \mathrm{O}\left(\mathrm{Ampuwa}^{\circledR}\right) & \text { to } 1 \mathrm{I} & \\ \mathrm{pH} \text { was adjusted with } \mathrm{HCl} \text { to } & 7.4 . \text { The solution was sterile filtered and stored at } \\ 4^{\circ} \mathrm{C} \text {. } & \end{array}$




\subsection{Chemicals}

All chemicals were of analytical grade and obtained from commercial sources as indicated.

Amersham Pharmacia Biotech /Freiburg, Germany

$\left[\alpha-{ }^{32} \mathrm{P}\right]$-labeled deoxy-cytidine-triphosphate (specific activity $3,000 \mathrm{Ci} / \mathrm{mmol}$ ), Ficoll ${ }^{\circledR} 400$

Biochrom /Berlin, Germany

M199, fetal calf serum, Trypan blue

Bioline /Luckenwalde, Germany

dNTP master mix

Bio-Rad /Munich, Germany

Tween 20, mixed bed resin AG 501-X8(D)

Böhringer /Mannheim, Germany

Ampicillin

Difco Laboratories /Detroit, MI, USA

LPS from Salmonella Minnesota, bactoagar, bacto-trypton, yeast extract

Fresenius /Bad Homburg, Germany

Ampuwa ${ }^{\circledR}$ water

Invitrogen /Karlsruhe, Germany

Agarose, guanidine isothiocyanate

MBI Fermentas Nilnius, Lithuania

$6 X$ loading dye solution, GeneRuler ${ }^{\mathrm{TM}}$ 100bp DNA Ladder Plus, GeneRuler ${ }^{\mathrm{TM}} 1 \mathrm{~kb}$ DNA Ladder Plus 
Merck /Darmstadt, Germany

All usual laboratory chemicals, acetic acid glacial, acetone, bromphenol blue, ethanol, 37\% formaldehyde, formamide, glucose, glycerol, Kaiser's glycerol gelatin, Meyer's hemalaun, methanol, $\beta$-mercaptoethanol, penicillin $G$, streptomycin, TEMED

Merial /Hallbergmoos, Germany

Pentobarbital sodium (Narcoren ${ }^{\circledR}$ )

Nyegaard /Oslo, Norway

Nycodenz ${ }^{\circledR}$

PAA /Linz, Austria

L-Glutamine

Paesel and Lorei /Frankfurt, Germany

Cesium chloride

Promega /Mannheim, Germany

Luciferase assay cell lysis reagent

Roth /Karlsruhe, Germany

Rotiphorese Gel 30 (30\% acrylamide stock solution with $0.8 \%$ bisacrylamide in proportion 37.5:1), glycine, sodium dodecyl sulfate (SDS)

Serva /Heidelberg, Germany

Ponceau S, Tris-HCl

Sigma-Aldrich Chemie /Munich, Germany

All usual laboratory chemicals, ammonium persulfate, antifoam A, CDTA, citric acid, dexamethasone, DMSO, DTT, EDTA, ethidium bromide, HEPES, MOPS, $\mathrm{N}$-lauroylsarcosyl, sodium acetate, sodium citrate, Triton X-100

Stratagene /Heidelberg, Germany)

QuikHyb ${ }^{\circledR}$ Hybridization Solution 
Universitaets Apotheke Goettingen /Göttingen, Germany

Turpentine oil

Zinsser Analytic /Frankfurt, Germany

Scintillation liquid

\subsection{Other materials}

Braunules 2G14, Braun /Melsungen, Germany

Cover-slips, 24x55 mm, Menzel-Gläser /Braunschweig, Germany

Culture dishes $(60 \mathrm{~mm})$, serological pipettes $(2,5,10,25 \mathrm{ml})$, transfer pipettes, plastic tubes (15 and $50 \mathrm{ml}$ ), Sarstedt /Germany

Hybond N nylon membrane, disposable NICK columns prepacked with Sephadex ${ }^{\circledR}$ G-50 DNA grade, Amersham Pharmacia Biotech /Freiburg, Germany

Hybridization glass tubes, Biometra /Göttingen, Germany

Microscope glass slides, 76x26 mm, Menzel-Gläser /Braunschweig, Germany

Nitrocellulose Transfer Membrane, $0.45 \mu \mathrm{m}, \mathrm{PROTRAN}^{\circledR}$, Whatman 3MM paper, Schleicher and Schuell /Dassel, Germany

Polyallomer thin-walled centrifuge tubes (5 ml), Beckman /Munich, Germany

Safe-Lock tubes $(0.2,0.5,1.5$ and $2 \mathrm{ml})$, Eppendorf /Hamburg, Germany

Scintillation vials (5 ml), Zinsser Analytic /Frankfurt, Germany

Sterile filter Nalgene, $0.2 \mu \mathrm{m}$, Sartorius /Göttingen, Germany

Sterile filter pipette tips, Biozym /Oldendorf, Germany 
96-well microtiter plates, Nunc Inc. /Naperville, IL, USA

X-ray films, Fuji /Düsseldorf, Germany

X-ray films X-Omat AR, Kodak /Rochester, USA

\subsection{Instruments}

Automatic pipettes, type Reference ${ }^{\circledR}$, Eppendorf /Hamburg, Germany

Automatic pipettes, type Pipetman, Gilson /Bad Camberg, Germany

Centrifuges and rotors:

\begin{tabular}{|l|c|}
\hline \multicolumn{2}{|c|}{ Bench-top, high speed and ultracentrifuges } \\
\hline $\begin{array}{l}\text { Beckman model J2-21 centrifuge } \\
\text { Beckman rotor JE-6B }\end{array}$ & Beckman /Munich, Germany \\
\hline $\begin{array}{l}\text { Centricon T-2070 ultracentrifuge } \\
\text { Centricon rotor TST55.5 - 55000 rpm }\end{array}$ & $\begin{array}{c}\text { Kontron Instruments/Neufahrn, } \\
\text { Germany }\end{array}$ \\
\hline $\begin{array}{l}\text { Eppendorf bench-top centrifuge, type MiniSpin } \\
5415 C\end{array}$ & Eppendorf /Hamburg, Germany \\
\hline $\begin{array}{l}\text { Hettich Mikro Rapid/K centrifuge } \\
\text { Hettich Rotina 3850 centrifuge } \\
\text { Hettich Rotixa/RP centrifuge }\end{array}$ & $\begin{array}{c}\text { Hettich /Tuttlingen, Germany } \\
\text { Minifuge GL centrifuge }\end{array}$ \\
\hline $\begin{array}{l}\text { Sigma 3K30 centrifuge } \\
\text { Rotor Nr 12156 - 16500 rpm } \\
\text { Rotor Nr 12153 - 22000 rpm }\end{array}$ & $\begin{array}{r}\text { Heraeus-Christ /Osterode, } \\
\text { Germany }\end{array}$ \\
\hline
\end{tabular}

Cryostat for tissue section preparation, Frigocut 2800 E, Reichert-Jung /Bensheim, Germany 
Eagle Eye ${ }^{\mathrm{TM}}$ system with built-in ultraviolet emitter, video camera and frame integrator, Stratagene Europe /Amsterdam, The Netherlands

Electroblotting apparatus, type Mini Trans-Blot ${ }^{\circledR}$, Bio-Rad /Munich, Germany

Electrophoresis apparatus, type Mini-Protean ${ }^{\circledR}$ III, Bio-Rad /Munich, Germany

Gas controlled incubators, Heraeus-Electronic /Hannover, Germany

Horizontal gel electrophoresis system, Horizon ${ }^{\circledR}$ 11-14, Gibco BRL /Gaithersburg, MD, USA

Hybridization oven, Biometra /Göttingen, Germany

Ice machine, Ziegra /Isernhagen, Germany

Incubator with shaking for cell culture, model 3-25, New Brunswick Scientific Co., Inc. /Edison, New Jersey, USA

Liquid scintillation counter Wallac 1409 / Turku, Finland

Magnetic mixer with warming, type M21/1 Framo-Gerätetechnik /Germany

Microwave oven, Siemens /Germany

Microplate reader MRX, Dynatech Laboratories /Chantilly, VA, USA

Microscope Axiovert 25, Zeiss /Oberkochen, Germany

Microscope Axioscop with fotocamera MC 100 Spot, Zeiss /Oberkochen, Germany

Peristaltic pump P-1, Amersham /Freiburg, Germany

pH-Meter 761 Calimatic, Knick /Berlin, Germany 
Power supply, Power Pac 300, Bio-Rad /Munich, Germany

Rocking platform, Biometra /Göttingen, Germany

Savant Speed Vac ${ }^{\circledR}$ concentrator, ThermoLife Sciences /Egelsbach, Germany

Scanning densitometer, Molecular Analyst, Bio-Rad/Hercules, CA, USA

Sterile bench, type Lamin Air, TL 2472, Heraeus /Hanau, Germany

Sterile bench, type MRF 0.612-GS, Prettl Laminarflow und Prozesstechnick / Bempflingen, Germany

Thermocycler, type Mastercycler ${ }^{\circledR}$ gradient, Eppendorf/Hamburg, Germany

Thermomixer 5436, Eppendorf /Hamburg, Germany

Thermostat, Heraeus /Hanau, Germany

Ultra-Turrax TP 18/10 homogenizer, Janke \& Kunkel /Staufen, Germany

Ultraviolet emitter, 312 nm, Bachofer /Reutlingen, Germany

UV spectrophotometer, RNA/DNA Calculator GeneQuant II, Pharmacia Biotech / Freiburg, Germany

UV-light crosslinker, Stratalinker ${ }^{\mathrm{TM}}$ 180, Stratagene /Heidelberg, Germany

Vortex, Genie $2^{\mathrm{TM}}$, Bender and Hobein /Zurich, Switzerland

Vortex, with platform, Schütt Labortechnic /Göttingen, Germany

Water bath 1083, GFL /Burgwedel, Germany

X-ray film cassettes $10 \times 18$, Siemens /Germany

X-ray film-developing machine SRX-101A, Konica Europe /Hohenbrunn, Germany 


\section{Methods}

\subsection{Methods of cell biology}

\subsubsection{Isolation of rat hepatocytes}

Hepatocytes were isolated from male Wistar rats by circulating perfusion with collagenase essentially as described previously (Seglen, 1973; Katz et al., 1979).

\section{Liver perfusion}

After laparotomy, the vena portae was canulated, vena cava inferior was ligated above the diaphragm to prevent flow of the perfusion media into a whole body circulation. Finally, the vena cava inferior was cut beneath the liver and canulated. The liver was perfused in non-recirculative mode through the portal vein with 150-200 $\mathrm{ml} \mathrm{CO}_{2}$-enriched preperfusion medium at a flow rate of $30 \mathrm{ml} / \mathrm{min}$ until the liver was free from blood. To break down components of extracellular matrix, the liver was perfused in recirculative mode with collagenase perfusion medium until it started to feel soft (about 7-11 $\mathrm{min}$ ).

Preparation of the hepatocyte suspension

After perfusion, the liver was excised and transferred into a sterile glass beaker filled with culture medium M 199 with additives. Glisson's capsule, i. e. collagen tissue around the liver, was carefully removed and discarded. To obtain a cell suspension, the tissue was disrupted mechanically using sterile forceps. Connective tissue and remainder of the liver capsule as well as big cell aggregates were removed by filtration of the primary cell suspension through a nylon mesh (pore size $79 \mu \mathrm{m}$ ). Non-parenchymal cells and cell debris were removed by numerous selective sedimentations $\left(20 \mathrm{~g}, 2 \mathrm{~min}, 4^{\circ} \mathrm{C}\right)$ in wash medium. After the last centrifugation, hepatocytes were suspended in medium M 199 with additives. $50 \mathrm{ml}$ of M 199 was added per $1 \mathrm{~g}$ of wet weight of the sedimented cells; the cell suspension typically had a density of about $10^{6} / 2.5 \mathrm{ml}$.

\section{Media and solutions for hepatocyte preparation and culture}

All media and solutions for cell culture were prepared in double distilled water, further purified by sterile filtration and stored at $4^{\circ} \mathrm{C}$. All solutions were prepared not more than one day before the isolation. 
$\underline{\text { Krebs-Ringer stock solution }}$

$\begin{array}{lll} & \text { For 1 I } & \text { Final concentration } \\ \mathrm{NaCl} & 7 \mathrm{~g} & 120 \mathrm{mM} \\ \mathrm{KCl} & 0.36 \mathrm{~g} & 4.8 \mathrm{mM} \\ \mathrm{MgSO}_{4} \times 7 \mathrm{H}_{2} \mathrm{O} & 0.296 \mathrm{~g} & 1.2 \mathrm{mM} \\ \mathrm{KH}_{2} \mathrm{PO}_{4} & 0.163 \mathrm{~g} & 1.2 \mathrm{mM} \\ \mathrm{NaHCO}_{3} & 2.016 \mathrm{~g} & 24.4 \mathrm{mM} \\ \mathrm{ddH}_{2} \mathrm{O} & \text { to } 1 \mathrm{I} & \end{array}$

The solution was equilibrated with carbogen and $\mathrm{pH}$ was adjusted to 7.35.

Preperfusion medium

EGTA
Krebs-Ringer stock solution
Collagenase perfusion medium

For $1 \mathrm{I} \quad$ Final concentration

$95.1 \mathrm{mg} \quad 0.25 \mathrm{mM}$

to 1 I

$\begin{array}{lll} & \text { For } 100 \mathrm{ml} & \text { Final concentration } \\ \text { HEPES } & 360 \mathrm{mg} & 15 \mathrm{mM} \\ \mathrm{CaCl}_{2} \times 2 \mathrm{H}_{2} \mathrm{O} & 58.8 \mathrm{mg} & 4 \mathrm{mM} \\ \text { Collagenase } & 50 \mathrm{mg} & \\ \text { Krebs-Ringer stock solution } & \text { to } 100 \mathrm{ml} & \end{array}$

The medium was prepared directly prior to isolation, equilibrated with carbogen for 30 min and finally sterile filtered.

Wash medium

$\begin{array}{lll}\mathrm{HEPES} / \mathrm{NaOH} \mathrm{pH} 7.4 & 4.77 \mathrm{~g} & 20 \mathrm{mM} \\ \mathrm{NaCl} & 7.00 \mathrm{~g} & 120 \mathrm{mM} \\ \mathrm{KCl} & 0.36 \mathrm{~g} & 4.8 \mathrm{mM} \\ \mathrm{MgSO}_{4} \times 7 \mathrm{H}_{2} \mathrm{O} & 0.30 \mathrm{~g} & 1.2 \mathrm{mM} \\ \mathrm{KH}_{2} \mathrm{PO}_{4} & 0.16 \mathrm{~g} & 1.2 \mathrm{mM} \\ \text { Bovine serum albumin }_{\mathrm{ddH}} \mathrm{O} & 4.00 \mathrm{~g} & 0.4 \% \\ & \text { to } 1 \mathrm{I} & \end{array}$


$\underline{\text { Medium M } 199 \text { with additives }}$

Final concentration

M199 with Earle's salts

without $\mathrm{NaHCO}_{3}$

11

Glucose $\times \mathrm{H}_{2} \mathrm{O}$

$1.1 \mathrm{~g}$

$5.5 \mathrm{mM}$

HEPES

$3.6 \mathrm{~g}$

$15 \mathrm{mM}$

$\mathrm{NaHCO}_{3}$

$1.5 \mathrm{~g}$

$18 \mathrm{mM}$

Bovine serum albumin

$4.0 \mathrm{~g}$

$0.4 \%$

The medium was equilibrated with carbogen until $\mathrm{pH}$ reached a value of 7.35.

Finally, the medium was sterile filtered.

\subsubsection{Isolation of rat Kupffer cells}

Rat liver macrophages (Kupffer cells) were isolated according to the method of Knook and Sleyster (Knook and Sleyster, 1976) as previously described with slight modifications.

Liver perfusion and preparation of cell suspension

The laparotomy and canulation were performed essentially as described above (see 3.1.1). The liver was perfused with preperfusion medium containing Gey's Balanced Salt Solution (GBSS) and sodium hydrocarbonate, followed by perfusion with enzyme solution 1 containing pronase with subsequent change to enzyme solution 2 containing pronase and collagenase.

After perfusion, the liver was excised and placed into the sterile Petri dish filled with enzyme solution 3 containing pronase, collagenase and DNase I and was mechanically disruptured with sterile forceps. The cell suspension obtained was stirred in the same perfusion solution for 30 min with simultaneous control of $\mathrm{pH}$ (7.5) and finally filtered through the sterile sieve and collected in $50 \mathrm{ml}$ polypropylene tubes. To separate big cell aggregates and major part of the parenchymal liver cells, the suspension was centrifuged for 4 min at $35 \mathrm{~g}\left(4^{\circ} \mathrm{C}\right)$. The supernatant was recentrifuged for $5 \mathrm{~min}$ at $640 \mathrm{~g}\left(4^{\circ} \mathrm{C}\right)$, the pellet was resuspended in $50 \mathrm{ml}$ of GBSS containing $100 \mu \mathrm{l}$ DNase I.

Separation of nonparenchymal liver cells

Nonparenchymal liver cells were separated using Nycodenz ${ }^{\circledR}$ density gradient as follows: the cell suspension was transferred into four sterile $50 \mathrm{ml}$ polypropylene 
tubes and centrifuged for $5 \mathrm{~min}$ at $640 \mathrm{~g}\left(4^{\circ} \mathrm{C}\right)$. The supernatant was discarded and the pellets were resuspended in small volume $(5-6 \mathrm{ml})$ of GBSS with $100 \mu \mathrm{l}$ DNase I and pooled together in one sterile $50 \mathrm{ml}$ polypropylene tube. $14 \mathrm{ml}$ of $30 \%$ Nycodenz was added and the volume was adjusted to $24 \mathrm{ml}$ with GBSS. This mixture was divided between four sterile $15 \mathrm{ml}$ polypropylene tubes and GBSS ( $1.5 \mathrm{ml}$ per tube) was carefully layered over the content of the tubes. The gradient was centrifuged for $15 \mathrm{~min}$ at $1,800 \mathrm{~g}\left(4^{\circ} \mathrm{C}\right)$. Afterwards, the interphase brown layer between Nycodenz and GBSS containing nonparenchymal liver cells was carefully transferred into sterile $50 \mathrm{ml}$ polypropylene tube and centrifuged for $5 \mathrm{~min}$ at $640 \mathrm{~g}\left(4^{\circ} \mathrm{C}\right)$.

\section{Purification of Kupffer cells by counterflow elutriation}

To obtain pure Kupffer cells, nonparenchymal liver cells were fractionated by centrifugal counterflow elutriation according to (Knook and Sleyster, 1976). The nonparenchymal liver cell pellet obtained in previous step was resuspended in 5-6 $\mathrm{ml}$ of $0.4 \% \mathrm{BSA} / \mathrm{GBSS}$, collected in a sterile $10 \mathrm{ml}$ syringe and injected in the elutriation system. Using JE-6B elutriation rotor assembled according to the manufacturer's instructions and spun at 2,500 rpm in a J2-21 centrifuge (Beckman Instruments), fractions enriched with sinusoidal endothelial cells, myofibroblasts and Kupffer cells were collected at flow rates of $19 \mathrm{ml} / \mathrm{min}, 23 \mathrm{ml} / \mathrm{min}$ and 55 $\mathrm{ml} / \mathrm{min}$, respectively.

The Kupffer cell fraction was sedimented by centrifugation $\left(5 \mathrm{~min}\right.$ at $640 \mathrm{~g}, 4^{\circ} \mathrm{C}$ ), counted in a Neubauer chamber and, after assessment of cell viability by Trypan blue staining, taken up in a culture medium.

\section{Media and solutions for Kupffer cell preparation and culture}

All media and solutions for cell culture were prepared in double distilled water, further purified by sterile filtration and stored at $4^{\circ} \mathrm{C}$, unless otherwise indicated.

\section{X GBSS (Gey's Balanced Salt Solution)}

\section{For 11}

$\mathrm{NaCl}$

$80 \mathrm{~g}$

$\mathrm{KCl}$

$\mathrm{MgSO}_{4} \times 7 \mathrm{H}_{2} \mathrm{O}$

$0.7 \mathrm{~g}$ 


$\begin{array}{lc}\mathrm{NaH}_{2} \mathrm{PO}_{4} \times \mathrm{H}_{2} \mathrm{O} & 1.7 \mathrm{~g} \\ \mathrm{CaCl}_{2} \times 2 \mathrm{H}_{2} \mathrm{O} & 2.2 \mathrm{~g} \\ \mathrm{KH}_{2} \mathrm{PO}_{4} & 0.3 \mathrm{~g} \\ \mathrm{MgCl}_{2} \times 6 \mathrm{H}_{2} \mathrm{O} & 2.1 \mathrm{~g} \\ \text { Glucose } & 10 \mathrm{~g} \\ \mathrm{ddH}_{2} \mathrm{O} & \text { to } 1 \mathrm{I}\end{array}$

\section{Preperfusion medium}

For 11

$\mathrm{NaHCO}_{3} \quad 227 \mathrm{mg}$

10X GBSS $100 \mathrm{ml}$

$\mathrm{ddH}_{2} \mathrm{O}$ to 1 I

The solution was prepared directly prior to isolation; $\mathrm{pH}$ was adjusted to 7.4.

\section{X GBSS without $\mathrm{NaCl}$}

For 11

$\mathrm{KCl} \quad 370 \mathrm{mg}$

$\mathrm{MgSO}_{4} \times 7 \mathrm{H}_{2} \mathrm{O} \quad 70 \mathrm{mg}$

$\mathrm{NaH}_{2} \mathrm{PO}_{4} \times \mathrm{H}_{2} \mathrm{O} \quad 170 \mathrm{mg}$

$\mathrm{CaCl}_{2} \times 2 \mathrm{H}_{2} \mathrm{O} \quad 220 \mathrm{mg}$

$\mathrm{NaHCO}_{3} \quad 227 \mathrm{mg}$

$\mathrm{KH}_{2} \mathrm{PO}_{4} \quad 30 \mathrm{mg}$

$\mathrm{MgCl}_{2} \times 6 \mathrm{H}_{2} \mathrm{O} \quad 210 \mathrm{mg}$

Glucose $\quad 1 \mathrm{~g}$

$\mathrm{dd}_{2} \mathrm{O}$ to $1 \mathrm{I}$

$\mathrm{pH}$ was adjusted to 7.4.

$\underline{30 \% \text { Nycodenz }^{\circledR}}$

For $100 \mathrm{ml}$

Nycodenz $^{\circledR} \quad 30 \mathrm{~g}$

1X GBSS without $\mathrm{NaCl}$ to $100 \mathrm{ml}$

The solution was dispensed into $14 \mathrm{ml}$ aliquots and stored at $-20^{\circ} \mathrm{C}$. 


\section{$0.4 \%$ BSA/GBSS}

For $500 \mathrm{ml}$

BSA $2 \mathrm{~g}$

1X GBSS to $500 \mathrm{ml}$

\section{Enzyme solutions}

All enzymes were dissolved in GBSS for $30 \mathrm{~min}$ at room temperature, agitating occasionally.

Enzyme solution 1

$\begin{array}{lc} & \text { For } 60 \mathrm{ml} \\ \text { Pronase E } & 120 \mathrm{mg} \\ \text { 1X GBSS } & \text { to } 60 \mathrm{ml}\end{array}$

Enzyme solution 2

For $150 \mathrm{ml}$

Pronase E $75 \mathrm{mg}$

Collagenase $\mathrm{H} \quad 80 \mathrm{mg}$

1X GBSS to $150 \mathrm{ml}$

Enzyme solution 3

For $100 \mathrm{ml}$

Pronase $\mathrm{E} \quad 20 \mathrm{mg}$

Collagenase $\mathrm{H} \quad 60 \mathrm{mg}$

DNase I stock $\quad 300 \mu \mathrm{l}$

$1 X$ GBSS to $100 \mathrm{ml}$

The DNase I was added to the solution immediately before application.

DNase I stock

$\begin{array}{lc} & \text { For } 10 \mathrm{ml} \\ \text { DNase I } & 100 \mathrm{mg} \\ \mathrm{ddH}_{2} \mathrm{O} & \text { to } 10 \mathrm{ml}\end{array}$

The solution was dispensed into $1 \mathrm{ml}$ aliquots and stored at $-20^{\circ} \mathrm{C}$. 


\subsubsection{Primary culture treatment and harvesting of rat liver cells}

The cultures of rat hepatocytes and Kupffer cells were performed on $60 \mathrm{~mm}$ polystyrol dishes and maintained at $37^{\circ} \mathrm{C}$ in a $95 \%$ air/ $5 \% \mathrm{CO}_{2}$ atmosphere and saturated humidity.

Primary culture of rat hepatocytes

Immediately after preparation, fetal calf serum (4 $\mathrm{ml} / 100 \mathrm{ml}$ suspension) was added to the hepatocyte suspension in order to make the cell adhesion to the polystyrol dishes more efficient. Furthermore, the antibiotics $(1 \mathrm{ml}$ of pen/strep stock solution per $100 \mathrm{ml}$ cell suspension) together with $10^{-7} \mathrm{M}$ dexamethasone and $10^{-9} \mathrm{M}$ insulin as permissive hormones were added. Rat hepatocytes were plated onto $60-\mathrm{mm}$ plastic dishes at a density of $1 \times 10^{6}$ and $2 \times 10^{6}$ cells per dish for transfection and RNA/protein isolation experiments, respectively.

After the initial $4 \mathrm{~h}$ attachment phase (for transfected cells $5 \mathrm{~h}$ ) the medium was changed, and the hepatocytes were further cultured in medium M 199 with the same concentrations of hormones and antibiotics as before but without fetal calf serum. A volume of $2.5 \mathrm{ml}$ medium per $60 \mathrm{~mm}$ culture dish and $6 \mathrm{ml}$ per $100 \mathrm{~mm}$ culture dish were added. After $24 \mathrm{~h}$ the medium was changed again.

Primary rat hepatocytes were usually treated with various proinflammatory cytokines of different concentrations on the next day after plaiting. The medium was changed $6 \mathrm{~h}$ prior to treatment, the stimuli were diluted to the required concentrations in the culture medium and added directly to the culture dishes by pipetting. The same amount of normal culture medium was pipetted to the dishes with cells which served later as experimental controls.

To stop the culture, dishes with cells were taken from the incubator, the cells were washed with phosphate buffered saline, $\mathrm{pH} 7.4$ and frozen at $-80^{\circ} \mathrm{C}$ for subsequent RNA or protein isolation. Alternatively, the transfected cells were subjected to lysis immediately after washing with subsequent detection of the luciferase activity. The fluorescence of GFP-transfected hepatocytes was observed by vital microscopy.

\section{Hormone and antibiotics stock solutions}

All solutions were sterile filtered, aliquoted and stored at $-20^{\circ} \mathrm{C}$. 


\section{Pen/strep stock}

For $100 \mathrm{ml}$

Penicillin G (sodium salt) $0.64 \mathrm{~g}$

Streptomycine sulfate $\quad 1.17 \mathrm{~g}$

$0.9 \% \mathrm{NaCl}$ to $100 \mathrm{ml}$

\section{Dexamethasone $(100 \mu \mathrm{M})$}

For $100 \mathrm{ml}$

Dexamethasone

$3.92 \mathrm{~g}$

$0.9 \% \mathrm{NaCl}$

to $100 \mathrm{ml}$

Dexamethasone was first dissolved in $0.3 \mathrm{ml}$ of ethanol and then adjuted to $100 \mathrm{ml}$ with $0.9 \% \mathrm{NaCl}$.

$\underline{\text { Insulin }(10 \mu \mathrm{M})}$

For $100 \mathrm{ml}$

Insulin $6 \mathrm{mg}$

BSA $\quad 100 \mathrm{mg}$

$0.9 \% \mathrm{NaCl}$ to $100 \mathrm{ml}$

Insulin was dissolved at $\mathrm{pH} 2.5$, neutrilized and then BSA was added.

\section{Culturing of Kupffer cells}

Rat Kupffer cells were taken up in the culture medium M 199 containing 15\% fetal calf serum, $100 \mathrm{U} / \mathrm{mL}$ penicillin, $100 \mu \mathrm{g} / \mathrm{mL}$ streptomycin, and $1 \%$ L-glutamine and plated onto $60-\mathrm{mm}$ plastic dishes at a density of $6 \times 10^{6}$ cells per dish.

Treatment of Kupffer cells with bacterial lipopolysaccharide $(500 \mathrm{ng} / \mathrm{ml})$ was carried out in a serum-reduced medium (0.3\% FCS) containing the same amount of antibiotics and L-glutamine for $24 \mathrm{~h}$, afterwards the cells were washed with phosphate buffered saline, $\mathrm{pH} 7.4$ and frozen at $-80^{\circ} \mathrm{C}$ for subsequent RNA isolation. Total cellular RNA isolated from LPS-treated Kupffer cells served as a positive control for detection of IL-6-specific transcripts.

\section{Culture medium}

For $100 \mathrm{ml}$

Pen/strep stock $\quad 1 \mathrm{ml}$ 
$\begin{array}{ll}\text { FCS } & 15 \mathrm{ml} \\ \text { L-Glutamine } & 1 \mathrm{ml} \\ \text { M } 199 & \text { to } 100 \mathrm{ml}\end{array}$

\subsection{Methods of molecular biology}

\subsubsection{Transformation of $E$. coli}

Competent E. coli DH5a cells, capable of taking up linear or circular (plasmid) double stranded DNA, were used for transformation.

The competent bacteria $(100 \mu \mathrm{l})$ were thawed on ice. Next, $100 \mathrm{ng}$ of plasmid DNA was added directly to the competent cells and the mixture was incubated on ice for $30 \mathrm{~min}$. Cells were subjected to heat shock by incubating at $42^{\circ} \mathrm{C}$ for 2 min and subsequently incubated on ice for $2 \mathrm{~min}$. Afterwards, $300 \mu \mathrm{l}$ of SOC medium was added to the cells followed by 40 min incubation at $37^{\circ} \mathrm{C}$ under continuous shaking at $225 \mathrm{rpm}$. After chilling on ice, transformed cells (50 $\mu \mathrm{l})$ were spread over a LBampicillin agar dish and incubated for $18 \mathrm{~h}$ at $37^{\circ} \mathrm{C}$.

Media and solutions used for E. coli transformation

$\underline{\text { SOC medium }}$

$0.5 \%$ yeast extract

$2 \%$ bacto-trypton

$10 \mathrm{mM} \mathrm{NaCl}$

$2.5 \mathrm{mM} \mathrm{KCl}$

$10 \mathrm{mM} \mathrm{MgSO}_{4}$

$10 \mathrm{mM} \mathrm{MgCl} 2$

$20 \mathrm{mM}$ glucose

Luria Bertani (LB) medium

For 11

Bacto-trypton $\quad 10 \mathrm{~g}$

Yeast extract $5 \mathrm{~g}$

$\mathrm{NaCl} \quad 5 \mathrm{~g}$

$\mathrm{ddH}_{2} \mathrm{O}$ to 1 I 
$\mathrm{pH}$ was adjusted with $\mathrm{NaOH}$ to 7.3 , the medium was sterilized by autoclaving and stored at $4^{\circ} \mathrm{C}$. Just prior to use, ampicillin was added to the medium at the final concentration of $50-100 \mu \mathrm{g} / \mathrm{ml}$.

\section{LB-ampicillin agar dishes}

Bactoagar was added to the LB medium to a final concentration of $1.5 \%$ followed by autoclaving. Afterward the medium was let to cool down to $55^{\circ} \mathrm{C}$ and ampicillin was added to a final concentration of $50 \mu \mathrm{g} / \mathrm{ml}$. This medium was poured into 10 $\mathrm{cm}$ sterile Petri-dishes and left undisturbed for about $30 \mathrm{~min}$ to solidify. LB-Agar dishes were stored in the dark at $4^{\circ} \mathrm{C}$.

\section{Ampicillin stock solution}

Ampicillin $\quad 100 \mathrm{mg} / \mathrm{ml}$

The powder was dissolved in sterile $\mathrm{ddH}_{2} \mathrm{O}$; the $\mathrm{pH}$ was adjusted with $\mathrm{HCl}$ to 7.0 ; $500 \mu \mathrm{l}$ aliquots were stored at $-20^{\circ} \mathrm{C}$.

\subsubsection{Purification of plasmid DNA}

Purification of plasmid DNA from transformed bacteria was performed using EndoFree ${ }^{\text {TM }}$ Plasmid Maxi Kit (Qiagen).

Qiagen plasmid purification protocol is based on a modified alkaline lysis procedure, followed by binding of plasmid DNA to Qiagen Anion-Exchange Resin under appropriate low-salt and $\mathrm{pH}$ conditions. RNA, proteins, and low-molecularweight impurities are removed by a medium-salt wash. Plasmid DNA is eluted in a high-salt buffer and then concentrated and desalted by isopropanol precipitation.

A single colony of transformed $E$. coli was picked from LB-ampicillin agar dish and inoculated into $2 \mathrm{ml}$ of ampicillin-containing LB medium, followed by incubation for $12 \mathrm{~h}$ at $37^{\circ} \mathrm{C}$ with vigorous shaking at $300 \mathrm{rpm}$. Afterwards, $850 \mu \mathrm{l}$ aliquot of bacteria suspension was mixed with $150 \mu \mathrm{l}$ of sterile $87 \%$ glycerol and stored at $80^{\circ} \mathrm{C}$ as a bacterial stock, other portion of this starter culture was diluted $1: 1,000$ in LB medium, i.e. $100 \mu \mathrm{l}$ of bacterial suspension was inoculated into $100 \mathrm{ml}$ of LB medium, and bacteria were grown at $37^{\circ} \mathrm{C}$ for $12-16 \mathrm{~h}$ with vigorous shaking at $300 \mathrm{rpm}$ to a density of approximately $3-4 \times 10^{9}$ cells per $\mathrm{ml}$, which corresponds to $\mathrm{OD}_{600}$ of 1-1.5. The bacterial cells were harvested by centrifugation at $6,000 \mathrm{~g}$ for 
$15 \mathrm{~min}$ at $4^{\circ} \mathrm{C}$. The supernatant was discarded and bacterial pellet was resuspended in $10 \mathrm{ml}$ of $\mathrm{P} 1$ buffer, containing RNase A, by pipetting up and down until no cell clumps remained.

To lyse the cells, $10 \mathrm{ml}$ of P2 buffer was added and mixed by gentle inverting (the mixture should not be vortexed to avoid shearing of genomic DNA). After 5 min of incubation at RT, $10 \mathrm{ml}$ of chilled P3 buffer was added to the lysate to precipitate genomic DNA, proteins and cell debris. Immediately after precipitation, lysate was transferred into the barrel of QIAfilter Cartridge and incubated there for $10 \mathrm{~min}$ at room temperature, which is essential for optimal performance of the QIAfilter Maxi Cartridge. During this 10-min incubation, floating layer of a precipitate was formed on top of the lysate. Subsequently, the lysate was cleared by pushing the liquid through the filter of the QIAfilter Maxi Cartridge using the plunger. After adding 2.5 $\mathrm{ml}$ of ER buffer, the filtered lysate was incubated on ice for $30 \mathrm{~min}$, and later on applied to a Qiagen-tip 500 column equilibrated with $10 \mathrm{ml}$ of QBT buffer. After the entire volume of lysate had entered the resin, the column was washed twice with $30 \mathrm{ml}$ of QC buffer. For all subsequent steps endotoxin-free reagents and plasticware were used. The plasmid DNA was eluted with $15 \mathrm{ml}$ of QN buffer. To precipitate the DNA, the eluate was mixed with $10.5 \mathrm{ml}$ of room-temperature isopropanol and centrifuge immediately at $15,000 \mathrm{~g}$ for $30 \mathrm{~min}$ at $4^{\circ} \mathrm{C}$. The supernatant was discarded and the DNA pellet was washed from precipitated salt with $5 \mathrm{ml}$ of endotoxin-free, room-temperature $70 \%$ ethanol, followed by centrifugation at $15,000 \mathrm{~g}$ for $10 \mathrm{~min}$. The supernatant was carefully decanted; the DNA pellet was air-dried for 5-10 min and redissolved by pipetting up and down in a suitable volume (100-500 $\mu$ ldepending on the size of the pellet) of endotoxinfree TE buffer.

To determine DNA concentration and the presence of protein in the probes, the OD at $260 \mathrm{~nm}$ (DNA) and $280 \mathrm{~nm}$ (protein) was measured. $1 \mathrm{OD}$ at $260 \mathrm{~nm} \approx 50$ $\mu \mathrm{g} D N A / \mathrm{ml}$. In a protein-free solution, the ratio $O D_{260} / O D_{280}$ is 2 . For the given experiments it was typically higher than 1.8.

The integrity and purity of the obtained plasmid DNA was controlled by agarose gel analysis (see 3.2.4) 


\section{Solutions used for plasmid DNA purification}

\begin{tabular}{|c|c|}
\hline P1 buffer (resuspension buffer ) & $50 \mathrm{mM}$ Tris $\cdot \mathrm{Cl}, \mathrm{pH} 8.0$ \\
\hline & $10 \mathrm{mM}$ EDTA \\
\hline & $100 \mu \mathrm{g} / \mathrm{ml}$ RNase A \\
\hline P2 buffer (lysis buffer) & $200 \mathrm{mM} \mathrm{NaOH}$ \\
\hline & $1 \%$ SDS \\
\hline P3 buffer (neutralization buffer) & 3.0 M potassium acetate, \\
\hline & pH 5.5 \\
\hline QBT buffer (equilibration buffer) & $750 \mathrm{mM} \mathrm{NaCl}$ \\
\hline & 50 mM MOPS, pH 7.0 \\
\hline & $15 \%$ isopropanol \\
\hline & $0.15 \%$ Triton $X-100$ \\
\hline QC buffer (washing buffer) & $1 \mathrm{M} \mathrm{NaCl}$ \\
\hline & 50 mM MOPS, pH 7.0 \\
\hline & $15 \%$ isopropanol \\
\hline QN buffer (elution buffer) & $1.6 \mathrm{M} \mathrm{NaCl}$ \\
\hline & $50 \mathrm{mM}$ MOPS, pH 7.0 \\
\hline & $15 \%$ isopropanol \\
\hline TE buffer & $10 \mathrm{mM}$ Tris $\cdot \mathrm{HCl}, \mathrm{pH} 8.0$ \\
\hline & 50 mM MOPS, pH 7.0 \\
\hline & $15 \%$ isopropanol \\
\hline
\end{tabular}

\subsubsection{Amplification of DNA by polymerase chain reaction (PCR)}

The polymerase chain reaction allows to amplify fragments due to repetitive cycles of DNA synthesis (Figure 9). The reaction uses two specific synthetic oligonucleotides (primers), that hybridize to sense and antisense DNA strands of the DNA fragment to be amplified, four deoxyribonucleotide triphosphates (dNTP's) and a heat-stable DNA polymerase. Each cycle consists of three reactions that take place under different temperatures. First, the double-stranded DNA is converted into its two single strands (denaturation at $95^{\circ} \mathrm{C}$ ). They serve as templates for the synthesis of new DNA. After heating, the reaction is cooled (45$60^{\circ} \mathrm{C}$ ) to allow the annealing (hybridization) of primers to the complementary DNA strands. Starting from the primers, DNA polymerase extends both DNA strands at $72^{\circ} \mathrm{C}$ (DNA synthesis) (Figure 9A). Since the DNA molecules synthesized in each 
cycle can serve as a template in the next cycle, the number of target DNA copies approximately doubles every cycle. Already after the third cycle, double stranded DNA molecules of the size corresponding to the distance between two primers are synthesized (Figure 9B). The repeating cycles of heating and cooling take place in a thermocycler.

The PCR reaction was performed with standard T3- and T7-specific primers to amplify rat HO-1, IL-6, and GAPDH cDNAs cloned into pBluescript II KS (+/-) vector for subsequent labeling and use in Northern blot analysis. The PCR lasted for 35 cycles under the following conditions:

1. $45 \mathrm{sec}$ denaturation at $95^{\circ} \mathrm{C}$

2. $45 \mathrm{sec}$ annealing at $50^{\circ} \mathrm{C}$

3. $60 \mathrm{sec}$ at $72^{\circ} \mathrm{C}$ DNA synthesis

The denaturation step at $95^{\circ} \mathrm{C}$ before the first cycle was extended for $2 \mathrm{~min}$. After the last cycle the synthesis step was prolonged for $10 \mathrm{~min}$ at $72^{\circ} \mathrm{C}$ to finish synthesis of incompletely synthesized DNA strands.

The PCR was performed with the Taq DNA-polymerase (5 U/ $\mu \mathrm{l}$ ) (Invitrogen). The specific buffers and solutions were received with polymerase. dNTP master mix from Bioline was used.

\section{PCR reaction mixture:}

$10 \mu \mathrm{l}$ 10X PCR buffer (500 mM Tris- $\mathrm{HCl}, \mathrm{pH}$ 9.1, $\left.140 \mathrm{mM}\left(\mathrm{NH}_{4}\right)_{2} \mathrm{SO}_{4}\right)$

$4 \mu \mathrm{MgCl}_{2}(50 \mathrm{mM})$

$0.8 \mu \mathrm{l} 100 \mathrm{mM}$ dNTP mix (25 mM of each dATP, dCTP, dGTP, dTTP)

$1.5 \mu \mathrm{l}(150 \mathrm{pmol}) \mathrm{T} 3$ primer

$1.5 \mu \mathrm{l}$ (150 pmol) T7 primer

$1 \mu$ template (100 ng plasmid DNA)

$0.5 \mu \mathrm{l}$ Taq polymerase (2.5 units)

$100 \mu$ l volume was adjusted with sterile $\mathrm{ddH}_{2} \mathrm{O}$ 
A

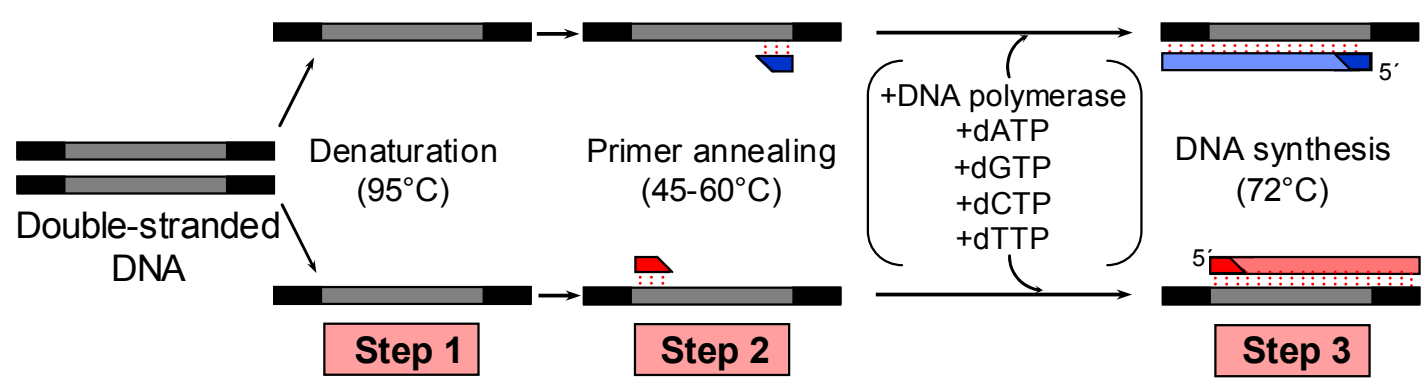

First cycle

B

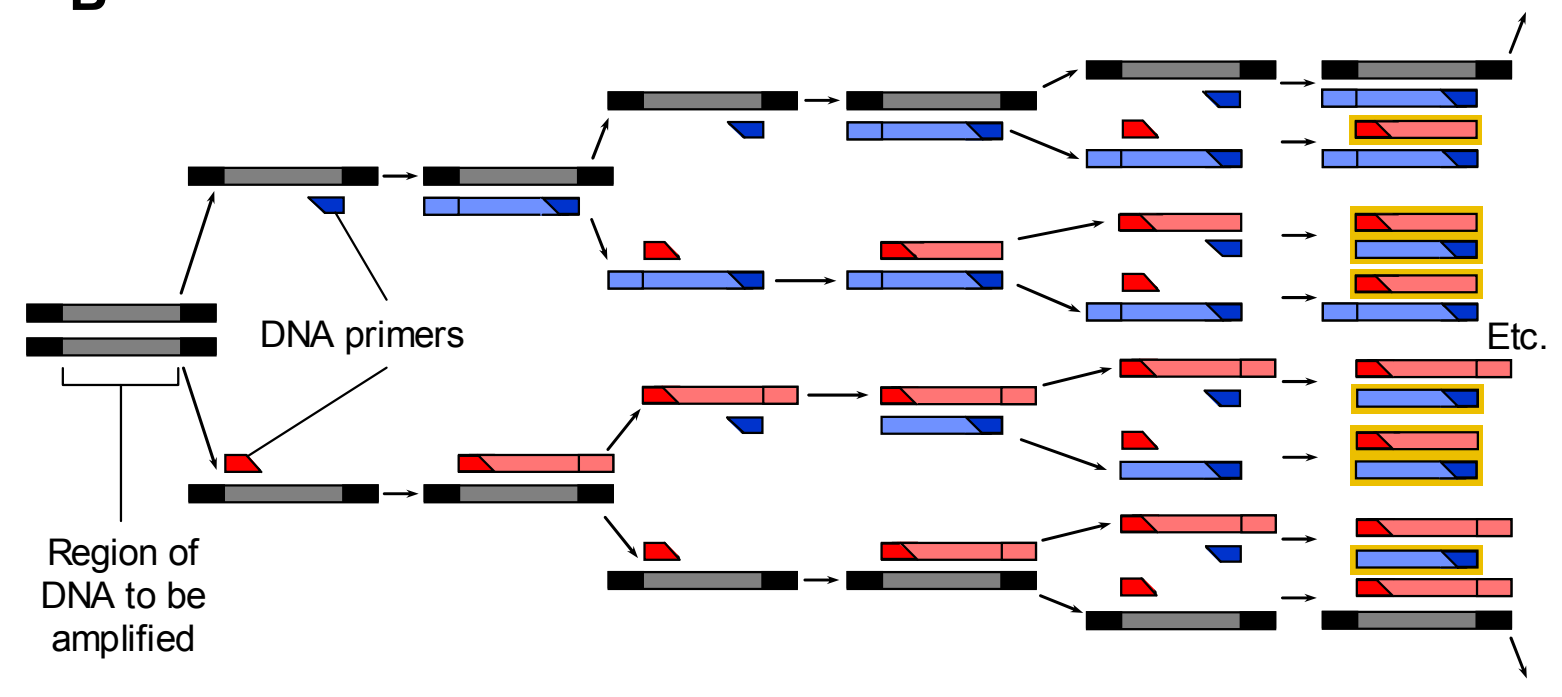

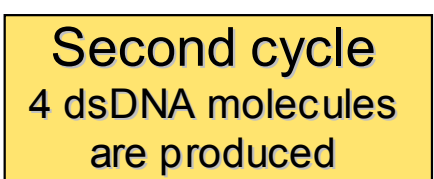

Third cycle

8 dsDNA molecules are produced

Figure 9. Amplification of DNA using the PCR technique. (A) After strand separation (step1), cooling of the DNA allows primers to hybridize to complementary sequences in the two DNA strands (step 2). In the presence of DNA polymerase and the four dNTPs, DNA is synthesized, starting from the two primers (step 3). (B) In the example illustrated, three cycles of reaction produce 16 DNA chains, 8 of each (boxed in yellow) are the same length as and correspond exactly to one or the other strand of the original bracketed sequence shown at the far left; the other strands contain extra DNA downstream of the original sequence, which is replicated in the first few cycles. After several more cycles, essentially all of the DNA strands have this unique length. 
To check the size of the PCR product and to control its purity and integrity, an $8 \mu \mathrm{l}$ aliquot of the PCR reaction was electrophoretically analyzed in a $1.25 \%$ agarose gel.

\subsubsection{Agarose gel electrophoresis of DNA}

For preparation of a $1.25 \% \mathrm{gel}, 1.25 \mathrm{~g}$ of agarose was dissolved by heating in 100 $\mathrm{ml}$ of $1 \mathrm{X}$ TAE buffer. For visualization of the bands, $8 \mu \mathrm{l}$ of ethidium bromide $(10 \mathrm{mg} / \mathrm{ml})$ was added to the mixture. After mixing, the gel was poured into the prepared gel plate. In the mean time of the polymerization, the samples were prepared for loading by mixing of $8 \mu$ of DNA probe with $2 \mu$ of 6 X Loading Dye Solution (MBI Fermentas).

After polymerization, the gel was placed into an electrophoresis chamber filled with $1 \mathrm{X}$ TAE buffer, the samples were loaded, and the electrophoresis was performed at $60 \mathrm{~V}$.

DNA bands, intercalating ethidium bromide, were visualized by UV detection. Ethidium bromide is a fluorescent dye which contains a planar group that intercalates between the stacked bases of the DNA. The fixed position of this group and its close proximity to the bases cause dye, bound to DNA, to display an increased fluorescence yield compared to that of the dye in free solution. Ultraviolet radiation at $254 \mathrm{~nm}$ is absorbed by the DNA and transmitted to the dye; radiation at $302 \mathrm{~nm}$ and $366 \mathrm{~nm}$ is absorbed by the bound dye itself. In both cases, the energy is reemitted at $590 \mathrm{~nm}$ in the red orange region of the visible spectrum. Hence, DNA can be visualized under a UV transilluminator. The gel was photographed using Eagle Eye ${ }^{\mathrm{TM}}$ system (Stratagene), a setup containing UV transilluminator, intensity control unit, video camera and printer.

\section{X Tris/acetate/EDTA (TAE) buffer}

Tris base

Sodium acetate

EDTA

$\mathrm{ddH}_{2} \mathrm{O}$
For 11

$122 \mathrm{~g}$

$32 \mathrm{~g}$

$14 \mathrm{~g}$

to 1 I
Final concentration

$1 \mathrm{M}$

$0.4 \mathrm{M}$

$40 \mathrm{mM}$

After EDTA was completely dissolved, $\mathrm{pH}$ was adjusted with acetic acid to 7.4; the buffer was autoclaved and stored at room temperature. 


\section{$\underline{\text { 1X TAE buffer }}$}

\begin{tabular}{ll}
\hline 20X TAE buffer & For 1 I \\
$\mathrm{ddH}_{2} \mathrm{O}$ & $50 \mathrm{ml}$ \\
& To 1 I
\end{tabular}

\subsubsection{Radioactive labeling of DNA}

For radioactive labeling of a full-length plasmid containing CDNA of interest, nick translation method was used. Alternatively, random primed DNA labeling was utilized for relatively short specific cDNA fragments.

\section{DNA labeling by nick translation method}

DNA labeling by nick translation method was performed using Nick Translation System kit (Invitrogen).

Nick translation requires the activity of two different enzymes. DNase I is used to cleave (nick) phosphodiester bonds at random sites in both strands of a doublestranded target DNA. E. coli DNA polymerase I is used to add deoxynucleotides to the 3'-hydroxyl termini created by DNase I. In addition to its polymerizing activity, DNA polymerase I carries a $5^{\prime} \rightarrow 3^{\prime}$ exonucleolytic activity that removes nucleotides from the $5^{\prime}$ side of the nick. The simultaneous elimination of nucleotides from the $5^{\prime}$ side and the addition of radiolabeled nucleotides to the $3^{\prime}$ side result in movement of the nick (nick trnslation) along the DNA, which becomes labeled to high specific activity (Kelly et al., 1970). The reaction is carried out at low temperature $\left(15^{\circ} \mathrm{C}\right)$.

In sterile $1.5 \mathrm{ml}$ tube placed on ice, nuclease free $\mathrm{H}_{2} \mathrm{O}$ was added to the solution containing $1 \mu \mathrm{g}$ of template DNA to bring the volume to $35 \mu \mathrm{l}$. Consequently the following reagents were added to the DNA in the indicated order:

$5 \mu \mathrm{l}$ dNTP mix (dATP, dTTP and dGTP)

$5 \mu \mathrm{l} \mathrm{a}-{ }^{32} \mathrm{P}-\mathrm{dCTP}(3,000 \mathrm{ci} / \mathrm{mmol}, 50 \mu \mathrm{Ci})$

$5 \mu \mathrm{l} \mathrm{Pol} \mathrm{I/DNase} \mathrm{I} \mathrm{mix}$

The components were mixed gently but thoroughly and centrifuged briefly in an Eppendorf bench-top centrifuge. The mixture was incubated at $15^{\circ} \mathrm{C}$ for $60 \mathrm{~min}$. Afterwards, $5 \mu$ of stop buffer was added to terminate the reaction. 
DNA labeling by random priming reaction

Random primed DNA labeling was performed using NEBlot ${ }^{\circledR}$ Kit (New England Biolabs) designed to produce labeled DNA probes using the method of Feinberg and Vogelstein (Feinberg and Vogelstein, 1983), where random sequence octadeoxynucleotides serve as primers for DNA synthesis in vitro from denaturated double-stranded template DNA by the Klenow Fragment of E. coli polymerase I. One labeled deoxyribonocleotide is used in the dNTP reaction mixture and is incorporated during primer directed DNA synthesis by DNA polymerase. The resulting labeled DNA is used as hybridization probe in Northern blot.

50-100 ng of template DNA was dissolved in nuclease free $\mathrm{H}_{2} \mathrm{O}$ (the volume of added water should not exceed $33 \mu \mathrm{l}$ ). The DNA was denatured by heating at $95^{\circ} \mathrm{C}$ for $5 \mathrm{~min}$ and subsequently chilled on ice for $5 \mathrm{~min}$. The following reagents were added to the DNA in the indicated order:

$5 \mu \mathrm{l}$ 10X labeling buffer (includes Random Octadeoxyribonucleotides)

$6 \mu \mathrm{l}$ dNTP mixure ( $2 \mu \mathrm{l}$ of dATP, dTTP and dGTP were mixed previously)

$5 \mu \mathrm{l} \mathrm{a-}{ }^{32} \mathrm{P}$-dCTP $(3,000 \mathrm{ci} / \mathrm{mmol}, 50 \mu \mathrm{Ci})$

$1 \mu$ l DNA Polymerase I - Klenow Fragment $\left(3^{\prime} \rightarrow 5^{\prime}\right.$ exo $)(5$ units $)$

The mixture was incubated at $37^{\circ} \mathrm{C}$ for $1 \mathrm{~h}$, followed by termination of the reaction by adding $5 \mu \mathrm{l}$ of $0.2 \mathrm{M}$ EDTA, $\mathrm{pH} 8.0$.

\section{Purification of labeled DNA}

Synthesized labeled DNA probe was separated from unincorporated nucleotides by gel filtration on Sephadex ${ }^{\circledR}$ G-50 using Pharmacia NICK Column (Pharmacia Biotech).

A column was opened according to the manufacturer's instructions and equilibrated with $3 \mathrm{ml}$ of $1 \mathrm{X}$ TE buffer, $\mathrm{pH}$ 8.0. After the entire volume of buffer had entered the gel, random priming reaction mixture was applied onto the column, followed by adding $400 \mu \mathrm{l}$ of $1 \mathrm{X}$ TE buffer. The flowthrough was collected in the tube placed under the column and kept for further measurement of radioactivity. A new tube for sample collection was placed under the column and the purified sample was eluted with $400 \mu \mathrm{l}$ of $1 \mathrm{X} \mathrm{TE}$. The sample obtained was subjected to measurement of radioactivity and stored at $-20^{\circ} \mathrm{C}$ until use for Northern blot hybridization. 
$\underline{10 X \mathrm{TE}}$

$\begin{array}{lll} & \text { For } 1 \mathrm{I} & \text { Final concentration } \\ 2 \mathrm{M} \text { Tris- } \mathrm{HCl}, \mathrm{pH} 7.4 & 50 \mathrm{ml} & 100 \mathrm{mM} \\ 0.5 \mathrm{M} \text { EDTA } & 20 \mathrm{ml} & 10 \mathrm{mM} \\ \text { RNase-free } \mathrm{H}_{2} \mathrm{O} & \text { to } 1 \mathrm{I} & \\ \mathrm{pH} \text { was controlled and if necessary adjusted with } \mathrm{NaOH} \text { or } \mathrm{HCl} \text { to } 7.6 . \text { The solution } \\ \text { was sterile filtered and stored at } 4^{\circ} \mathrm{C} \text {. }\end{array}$

$\underline{1 X T E}$

\begin{tabular}{ll}
\hline 10X TE & For $500 \mathrm{ml}$ \\
RNase-free $\mathrm{H}_{2} \mathrm{O}$ & $50 \mathrm{ml}$ \\
& to $500 \mathrm{ml}$
\end{tabular}

Measurement of $\beta$-radioactivity

After the purification step as described above, the radioactivity of labeled cDNA samples was measured using Wallac 1409 liquid scintillation $\beta$-counter (Turku /Finland). $2 \mu$ aliquots from the flowthrough and elution fractions were transferred to screw-lid plastic tubes containing $5 \mathrm{ml}$ of scintillation liquid, mixed by inverting and subjected to radioactivity measurements. $\beta$-Radioactivity of the samples was expressed in counts per minute (cpm). The activity value in flowthrough fraction was used as means to assess the efficiency of radioactive nucleotide incorporation. For effective labeling this value should not exceed $10 \%$ of the radioactivity value in the cDNA sample.

\subsubsection{Isolation of total RNA}

RNA isolation procedure using silicate columns

The isolation of total RNA from cultured rat hepatocytes and Kupffer cells was conducted using the NucleoSpin ${ }^{\circledR}$ RNAll kit (Macherey-Nagel) in accordance to the protocol for cultured animal cells.

NucleoSpin ${ }^{\circledR}$ RNA method utilizes the silica membrane which adsorbs the RNA from the cell lysate. Contaminating DNA, which is also bound to the membrane, is removed with a solution containing DNase. Salts, metabolites and macromolecular 
cellular components are washed away in two washing steps. Pure RNA is finally eluted under low ionic strength conditions with RNase-free water.

The cells frozen on the culture dishes $\left(2 \times 10^{6}\right.$ cells per $6 \mathrm{~cm}$ culture dish) were thawed on ice. $350 \mu$ of RA1 buffer with freshly added $\beta$-mercaptoethanol was applied to the dish, and cells were scraped with a disposable scraper, transferred to RNase-free $1.5 \mathrm{ml}$ tubes and homogenized by passing 5 times through a $22 \mathrm{G}$ injection canula connected to a syringe. This step was performed rapidly to prevent degradation of the RNA. Next, lysates were pipetted directly onto NucleoSpin ${ }^{\circledR}$ Filter unit, sitting in $2 \mathrm{ml}$ collection tubes, and centrifuged for $1 \mathrm{~min}$ at $11,000 \mathrm{~g}$. This step was performed to reduce viscosity and clear the lysates. Then, $350 \mu \mathrm{l}$ of $70 \%$ ethanol was added to each filtered lysate and mixed by vortexing. $700 \mu$ of each sample was applied to a NucleoSpin ${ }^{\circledR}$ RNA II column sitting in a 2 $\mathrm{ml}$ collection tube, and centrifuged for $30 \mathrm{sec}$ at $8,000 \mathrm{~g}$. To desalt the columns prior to DNA digest, $350 \mu$ of MDB buffer was pipetted onto NucleoSpin ${ }^{\circledR}$ RNA II column, followed by centrifugation for $1 \mathrm{~min}$ at $11,000 \mathrm{~g}$. To digest DNA bound to the membrane, $95 \mu \mathrm{l}$ of DNase reaction mixture was applied directly onto the center of the silica membrane of the column, followed by incubation at room temperature for $15 \mathrm{~min}$. To wash the silica membrane, $200 \mu \mathrm{l}$ of RA2 buffer was added to the NucleoSpin ${ }^{\circledR}$ RNA II column followed by centrifugation for $30 \mathrm{sec}$ at $8,000 \mathrm{~g}$. To continue washing, $600 \mu \mathrm{l}$ of RA3 buffer was applied and columns were centrifuged for $30 \mathrm{sec}$ at $8,000 \mathrm{~g}$. The last washing step was performed with $250 \mu \mathrm{l}$ of RA3 buffer, followed by centrifugation for $2 \mathrm{~min}$ at $11,000 \mathrm{~g}$ to dry the membrane completely. Afterwards, the NucleoSpin ${ }^{\circledR}$ RNA II columns were placed into nuclease-free 1.5 collection tubes, the RNA was eluted with $60 \mu$ of RNasefree $\mathrm{H}_{2} \mathrm{O}$ pipetted directly onto the silica membrane and columns were centrifuged at $11,000 \mathrm{~g}$ for $1 \mathrm{~min}$.

To determine the concentration and purity of the RNA obtained, the aliquot of RNA sample was diluted $1: 100$ in RNase-free $\mathrm{H}_{2} \mathrm{O}$ and the extinction at $260 \mathrm{~nm}$ and $280 \mathrm{~nm}$ was measured spectrophotometrically (GeneQuant II, Pharmacia Biotech). The ratio of the OD at $260 \mathrm{~nm}$ and at $280 \mathrm{~nm}$ served as a measure of RNA purity. In a protein-free solution, the ratio $O D_{260} / O D_{280}$ is 2 . Due to minor protein contaminations this coefficient is usually somewhat lower. In our experiments it was typically higher than 1.8 . 


\section{Solutions used for RNA isolation}

All solutions used for RNA isolation were provided in the NucleoSpin ${ }^{\circledR}$ RNAll kit and their detailed composition is not described. Buffers RA1, RA2 and MDB contain thiocyanate.

\section{$\underline{\text { RA1 buffer }}$}

$\begin{array}{ll}\text { RA1 buffer (Macherey-Nagel) } & 1000 \mu \mathrm{l} \\ \beta \text {-Mercaptoethanol } & 10 \mu \mathrm{l}\end{array}$

DNase reaction mixture
DNase I (Macherey-Nagel)
DNase reaction buffer (Macherey- $90 \mu \mathrm{l}$
Nagel)

For 1 sample

\section{$\underline{\text { RA3 buffer }}$}

RA3 buffer (concentrate, Macherey- $12.5 \mathrm{ml}$

Nagel

$100 \%$ ethanol

$50 \mathrm{ml}$

Isolation of RNA by density-gradient ultracentrifugation

Total RNA was isolated from different rat tissues including liver, spleen, kidney, lung, heart, skeletal muscle, small and large intestine by means of guanidine isothiocyanate extraction, cesium chloride density-gradient ultracentrifugation and ethanol precipitation according to method of Chirgwin (Chirgwin et al., 1979).

This method is a versatile and efficient way to extract intact RNA from most tissues and cultured cells, even if the endogenous level of RNase is high. The cells are rapidly lysed in guanidine isothiocyanate-containing buffer, which ensures inactivation of RNases. The lysate is layered onto a $\mathrm{CsCl}$ gradient and spun in an ultracentrifuge. Proteins remain in the aqueous guanidine portion, DNA bands in the $\mathrm{CsCl}$, and RNA pellets in the bottom of the tube. The RNA is recovered by 
redissolving the pellet. The recovery of RNA is usually excellent if the capacity of the gradient is not exceeded.

About $100 \mathrm{mg}$ of frozen tissue was homogenized with Ultra-Turrax TP 18/10 homogenizer 3 times for $10 \mathrm{sec}$ each in $3 \mathrm{ml}$ of ice-cold GITC buffer with freshly added Antifoam A (Sigma). The homogenates were centrifuged for $10 \mathrm{~min}$ at $3,500 \mathrm{rpm}$ in a Rotixa/RP centrifuge (Hettich) at $4^{\circ} \mathrm{C}$ to pellet connective tissue and large cell debris. Meanwhile, $2 \mathrm{ml}$ of $\mathrm{CsCl}$ buffer was poured into 5-ml polyallomer ultracentrifuge tubes (6 per preparation). The cleared guanidine lysed samples were carefully layered on top of the $\mathrm{CsCl}$ buffer. The samples were centrifuged overnight $(21 \mathrm{~h})$ at $35,000 \mathrm{rpm}$ in a Kontron TST55 rotor at $20^{\circ} \mathrm{C}$. The supernatants were carefully removed by aspiration and the transparent gelatin-like RNA pellets were gently washed (preserving undisturbed) with $200 \mu$ of $70 \%$ ethanol at room temperature.

The pellets were reconstituted in $200 \mu \mathrm{l}$ of RNase-free water by pipetting and transferred into sterile $1.5 \mathrm{ml}$ reaction tubes and the procedure was immediately continued to RNA precipitation. The RNA was precipitated with $450 \mu \mathrm{l}$ of $100 \%$ ethanol in the presence of sodium acetate, $\mathrm{pH} 5.4$ (20 $\mu \mathrm{l}$ of $2 \mathrm{M}$ solution per pellet) overnight at $-20^{\circ} \mathrm{C}$.

The RNA precipitates were pelleted by centrifugation for $30 \mathrm{~min}$ at 12,000 rpm in an Eppendorf bench-top centrifuge placed in cold room $\left(4^{\circ} \mathrm{C}\right)$. Supernatants were discarded and pellets were washed with $200 \mu \mathrm{l}$ of ice-cold $70 \%$ ethanol to remove all traces of sodium acetate. After subsequent recentrifugation as described, the supernatants were discarded and the pellets were dried for $30 \mathrm{~min}$ at room temperature. Afterwards, the pellets were reconstituted in $100 \mu$ l of RNase-free water.

To determine the concentration and purity of the RNA obtained, the aliquot of RNA sample was diluted 1:100 in RNase-free $\mathrm{H}_{2} \mathrm{O}$ and the extinction at $260 \mathrm{~nm}$ and $280 \mathrm{~nm}$ was measured spectrophotometrically (GeneQuant II, Pharmacia Biotech). The ratio of the OD at $260 \mathrm{~nm}$ and at $280 \mathrm{~nm}$ served as a measure of RNA purity. In a protein-free solution, the ratio $O D_{260} / O D_{280}$ is 2 . Due to minor protein contaminations this coefficient is usually somewhat lower. In our experiments it was typically higher than 1.8 . 


\section{GITC buffer}

$\begin{array}{lll} & \text { For } 200 \mathrm{ml} & \text { Final concentration } \\ \text { Guanidine isothiocyonate } & 94.53 \mathrm{~g} & 4 \mathrm{M} \\ 0.25 \mathrm{M} \text { sodium citrate } & 20 \mathrm{ml} & 25 \mathrm{mM} \\ \text { N-lauroylsarcosyl } & 1 \mathrm{~g} & 0.5 \% \\ \text { RNase-free } \mathrm{H}_{2} \mathrm{O} & \text { to } 200 \mathrm{ml} & \end{array}$

The solution was sterile filtered and stored in the dark at $4^{\circ} \mathrm{C}$. $\beta$-Mercaptoethanol was added just prior to use at the quantity of $10 \mu \mathrm{l}$ per $1 \mathrm{ml}$ of GITC buffer.

\section{$\underline{\mathrm{CsCl} \text { buffer }}$}

$\begin{array}{lll} & \text { For } 200 \mathrm{ml} & \text { Final concentration } \\ \text { Cesium chloride } & 192 \mathrm{~g} & 5.7 \mathrm{M} \\ 0.25 \mathrm{M} \text { sodium citrate } & 20 \mathrm{ml} & 25 \mathrm{mM} \\ 0.5 \mathrm{M} \text { EDTA } & 40 \mathrm{ml} & 100 \mathrm{mM} \\ \text { RNase-free } \mathrm{H}_{2} \mathrm{O} & \text { to } 200 \mathrm{ml} \\ \text { pH was adjusted with } 0.25 \mathrm{M} \text { citric acid to } 7.5 ; \text { the solution was sterile filtered and } \\ \text { stored at room temperature. }\end{array}$

\subsubsection{Northern blot analysis}

Northern blot analysis is a method to quantify RNA expression. The RNA is separated in a denaturing formaldehyde/agarose gel, transferred by capillary transfer to a nylon membrane and fixed by UV crosslinking. The RNA of interest is identified by hybridization with a specific radiolabeled cDNA probe.

All solutions used for the Northern blot were autoclaved, the electrophoresis and blot chambers, gel plates and combs were kept in freshly prepared $0.1 \%$ DEPC solution for 10-20 min before use to inactivate RNases.

Preparation of RNA samples

Each RNA probe (5-10 $\mu \mathrm{g}$ of total RNA) in a volume not more than $5 \mu$ was mixed with $7.5 \mu \mathrm{l}$ of sample buffer. If the volume of probe exceeded $5 \mu \mathrm{l}$, the sample was concentrated in a vacuum centrifuge until the volume was reduced to $5 \mu$ l. RNA probes mixed with sample buffer were denatured by heating at $65^{\circ} \mathrm{C}$ for $10 \mathrm{~min}$. Afterwards, the samples were briefly chilled on ice and centrifuged for $1 \mathrm{~min}$ at $10,000 \mathrm{rpm}$ in an Eppendorf bench-top centrifuge. Each sample was mixed with 3 
$\mu \mathrm{l}$ of loading buffer and recentrifuged for $1 \mathrm{~min}$ at 10,000 rpm in an Eppendorf bench-top centrifuge.

\section{Electrophoresis conditions}

The denatured formaldehyde/agarose gel (1\%) was prepared as follows: at first, 1 $\mathrm{g}$ of agarose was dissolved in $72.2 \mathrm{ml}$ of RNase-free water (Ampuwa ${ }^{\circledR}$ ) by heating in microwave oven and then slightly cooled to approximately $70^{\circ} \mathrm{C}$, followed by sequential adding $10 \mathrm{ml}$ of $10 \mathrm{X}$ running buffer and $16.7 \mathrm{ml}$ of $37 \%$ formaldehyde. Next, $8 \mu$ l of ethidium bromide $(10 \mathrm{mg} / \mathrm{ml})$ was added to the mixture for visualization of $28 \mathrm{~S}$ and $18 \mathrm{~S}$ rRNA bands served for estimation of apparent molecular weight of the RNAs of interest in further hybridization steps. The mixture was poured into the prepared gel plate and let to polymerize under a fume hood for 20-30 min.

Immediately after preparation, the samples were loaded onto the gel, and the electrophoresis was performed at constant voltage of $80 \mathrm{~V}$ for 1-1.5 $\mathrm{h}$.

After electrophoresis, the quality of RNA was estimated under UV transilluminator built-in Eagle Eye ${ }^{\mathrm{TM}}$ system (Stratagene); the gel was photographed, and the procedure was immediately continued to blotting.

\section{Transfer of RNA to nylon membrane}

After the separation of RNA in the gel, it was transferred to a nylon membrane by capillary transfer. The system for transfer was assembled as depicted on Figure 10. A plastic tray was filled with $500 \mathrm{ml}$ of $20 \mathrm{X}$ SSC. A piece of Whatman $3 \mathrm{MM}$ filter was soaked in 20X SSC and draped over the glass plate placed over the tray with both ends hanging into buffer to act as wick. Any bubbles between the filter and glass plate were smoothed out. The gel was carefully placed upside down over the filter. The bubbles between the gel and wick were carefully removed. The nylon membrane wetted in 2X SSC was placed on top of the gel and smoothed. Two other pieces of Whatman 3MM filters wetted in 2X SSC were sequentially flat laid on top of nylon filter and smoothed. A stack of paper towels was placed on top, covered with another glass plate and pressed with $1 \mathrm{~kg}$ blotting weight. The transfer was carried out overnight.

After the transfer, RNA was fixed on the membrane by UV crosslinking for 2 min from both sides using Stratalinker ${ }^{\mathrm{TM}} 180$ (Stratagene) set at "autocrosslink" mode. 


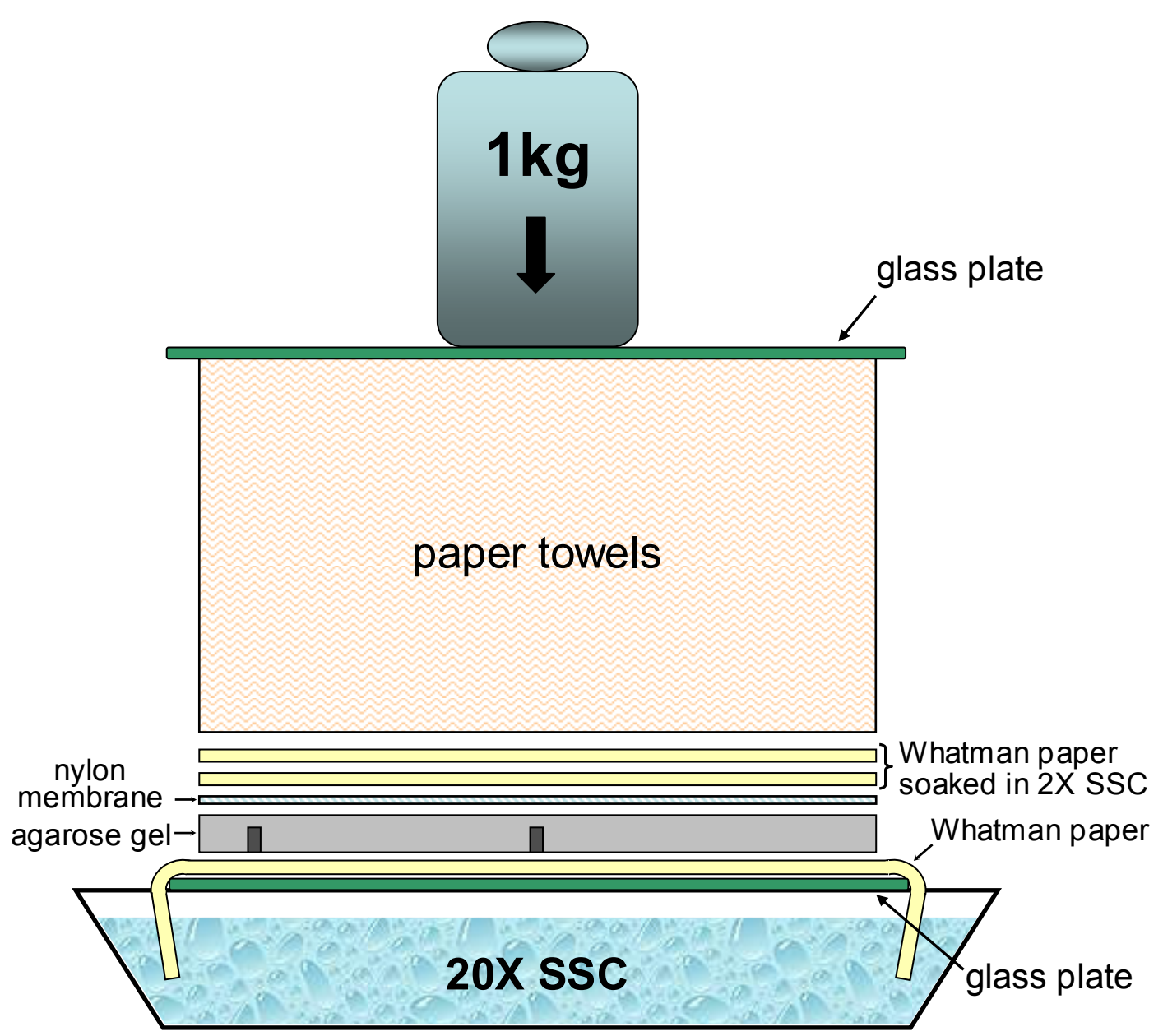

Figure 10. Scheme of the system for capillary transfer of RNA on nylon membrane. For explanations, see the text.

Hybridization of RNA with radiolabeled $c D N A$ probe

After crosslinking, the nylon membrane was rinsed with $1 \mathrm{X}$ TE buffer to wash away any traces of agarose. Afterwards, the membrane was placed into a hybridization tube, and any bubbles between the membrane and internal wall of the tube were carefully removed. The prehybridization which is necessary to prevent unspecific binding was performed for $1 \mathrm{~h}$ with $10 \mathrm{ml}$ of QuikHyb ${ }^{\circledR}$ hybridization solution at $68^{\circ} \mathrm{C}$ in a hybridization oven. Radiolabeled probe prepared as described in 3.2.5 was mixed with double volume of salmon sperm DNA and afterwards denatured for $5 \mathrm{~min}$ at $95^{\circ} \mathrm{C}$. After chilling on ice, the DNA probe was mixed with QuikHyb $^{\circledR}$ solution in the hybridization tube. The hybridization was carried out for $1 \mathrm{~h}$ at $68^{\circ} \mathrm{C}$ in a hybridization oven.

After hybridization, the membrane was rinsed in the tube with $30 \mathrm{ml}$ of $2 X$ SSC/0.1\% SDS, next portion of $2 \mathrm{X}$ SSC/0.1\% SDS was added followed by 
washing for $30 \mathrm{~min}$ at $55^{\circ} \mathrm{C}$ in a hybridization oven. Afterwards, the membrane was transferred to a plastic tray and further washed in $2 \mathrm{X}$ SSC/0.1\% SDS with shaking at room temperature. The radioactivity was controlled and when it reached approximately $100 \mathrm{cpm}$, the washing was stopped. The membrane was wrapped in a cling film, placed in an X-ray film cassette and exposed to X-ray film, which was developed afterward according to the manufacturer's instructions.

10X running buffer

$\begin{array}{lll} & \text { For } 500 \mathrm{ml} & \text { Final concentration } \\ \text { MOPS } & 20 \mathrm{~g} & 200 \mathrm{mM} \\ \text { 2M sodium acetate } & 12.5 \mathrm{ml} & 50 \mathrm{mM} \\ 0.5 \mathrm{M} \text { EDTA } & 10 \mathrm{ml} & 10 \mathrm{mM} \\ \mathrm{RNase}-\text { free } \mathrm{H}_{2} \mathrm{O}\left(\text { Ampuwa }^{\circledR}\right) & \text { to } 500 \mathrm{ml} & \\ \text { pH was adjusted with } 5 \mathrm{~N} \mathrm{NaOH} \text { to } 7.0 ; & \text { the solution was sterile filtered and stored } \\ \text { in the dark at } 4{ }^{\circ} \mathrm{C} . & \end{array}$

$\underline{1 X \text { running buffer }}$

$\begin{array}{ll} & \text { For 1 I } \\ \text { 10X running buffer } & 100 \mathrm{ml} \\ \left.\text { RNase-free water (Ampuwa }{ }^{\circledR}\right) & \text { to 1 I }\end{array}$

The solution was stored at room temperature for 1-2 weeks.

\section{Sample buffer}

$\begin{array}{ll}\text { Deionized formamide } & 500 \mu \mathrm{l} \\ 37 \% \text { formaldehyde } & 169 \mu \mathrm{l} \\ 10 X \text { running buffer } & 100 \mu \mathrm{l}\end{array}$

The solution was dispensed into $1 \mathrm{ml}$ aliquots and stored at $-20^{\circ} \mathrm{C}$ for $2-3$ months.

\section{Deionized formamide}

$\begin{array}{ll}\text { Formamide } & 100 \mathrm{ml} \\ \text { Mixed Bed Resin AG 501-X8 (D) } & 10 \mathrm{~g}\end{array}$


The mixture was stirred for $30 \mathrm{~min}$ in the dark at room temperature, afterwards it was sterile filtered, dispensed into $50 \mathrm{ml}$ aliquots and stored in the dark at $-20^{\circ} \mathrm{C}$.

Loading buffer

10X running buffer $5 \mathrm{ml}$

RNase-free $\mathrm{H}_{2} \mathrm{O}\left(\right.$ Ampuwa $\left.^{\circledR}\right) \quad 3 \mathrm{ml}$

Ficoll 400

Bromophenol blue $10 \mathrm{mg}$

The solution was dispensed into $0.5 \mathrm{ml}$ aliquots and stored for 2-3 months at $20^{\circ} \mathrm{C}$

$\underline{20 X \text { SSC }}$

$\begin{array}{ll} & \text { For } 2 \mathrm{I} \\ \mathrm{NaCl} & 350.6 \mathrm{~g} \\ \text { Sodium citrate } \times 2 \mathrm{H}_{2} \mathrm{O} & 176.4 \mathrm{~g} \\ \mathrm{ddH}_{2} \mathrm{O} & \text { to } 1 \mathrm{I}\end{array}$

The solution was autoclaved and stored at room temperature.

$\underline{2 \times S S C}$

$\begin{array}{ll} & \text { For } 500 \mathrm{ml} \\ 20 \times \text { SSC } & 50 \mathrm{ml} \\ \mathrm{ddH}_{2} \mathrm{O} & \text { to } 500 \mathrm{ml}\end{array}$

10X TE

$\begin{array}{lll} & \text { For 1 I } & \text { Final concentration } \\ 2 \mathrm{M} \text { Tris- } \mathrm{HCl}, \mathrm{pH} 7.4 & 50 \mathrm{ml} & 100 \mathrm{mM} \\ 0.5 \mathrm{M} \text { EDTA } & 20 \mathrm{ml} & 10 \mathrm{mM} \\ \text { RNase-free } \mathrm{H}_{2} \mathrm{O} & \text { to } 1 \mathrm{I} & \\ \mathrm{pH} \text { was controlled and if necessary adjusted with } \mathrm{NaOH} \text { or } \mathrm{HCl} \text { to } 7.6 . \text { The solution } \\ \text { was sterile filtered and stored at } 4^{\circ} \mathrm{C} .\end{array}$


$\underline{1 X T E}$

\begin{tabular}{ll} 
10X TE & For $500 \mathrm{ml}$ \\
RNase-free $\mathrm{H}_{2} \mathrm{O}$ & $50 \mathrm{ml}$ \\
& to $500 \mathrm{ml}$ \\
$2 \mathrm{XSC} / 0.1 \% \mathrm{SDS}$ & \\
\hline & For $500 \mathrm{ml}$ \\
$20 X \mathrm{SSC}$ & $50 \mathrm{ml}$ \\
$20 \% \mathrm{SDS}$ & $2.5 \mathrm{ml}$ \\
$\mathrm{ddH}_{2} \mathrm{O}$ & to $500 \mathrm{l}$
\end{tabular}

In the case of precipitation of the SDS, the solution was warmed until clear.

\subsubsection{Transient transfection of primary rat hepatocytes}

For transfection of primary hepatocytes, the calcium phosphate precipitation method was used. All the protocols for calcium phosphate precipitation, including the protocol used in the present study, are modifications of the protocol from Graham and van der Eb (Graham and van der Eb, 1973). The principle of the method is that the DNA forms together with calcium phosphate small precipitates which are taken up by cells via the process of endocytosis. The precipitate is obtained when the DNA/calcium chloride solution is mixed with a solution containing phosphate.

The transfection mixture was prepared in polystyrol tubes to prevent adhesion of the DNA to the walls of the vessel. After pipetting, the components were mixed and left for 5-10 min at RT. During this time the DNA/calcium phosphate precipitates were formed, which was observed as a light turbidity of the solution. Finally, $250 \mu \mathrm{l}$ of the mixture was added to $1 \times 10^{6}$ hepatocytes freshly plated in 2.5 $\mathrm{ml}$ of medium on $60 \mathrm{~mm}$ culture dish. The cells were incubated at $37^{\circ} \mathrm{C}$ in humid atmosphere with $5 \% \mathrm{CO}_{2}$. The medium was changed $5 \mathrm{~h}$ post transfection and the cells were further cultured under the serum-free conditions.

\section{Transfection mixture}

Transfection mixture was prepared in the following order: $2 \mu \mathrm{g}$ of plasmid DNA was diluted in appropriate volume of $\mathrm{ddH}_{2} \mathrm{O}$ and subsequently mixed with $\mathrm{CaCl}_{2}$. Afterwards, the obtained mixture was added dropwise to equal volume of $2 X \mathrm{HBS}$. 
For one dish $(60 \mathrm{~mm}) \quad$ Final concentration

Plasmid DNA $2 \mu \mathrm{g}$

$\mathrm{ddH}_{2} \mathrm{O}$ to $112.5 \mu \mathrm{l}$

$2.5 \mathrm{M} \mathrm{CaCl}_{2} \quad 12.5 \mu \mathrm{l} \quad 125 \mathrm{mM}$

2X HBS $125 \mu \mathrm{l}$

\section{X HBS}

For $100 \mathrm{ml} \quad$ Final concentration

$\begin{array}{lll}\text { HEPES } & 1.192 \mathrm{~g} & 50 \mathrm{mM} \\ \mathrm{NaCl} & 1.636 \mathrm{~g} & 280 \mathrm{mM} \\ \mathrm{Na}_{2} \mathrm{HPO}_{4} & 0.267 \mathrm{~g} & 1.5 \mathrm{mM} \\ \mathrm{ddH}_{2} \mathrm{O} & \text { to } 100 \mathrm{ml} & \end{array}$

$\mathrm{pH}$ was adjusted with $5 \mathrm{~N} \mathrm{NaOH}$ to 7.10 , the buffer was dispensed in $10 \mathrm{ml}$ aliquots and stored at $-20^{\circ} \mathrm{C}$.

\section{$2.5 \mathrm{M}$ calcium chloride}

$\begin{array}{lll} & \text { For } 100 \mathrm{ml} & \text { Final concentration } \\ \mathrm{CaCl}_{2} & 36.75 \mathrm{~g} & 2.5 \mathrm{M} \\ \mathrm{ddH}_{2} \mathrm{O} & \text { to } 100 \mathrm{ml} & \end{array}$

\subsubsection{Detection of luciferase activity}

The detection of luciferase activity in the cells transfected with reporter vectors containing the luciferase gene from north american firefly (Photinus pyralis) was performed with the Luciferase Assay Kit (Berthold, Pforzheim). The luciferase assay is based on the enzyme-catalyzed chemiluminescence. Luciferin present in the luciferase assay reagent is oxidized by luciferase in the presence of ATP, air oxygen and magnesium ions. This reaction produces light with a wave length of $562 \mathrm{~nm}$. The luminescence can be measured by a luminometer.

\section{Preparation of cell lysates}

After the desired culture time, the medium was aspirated and cells were washed twice with PBS ( $2 \mathrm{ml}$ per $60 \mathrm{~mm}$ dish). Next, $300 \mu$ l of lysis buffer was added to the dish and cells were incubated for $15 \mathrm{~min}$ at room temperature on a rocking platform with slow agitation. After scraping the cells with a cell-scraper, cell lysates were transferred in tubes and placed on ice with subsequent freezing them in 
liquid nitrogen for about $1 \mathrm{~min}$. Afterwards, the tubes were removed from liquid nitrogen; cell lysates were thawed at room temperature and centrifuged at 14,000 rpm in Eppendorf benchtop MiniSpin centrifuge for $1 \mathrm{~min}$ at room temperature. Aliquots of obtained supernatants were used for detection of luciferase activity.

\section{Luciferase detection}

$20 \mu \mathrm{l}$ of the supernatant from the cell lysate, obtained as described above, was automatically mixed in the luminometer with $100 \mu$ of luciferase assay reagent, prepared directly before use by mixing of equal parts of solutions $A$ and $B$ provided in the assay kit. The reaction was measured 10 times for $2 \mathrm{sec}$. The intensity of luminescence is constant for $20 \mathrm{sec}$ and then decreases with a half-life period of 5 min. No information about the composition of solution A and B was given by the supplier.

\section{$\underline{5 X \text { lysis buffer }}$}

$\begin{array}{lll} & \text { For } 200 \mathrm{ml} & \text { Final concentration } \\ 2 \mathrm{M} \text { Tris-HCl } & 12.5 \mathrm{ml} & 125 \mathrm{mM} \\ 200 \mathrm{mM} \text { CDTA } & 10 \mathrm{ml} & 10 \mathrm{mM} \\ 500 \mathrm{mM} \text { DTT } & 4 \mathrm{ml} & 10 \mathrm{mM} \\ 85 \% \text { glycerol } & 115 \mathrm{ml} & 50 \% \\ \text { Triton X-100 } & 10 \mathrm{ml} & 5 \% \\ \mathrm{ddH}_{2} \mathrm{O} & \text { to } 200 \mathrm{ml} & \\ \text { pH was adjusted with } \mathrm{H}_{3} \mathrm{PO}_{4} \text { to } 7.8 \text {; the solution was autoclaved. }\end{array}$

1X lysis buffer was prepared by diluting $5 \mathrm{X}$ stock in $\mathrm{ddH}_{2} \mathrm{O}$ just prior to use on the basis of $300 \mu \mathrm{l}$ per $60 \mathrm{~mm}$ culture dish.

\subsection{Biochemical methods}

\subsubsection{Protein extraction from liver tissue and cultured hepatocytes}

Preparation of tissue homogenates

All steps were performed at $4^{\circ} \mathrm{C}$ to prevent proteolytic degradation of the proteins. About $100 \mathrm{mg}$ of frozen tissue was homogenized with Ultra-Turrax TP 18/10 model homogenizer 3 times for $10 \mathrm{sec}$ each in 10 volumes of $50 \mathrm{mM}$ Tris- $\mathrm{HCl}$ buffer, $\mathrm{pH}$ 7.4, containing $150 \mathrm{mM} \mathrm{NaCl}, 1 \mathrm{mM}$ EDTA, 1\% Triton X-100, 1mM 
PMSF, $1 \mathrm{mM}$ benzamidine, $1 \mu \mathrm{g} / \mathrm{ml}$ leupeptin, $10 \mu \mathrm{M}$ chymostatin, $1 \mu \mathrm{g} / \mathrm{ml}$ antipain, $1 \mu \mathrm{g} / \mathrm{ml}$ pepstatin A. Crude homogenates were passed 5 times through a $22 \mathrm{G}$ injection canula connected to a syringe. To pellet the nuclei and particular matter, crude homogenates were centrifuged for $5 \mathrm{~min}$ at $10,000 \mathrm{~g}\left(4^{\circ} \mathrm{C}\right)$ and the protein concentration of supernatants was determined by the bicinchoninic acid (BCA) method (Smith et al., 1985) using the BCA protein assay reagent kit (Pierce, Bonn, Germany). Prepared homogenates were dispensed in aliquots and stored at $-20^{\circ} \mathrm{C}$ until use.

Preparation of cell lysates

All steps of the procedure were performed at $4^{\circ} \mathrm{C}$ to prevent proteolytical degradation of the proteins. The cells frozen on the culture dishes were thawed on ice. $1 \mathrm{X}$ ice-cold lysis buffer, comprised of $150 \mathrm{mM} \mathrm{NaCl}, 1 \mathrm{mM}$ EDTA, 1\% Triton $\mathrm{X}-100,50 \mathrm{mM}$ Tris- $\mathrm{HCl}, \mathrm{pH} 7.4$ and supplemented with protease inhibitors, was added to the cells ( $360 \mu$ per $6 \mathrm{~cm}$ dish) followed by incubation on ice for $10 \mathrm{~min}$. Afterwards, the cells were scraped with a disposable scraper, transferred to new tubes and passed 5 times through a $22 \mathrm{G}$ injection canula connected to a syringe. To pellet the nuclei and particular matter, prepared lysates were centrifuged for 5 min at $10,000 \mathrm{~g}\left(4^{\circ} \mathrm{C}\right)$ and the protein concentration of supernatants was determined by BCA method using the kit from Pierce. Prepared lysates were aliquoted and stored at $-20^{\circ} \mathrm{C}$ until use.

10X homogenization buffer (for tissue and cell processing)

For $100 \mathrm{ml}$

Final concentration

$\begin{array}{lll}2 \mathrm{M} \text { Tris-HCl, } \mathrm{pH} 7.4 & 2.5 \mathrm{ml} & 50 \mathrm{mM} \\ 500 \mathrm{mM} \text { EDTA } & 200 \mu \mathrm{l} & 1 \mathrm{mM} \\ \mathrm{NaCl} & 0.877 \mathrm{~g} & 150 \mathrm{mM} \\ \mathrm{ddH}_{2} \mathrm{O} & \text { to } 100 \mathrm{ml}\end{array}$

1X homogenization buffer with additives

For $10 \mathrm{ml} \quad$ Final concentration

10X homogenization buffer $1 \mathrm{ml} \quad 1 \mathrm{X}$

Triton X-100 $100 \mu \mathrm{l}$

$\mathrm{ddH}_{2} \mathrm{O} \quad 9 \mathrm{ml}$ 
Prior to use the following protease inhibitors were added:

$\begin{array}{lll} & \text { For } 10 \mathrm{ml} & \text { Final concentration } \\ 500 \mathrm{mM} \text { PMSF } & 20 \mu \mathrm{l} & 1 \mathrm{mM} \\ 10 \mathrm{mg} / \mathrm{ml} \text { leupeptin } & 1 \mu \mathrm{l} & 1 \mu \mathrm{g} / \mathrm{ml} \\ 1 \mathrm{M} \text { benzamidine } & 10 \mu \mathrm{l} & 1 \mathrm{mM} \\ 8.25 \mathrm{mM} \text { chymostatin } & 10 \mu \mathrm{l} & 8.25 \mu \mathrm{M} \\ 1 \mathrm{mg} / \mathrm{ml} \text { pepstatin } & 10 \mu \mathrm{l} & 1 \mu \mathrm{g} / \mathrm{ml} \\ 10 \mathrm{mg} / \mathrm{ml} \text { antipain } & 1 \mu \mathrm{l} & 1 \mu \mathrm{g} / \mathrm{ml}\end{array}$

\section{Protease inhibitors stocks}

Stock concentration

PMSF

$87.1 \mathrm{mg}$ in $1 \mathrm{ml}$ DMSO

$500 \mathrm{mM}$

Leupeptin

$1 \mathrm{mg}$ in $0.1 \mathrm{ml} \mathrm{H}_{2} \mathrm{O}$

$10 \mathrm{mg} / \mathrm{ml}$

Benzamidine

$313.2 \mathrm{mg}$ in $2 \mathrm{ml} \mathrm{H} \mathrm{H}_{2} \mathrm{O}$

$1 \mathrm{M}$

Chymostatin

$1 \mathrm{mg}$ in $0.2 \mathrm{ml}$ DMSO

$8.25 \mathrm{mM}$

Pepstatin A

$1 \mathrm{mg}$ in $1 \mathrm{ml}$ DMSO:acetic $1 \mathrm{mg} / \mathrm{ml}$

acid $(9: 1)$

Antipain

$1 \mathrm{mg}$ in $0.1 \mathrm{ml} \mathrm{H}_{2} \mathrm{O}$

$10 \mathrm{mg} / \mathrm{ml}$

Protease inhibitors stocks were dispensed into small aliquots and stored at $-20^{\circ} \mathrm{C}$.

\section{Product information (Sigma)}

Antipain: inhibits reversibly serine/cysteine proteases and some trypsin-like serine proteases. Its action resembles leupeptin, but it inhibits plasmin less and cathepsin A more than does leupeptin. Antipain also inhibits papain, trypsin, cathepsin B, cathepsin D, chymotrypsin, pepsin, and calpain I.

Benzamidine: inhibits reversibly trypsin-like enzymes and serine proteases. Furthermore, it is a strong competitive inhibitor of trypsin, thrombin and plasmin. Benzamidine is sensitive to oxidation and for the most part interchangeable with pepstatin $A$.

Chymostatin: inhibits strongly a lot of proteases, including chymotrypsin, chymotrypsin-like serine proteases, chymases and lysosomal cysteine proteases such as cathepsins B, H and L. Inhibits weakly human leukocyte elastase. 
Leupeptin: inhibits reversibly and competitively serine and thiol proteases such as trypsin, plasmin, proteinase $\mathrm{K}$, kallikrein, papain, thrombin and cathepsin $A$ and $B$. Not affected are $\alpha, \beta, y$ and $\delta$ chymotrypsins, pepsin, cathepsin D, elastase, renin and thermolysin.

Pepstatin A: inhibits acid proteases (aspartyl peptidases). It forms 1:1 complex with proteases such as pepsin, renin, cathepsin D, bovine chymosin, solubilized $\mathrm{y}$-secretase, retroviral protease, and protease $\mathrm{B}$ (Aspergillus niger). The inhibitor is highly selective and does not inhibit thiol proteases, neutral proteases or serine proteases.

PMSF: inhibits serine proteases such as chymotrypsin, trypsin and thrombin as well as thiol protease papain. Does not inhibit metalloproteases, most thiol and aspartate proteases. PMSF is very unstable in the presence of water.

\subsubsection{Western blot analysis}

\section{Sample preparation}

Aliquots of prepared tissue homogenates and cell lysates were denatured in sample buffer containing $2 \%$ SDS, $10 \%$ glycerol, $50 \mu \mathrm{g} / \mathrm{ml}$ bromphenol blue, $2 \% \beta$ mercaptoethanol and $50 \mathrm{mM}$ Tris- $\mathrm{HCl}, \mathrm{pH} 6.8$ by boiling at $95^{\circ} \mathrm{C}$ for 10 min and 15 $\mu \mathrm{g}$ of total protein was subjected to SDS-polyacrylamide gel electrophoresis (SDSPAGE).

\section{Casting of SDS-polyacrylamide gel}

For all applications described, a Tris/glycine SDS polyacrylamide gel (SDS-PAAG) system was used according to the method of Laemmli (Laemmli, 1970). For hand casting of the gels for vertical electrophoresis, a Mini-PROTEAN ${ }^{T M}$ III Electrophoresis Cell (Bio-Rad) was used. 12.5\% separating gels and $4 \%$ stacking gel were prepared as described below. The casting of the gels was performed according to the manufacturer's instructions. Precast $12 \%$ Tris/glycine SDS-PAAG (Bio-Rad) compatible with this system was used alternatively.

The separation gel $(7.5 \mathrm{ml}$ for $1.5 \mathrm{~mm}$ gel thickness) was poured between the inner $(7.3 \times 10.2 \mathrm{~cm})$ and outer $(8.3 \times 10.2 \mathrm{~cm})$ glass plates. The gel was carefully 
overlaid with water-saturated isobutanol to create a barrier to oxygen, which inhibits the polymerization. After the gel has set (about $30 \mathrm{~min}$ at RT), the overlay was poured off and the top of the separating gel was washed with distilled water. The solution of stacking gel was poured directly onto the polymerized separating gel. The slots were formed by placing the appropriative comb into the gel solution. The polymerization took approximately $10 \mathrm{~min}$.

SDS-polyacrylamide gel electrophoresis (SDS-PAGE) and electrophoretic transfer The samples were loaded onto the bottom of the wells. Electrophoresis was run at constant $20 \mathrm{~mA}$ per gel. The Rainbow ${ }^{\mathrm{TM}}$ colored protein markers (Amersham Pharmacia Biotech) were used as molecular weight standards. Electrophoretic transfer was carried out essentially as described by Towbin (Towbin et al., 1979). Prior to stopping the gel running, fiber pads, filter paper and nitrocellulose transfer membrane (0.45 $\mu \mathrm{M}$ pore size) were soaked in transfer buffer. After electrophoresis, the gel was removed out of the plates and immersed in transfer buffer. For electrophoretic transfer of proteins from the gel to a membrane, a MiniTrans-Blot ${ }^{\circledR}$ Cell (Bio-Rad), compatible with described system for electrophoresis, was utilized. The transblot sandwich was assembled according to the manufacturer's instructions from Bio-Rad in the following order starting from the anode side: sponge, 2 sheets of filter paper, nitrocellulose membrane, gel, 2 sheets of filter paper, sponge. The assembled transblot sandwich was inserted into the transblot cell filled with transfer buffer. Ice-cooling unit was set behind the cathode side of transblot cell. The transfer ran for $2 \mathrm{~h}$ at $350 \mathrm{~mA}$ with one change of the ice-cooling unit after the first hour.

\section{Staining the membrane with Ponceau S}

Ponceau $S$ can be used routinely to verify quality of protein transfer from SDSPAAG to nitrocellulose membrane. It is applied in acidic aqueous solution. Staining is rapid but not permanent; the red stain is washed away in subsequent processing. Since the binding is reversible, the stain is compatible with most antigen visualization techniques.

The membrane was immersed in freshly diluted Ponceau S solution and incubated for 5-10 min at room temperature with gentle agitation on the rocking platform. Afterwards, the membrane was distained for 1-2 min with several changes of TBS. 
After visualization of distinctly visible protein bands, the dye was washed away completely with washing buffer.

\section{Immunovisualization}

After transfer, the membrane was incubated on the rocking platform with blocking solution for overnight at $4^{\circ} \mathrm{C}$. Next, the membrane was incubated with primary antibody diluted in antibody dilution buffer for $2 \mathrm{~h}$ at room temperature. After washing (six times, five min on each occasion), the membrane was incubated with HRP-conjugated secondary antibody diluted in antibody dilution buffer for $1 \mathrm{~h}$ at room temperature. Afterwards, the membrane was washed as before. For the chemiluminescent detection SuperSignal ${ }^{\circledR}$ West Pico Chemiluminescent Substrate (Pierce) was used. Substrate working solution was prepared by mixing of equal volumes of two substrate components. The membrane was incubated with substrate working solution for $5 \mathrm{~min}$ at room temperature, laid between two sheets of transparent plastic protector and exposed to X-ray film, which was developed afterward according to the manufacturer's instructions.

$\underline{5 X \text { sample buffer }}$

$\begin{array}{lll} & \text { Per } 20 \mathrm{ml} & \text { Final concentration } \\ \text { Tris- } \mathrm{HCl} & 0.79 \mathrm{~g} & 250 \mathrm{mM} \\ \text { SDS } & 2 \mathrm{~g} & 10 \% \\ \text { Glycerol } & 10 \mathrm{ml} & 50 \%\end{array}$

The components were dissolved in $\mathrm{ddH}_{2} \mathrm{O}$ (up to $18 \mathrm{ml}$ ), $\mathrm{pH}$ was adjusted with $\mathrm{HCl}$ to 6.8 and finally the following components were added:

$\begin{array}{lll} & \text { Per } 20 \mathrm{ml} & \text { Final concentration } \\ \text { Bromphenol blue } & 5 \mathrm{mg} & 250 \mu \mathrm{g} / \mathrm{ml} \\ \text { B-Mercaptoethanol } & 2 \mathrm{ml} & 10 \%\end{array}$

The solution was aliquoted and stored at $-20^{\circ} \mathrm{C}$. Protein samples were mixed with sample buffer in the proportion of $4: 1$, respectively.

Separating gel

\begin{tabular}{|c|c|c|}
\hline \multirow{2}{*}{ Components } & \multicolumn{2}{|c|}{$12.5 \%$ gel } \\
\cline { 2 - 3 } & For $10 \mathrm{ml}$ & For $15 \mathrm{ml}$ \\
\hline Rotiphorese Gel 30 & $4.17 \mathrm{ml}$ & $6.25 \mathrm{ml}$ \\
\hline
\end{tabular}




\begin{tabular}{|c|c|c|}
\hline $4 \mathrm{X}$ Tris/SDS, $\mathrm{pH} 8.8$ & $2.5 \mathrm{ml}$ & $3.75 \mathrm{ml}$ \\
\hline $\mathrm{ddH}_{2} \mathrm{O}$ & $3.33 \mathrm{ml}$ & $5 \mathrm{ml}$ \\
\hline $10 \%$ APS & $33 \mu \mathrm{l}$ & $50 \mu \mathrm{l}$ \\
\hline TEMED & $7 \mu \mathrm{l}$ & $10 \mu \mathrm{l}$ \\
\hline
\end{tabular}

4\% stacking gel

Component

Rotiphorese Gel 30

4X Tris/SDS, pH 6.8

$\mathrm{dd}_{2} \mathrm{O}$

10\% APS

TEMED

$\underline{4 X \text { Tris/SDS, } \mathrm{pH} 6.8}$

Tris base

SDS

$\mathrm{ddH}_{2} \mathrm{O}$

$\mathrm{pH}$ was adjusted with $37 \%$ temperature.

\section{$\underline{4 X \text { Tris/SDS, } \mathrm{pH} 8.8}$}

For $100 \mathrm{ml}$

$6.05 \mathrm{~g}$

$0.4 \mathrm{~g}$

to $100 \mathrm{ml}$
$0.67 \mathrm{ml}$

$1.25 \mathrm{ml}$

$3.08 \mathrm{ml}$

$30 \mu \mathrm{l}$

$10 \mu \mathrm{l}$
Amount

\footnotetext{
For $250 \mathrm{ml}$

Tris base

$45.5 \mathrm{~g}$

SDS

$1 \mathrm{~g}$

$\mathrm{dd}_{2} \mathrm{O}$

to $250 \mathrm{ml}$

$\mathrm{pH}$ was adjusted with $37 \% \mathrm{HCl}$ to 6.8 ; the solution was stored at room temperature.
} 
$\underline{\text { 5X SDS-PAGE running buffer }}$

$\begin{array}{lc} & \text { For } 2 \mathrm{I} \\ \text { Tris base } & 30.2 \mathrm{~g} \\ \mathrm{SDS} & 144 \mathrm{~g} \\ \mathrm{ddH}_{2} \mathrm{O} & \text { to } 2 \mathrm{I} \\ \mathrm{pH} \text { was adjusted with } 37 \% \mathrm{HCl} \text { to } 8.3 ; \text { the solution was stored at room } \\ \text { temperature. }\end{array}$

1X SDS-PAGE running buffer

\begin{tabular}{ll}
\hline $5 X$ stock & For 2 I \\
$\mathrm{ddH}_{2} \mathrm{O}$ & $400 \mathrm{ml}$ \\
& to 2 I
\end{tabular}

$\underline{5 X \text { transfer buffer }}$

For 21

$39.4 \mathrm{~g}$

Tris base

$144 \mathrm{~g}$

to 21

Glycine

$\mathrm{ddH}_{2} \mathrm{O}$

$\mathrm{HCl}$ to 8.3; the solution was stored at room temperature.

$\underline{1 X \text { transfer buffer }}$

For 21

$400 \mathrm{ml}$

$400 \mathrm{ml}$

$1 \mathrm{ml}$

to 21

10X Ponceau S solution

Ponceau S

Trichloroacetic acid

Sulfosalicylic acid

$\mathrm{dd}_{2} \mathrm{O}$
For $100 \mathrm{ml}$

$2 \mathrm{~g}$

$30 \mathrm{ml}$

$30 \mathrm{ml}$

to $100 \mathrm{ml}$
Final concentration $1 \mathrm{X}$

$20 \%$

$0.01 \%$

Final concentration

$2 \%$

$30 \%$

$30 \%$ 
1X Ponceau S solution

$\begin{array}{ll} & \text { For } 50 \mathrm{ml} \\ \text { 10X Ponceau S } & 5 \mathrm{ml} \\ \mathrm{ddH}_{2} \mathrm{O} & \text { to } 50 \mathrm{ml}\end{array}$

10X washing buffer

For 21

Tris base $\quad 48.4 \mathrm{~g}$

$\mathrm{NaCl} \quad 58.48 \mathrm{~g}$

$\mathrm{ddH}_{2} \mathrm{O}$ to 2 I

$\mathrm{pH}$ was adjusted with $\mathrm{HCl}$ to 7.4 ; the solution was stored at room temperature.

1X washing buffer

$\begin{array}{lll} & \text { For } 5 \mathrm{l} & \text { Final concentration } \\ 10 \mathrm{X} \text { stock } & 500 \mathrm{ml} & 1 \mathrm{X} \\ \text { Tween } 20 & 5 \mathrm{ml} & 0.1 \% \\ \mathrm{ddH}_{2} \mathrm{O} & \text { to } 5 \mathrm{I} & \end{array}$

Blocking reagent

$\begin{array}{lll} & \text { For } 50 \mathrm{ml} & \text { Final concentration } \\ \text { Nonfat dry milk } & 2.5 \mathrm{~g} & 5 \% \\ \text { 1X washing buffer } & \text { to } 50 \mathrm{ml} & \end{array}$

The solution should be prepared freshly and stored at $4^{\circ} \mathrm{C}$.

Antibody incubation buffer

$\begin{array}{lll} & \text { For } 50 \mathrm{ml} & \text { Final concentration } \\ 5 \% \text { nonfat milk } & 5 \mathrm{ml} & 0.5 \% \\ 1 \mathrm{X} \text { washing buffer } & \text { to } 50 \mathrm{ml} & \end{array}$

Primary antibodies were used in the following dilutions:

Antibody

Used dilution

anti-HO-1 rabbit polyclonal antiserum

$1: 2,000$

anti- $\beta$-actin mouse monoclonal antibody

$1: 10,000$ 
Secondary HRP-conjugated antibodies were used in the following dilution:

Antibody

Donkey anti-rabbit whole Ig

Rabbit anti-mouse Ig
Used dilution

$1: 10,000$

$1: 10,000$

\subsubsection{Enzyme-Linked Immunosorbent Assay (ELISA)}

To measure IL-6 concentration in rat serum, the Quantikine ${ }^{\circledR}$ M rat IL-6 immunoassay kit (R\&D Systems, Wiesbaden, Germany), based on solid phase ELISA, was used. This assay employs the quantitative sandwich enzyme immunoassay technique. A microplate is pre-coated with monoclonal antibody specific for rat IL-6. Samples are pipetted into the wells and any IL-6 present is bound by immobilized antibody. After washing away any unbound material, an enzyme-linked polyclonal antibody specific for rat IL-6 is added. Any unbound antibody-enzyme reagent is washed away, and a substrate solution is added to the wells. The enzymatic reaction yields a blue-colored product that turns yellow when the stop solution is added. The intensity of the color measured colorimetrically is proportional to the amount of rat IL-6 bound in the initial step.

\section{Reagent preparation}

Since all samples should be pipetted within $15 \mathrm{~min}$, reagents needed for the assay were prepared prior to assay procedure. All reagents were provided with Quantikine ${ }^{\circledR}$ M rat IL-6 immunoassay kit.

\section{Rat IL-6 control}

The rat IL-6 control, provided with kit, was reconstituted with $1 \mathrm{ml}$ double distilled water.

\section{$\underline{\text { Rat IL-6 conjugate concentrate }}$}

$$
\text { For } 96 \text { wells }
$$

Conjugate concentrate

$$
0.5 \mathrm{ml}
$$

Conjugate diluent 


\section{Washing buffer}

\begin{tabular}{ll}
\hline & For 96 wells \\
Washing buffer concentrate & $25 \mathrm{ml}$ \\
$\mathrm{ddH}_{2} \mathrm{O}$ & to $625 \mathrm{ml}$
\end{tabular}

\section{Substrate solution}

Equal volumes of color reagents $\mathrm{A}$ and $\mathrm{B}$, provided by kit, were mixed together, and solution was used with $15 \mathrm{~min}$.

\section{Standard and sample preparation}

Rat IL-6 standard was reconstituted with $2 \mathrm{ml}$ of calibrator diluent RD5-16. This stock solution $(2000 \mathrm{pg} / \mathrm{ml})$ was used to prepare a dilution series ranging from $31.2 \mathrm{pg} / \mathrm{ml}$ to $2000 \mathrm{pg} / \mathrm{ml}$. Calibrator diluent RD5-16 served as zero standard.

Blood was sampled from the vena cava inferior of control and treated rats, allowed to clot overnight at $4^{\circ} \mathrm{C}$ and centrifuged for $20 \mathrm{~min}$ at 2,000 g. Serum was collected and stored in aliquots at $-20^{\circ} \mathrm{C}$ until use. Prior to assay, serum samples were diluted 2 fold into calibration diluent RD5-16.

\section{Assay procedure}

The whole procedure was performed at room temperature. All samples, standards and controls were assayed in duplicates. To synchronize the reaction in each well, all reagents were pipetted using a multi-channel pipette.

$50 \mu \mathrm{l}$ of assay diluent RD1-54 was added to each well. Standards, control and samples were added in a quantity of $50 \mu \mathrm{l}$ per well. The components were mixed by gentle tapping the plate frame for $1 \mathrm{~min}$. After that, the plate was covered with the adhesive strip provided and incubated for $2 \mathrm{~h}$ at room temperature. Afterwards, each well was aspirated and washed with $400 \mu \mathrm{l}$ of wash buffer using a manifold dispenser, and procedure was repeated four times for a total of five washes. For good performance, the liquid was removed completely by aspirating at each step. After washing, $100 \mu \mathrm{l}$ of rat IL-6 conjugate was added to each well. The plate was covered with a new adhesive strip and incubated for another $2 \mathrm{~h}$ at room temperature. The aspiration-washing procedure was performed as described above. Subsequently, $100 \mu \mathrm{l}$ of substrate solution was added to each well to start enzymatic reaction and plate was incubated in the dark for $30 \mathrm{~min}$ at room 
temperature. To stop the enzymatic reaction, $100 \mu \mathrm{l}$ of stop solution was added to each well, followed by determination of optical density of each well using a microplate reader (Dynatech Laboratories) set to dual wavelength mode (test filter $-450 \mathrm{~nm}$, reference filter - $570 \mathrm{~nm}$ ).

The calculation of results was performed with a program (Dynatech MRX software, version 1.33) created in accordance to the manual instructions (Quantikine ${ }^{\circledR} \mathrm{M}$ rat IL-6 immunoassay kit).

\subsubsection{Immunohistochemical analysis}

Immunoenzymatic/immunohistochemical (IHC) staining techniques allow for the visualization of tissue (cell) antigens. These techniques are based on the immunoreactivity of antibodies and the chemical properties of enzymes or enzyme complexes which react with colorless substrate-chromogens to produce a colored end-product. In the present study, indirect IHC technique where enzyme-labeled secondary antibody reacts with the antigen-bound primary antibody was used. The indirect method significantly improves the sensitivity of IHC staining compared to direct technique where enzymes are directly conjugated to the primary antibody. IHC technique can be divided into four steps, such as cell or tissue preparation, fixation, antibody binding, and detection.

\section{Preparation and fixation of tissue sections}

Preparing frozen tissue sections is the gentlest method for the preparation of samples and gives good preservation of cell structure and antigens.

Snap-frozen tissue blocks (approximately $1.0 \times 1.0 \times 0.5 \mathrm{~cm}$ ) were sliced in $5 \mu \mathrm{m}$ sections using a cryostat (Frigocut $2800 \mathrm{E}$ ) at the object temperature of $-20^{\circ} \mathrm{C}$ and the chamber temperature of $-23^{\circ} \mathrm{C}$. The sections were placed on glass slides and air-dried for 2-3 $\mathrm{h}$ at room temperature. Dried sections were fixed for $10 \mathrm{~min}$ in icecold methanol followed by $10 \mathrm{sec}$ fixation in ice-cold acetone and allowed to airdry until completely dehydrated. Afterwards, the slides were proceeded with immunostaining or wrapped in aluminum foil and stored at $-20^{\circ} \mathrm{C}$ for up to six months. Prior to immunostaining, wrapped frozen sections were equilibrated to room temperature.

Alternatively, non-fixed tissue sections were subjected to hematoxylin-eosin staining to monitor tissue structure and quality of sections. Hematoxylin-eosin staining was performed as follows: the slides were placed for $5 \mathrm{~min}$ in hematoxylin, 
then washed for 10 min with tap water, placed afterwards for $10 \mathrm{sec}$ in eosin solution and washed again for 5 min with tap water. Finally, the sections were covered with Kaiser's glycerol gelatin and coverslipped.

Inhibition of endogenous peroxidases and blocking of nonspecific binding

Prior to staining procedure, endogenous tissue peroxidases were inhibited by incubation of sections with peroxidase inhibition solution, containing glucose oxidase, sodium azide and glucose, for $20 \mathrm{~min}$ at room temperature. Afterwards, the sections were washed with PBS 2 times for 5 min on each occasion. Next, the slides were placed in a humidified chamber, covered with blocking solution, containing $300 \mu \mathrm{g}$ of human IgG in $1 \mathrm{ml}$ of heat inactivated FCS, and incubated for $20 \mathrm{~min}$ at $37^{\circ} \mathrm{C}$ to minimize nonspecific staining. Then washing in PBS was performed 2 times for 5 min.

Incubation with antibodies

After washing, the slides were covered with primary antibody diluted in PBS ( $300 \mu \mathrm{l}$ per slide) and incubated for $60 \mathrm{~min}$ at room temperature in humidified chamber. For negative control, the incubation with primary antibody was omitted. Meanwhile, HRP-conjugated secondary antibody was preabsorbed with heat inactivated normal rat serum to avoid crossreactivity. For this purpose, $10 \mu$ of rat serum was added to $50 \mu \mathrm{l}$ of secondary antibody and incubated $60 \mathrm{~min}$ at $37^{\circ} \mathrm{C}$, followed by centrifugation for 5 min at maximum speed of an Eppendorf bench-top centrifuge in order to pellet any precipitates. Afterwards, $50 \mu \mathrm{l}$ of supernatant was transferred into a new tube and mixed with $350 \mu$ l of PBS and $600 \mu$ l of $\gamma$-globulinfree serum.

After incubation with primary antibody, the slides were washed in PBS 3 times for $5 \mathrm{~min}$. Afterwards, the slides were covered with secondary antibody (300 $\mu$ per slide), prepared as described above, and incubated for $60 \mathrm{~min}$ at room temperature in a humidified chamber. Next, the washing step was performed as before.

\section{Visualization of immune complexes}

For immunovisualization, liquid $\mathrm{DAB}+$ chromogen substrate (Dako) was used. Upon oxidation, DAB forms a brown end-product at the site of the target antigen. The working reagent was prepared by mixing $20 \mu$ of the DAB Chromogen with $1 \mathrm{ml}$ of Substrate buffer supplied. The slides were covered with freshly prepared 
working solution (300 $\mu \mathrm{l}$ per slide) and incubated $10 \mathrm{~min}$ at room temperature. Next, the slides were washed 2 times for $5 \mathrm{~min}$ in distilled water and the sections were counterstained with Meyer's hemalaun (Merck) for $5 \mathrm{~min}$. After subsequent washing step (10 $\mathrm{min}$ in tap water), the sections were covered with Kaiser's glycerol gelatin and mounted with cover-slips.

\section{$\underline{\text { Peroxidase inhibition solution }}$}

$\begin{array}{ll} & \text { For } 100 \mathrm{ml} \\ \text { Glucose } & 180 \mathrm{mg} \\ \text { Glucose oxidase } & 5 \mathrm{mg} \\ 1 \mathrm{M} \text { sodium azide } & 100 \mu \mathrm{l} \\ \text { PBS } & \text { to } 100 \mathrm{ml}\end{array}$

The solution was prepared just prior to use. The components were dissolved in PBS, placed in prewarmed cuvette and incubated for 10 min at $37^{\circ} \mathrm{C}$ in water bath.

\section{Blocking solution}

\begin{tabular}{ll}
\hline $10 \mathrm{mg} / \mathrm{ml}$ human $\mathrm{lgG}$ & For $1 \mathrm{ml}$ \\
Heat inactivated FCS & $30 \mu \mathrm{l}$ \\
& to $1 \mathrm{ml}$
\end{tabular}

Working solution for immunovisualization was prepared by mixing $20 \mu$ of DAB+ chromogen (containing 3,3'-diaminobenzidine in chromogen solution) and $1 \mathrm{ml}$ of substrate buffer (containing imidazole- $\mathrm{HCl}, \mathrm{pH} 7.5$, hydrogen peroxide and an antimicrobial agent).

Primary antibodies were used in the following dilutions:

Antibody

anti-HO-1 mouse monoclonal antibody

anti-rat-ED1 mouse monoclonal antibody

anti-rat-ED2 mouse monoclonal antibody

\section{Used dilution}

$1: 500$

$1: 100$

$1: 100$

Secondary HRP-conjugated antibody was used in the following dilution:

Antibody

Rabbit anti-mouse lg
Used dilution

$1: 20$ 


\subsubsection{Statistical analysis}

Autoradiographic and immunoreactive bands after Nothern and Western blots, respectively, were evaluated by densitometric scanning using Molecular Analyst scanning densitometer (Bio-Rad). The relative densities of bands were expressed as a fold of increase compared to respective controls.

Results of IL-6 plasma concentration measurements are presented as means $\pm S E M$. Data obtained from luciferase activity measurements were analyzed by Student's $t$-test for paired values and presented as means $\pm S E M$. A value of $p<0.05$ was accepted as statistically significant.

\subsubsection{Safety measures}

All operations with genetically modified organisms and plasmid DNA were performed in accordance to the "Gentechnikgesetz" of 1990 and to the rules prescribed by the "Gentechnik-Sicherheitsverordnung" of 1990. Materials

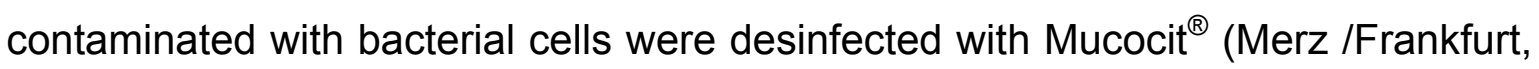
Germany) and autoclaved.

Ethidium bromide, formaldehyde, DEPC and other chemicals deleterious for the environment, when used in the course of the work, were carefully managed and disposed properly in accordance with institutional guidelines.

All the operations with radioactive chemicals were performed in a radioactivity class II laboratory and the radioactive waste was disposed according to the institutional instructions. 


\section{Results}

\subsection{Studies in vivo: HO-1 expression in a turpentine oil (TO) model of the acute phase response (APR) in rats}

An acute phase reaction in rats was induced by a single intramuscular injection of TO; control animals received no injection. Tissue and blood specimens were collected from the control and treated animals at the following time points: $0.5 \mathrm{~h}$, $1 \mathrm{~h}, 2 \mathrm{~h}, 4 \mathrm{~h}, 6 \mathrm{~h}, 12 \mathrm{~h}, 24 \mathrm{~h}, 36 \mathrm{~h}$ and $48 \mathrm{~h}$. Tissues were snap-frozen in liquid nitrogen and kept further at $-80^{\circ} \mathrm{C}$ for subsequent RNA, protein extraction and preparation of cryostat sections. Serum from blood samples was separated by clotting and subsequent centrifugation and stored at $-20^{\circ} \mathrm{C}$ until use for the rat IL-6 specific ELISA. Northern blot hybridizations of total RNA from various tissues were performed with cDNAs specific for HO-1, a2-macroglobulin, albumin, IL-6, GAPDH and with a $28 \mathrm{~S}$ rRNA-specific oligonucleotide. Western blot analysis of hepatic protein extracts was carried out using antibodies against rat $\mathrm{HO}-1$ and $\beta$-actin. Liver and muscular tissues were used for preparation of cryostat sections with subsequent hematoxylin/eosin staining and immunohistochemical analysis.

\subsubsection{HO-1 expression in the liver and extrahepatic tissues during a turpentine oil (TO)-induced acute phase response (APR) in rats}

Expression of hepatic HO-1 mRNA and protein during a turpentine oil (TO)induced acute phase reaction

To define the time-course of hepatic HO-1 mRNA expression during TO-induced acute phase reaction in rats, Northern blot analysis of total RNA prepared from whole liver tissue at various time points after single injection of TO was performed using radiolabeled $\mathrm{HO}-1$ cDNA as a probe. As indicated in Figure 11A, HO-1 specific transcript levels were dramatically increased 4-6 h after TO administration with a maximum at $6 \mathrm{~h}$. Since $\alpha 2-$ macroglobulin is a well-known positive, and albumin a negative acute phase proteins in rats (Schreiber et al., 1986), hybridizations with a2-macroglobulin- and albumin-specific cDNAs were performed to ensure development of the acute phase response in the treated animals. The a2-macroglobulin mRNA levels were elevated from 4 to $24 \mathrm{~h}$ and albumin mRNA decreased reaching lowest levels 24 to $36 \mathrm{~h}$ after TO injection (Figure 11A), which 
is in accordance with published data (Knittel et al., 1997). Hybridization with GAPDH-specific cDNA was used to control equal loading of RNA.

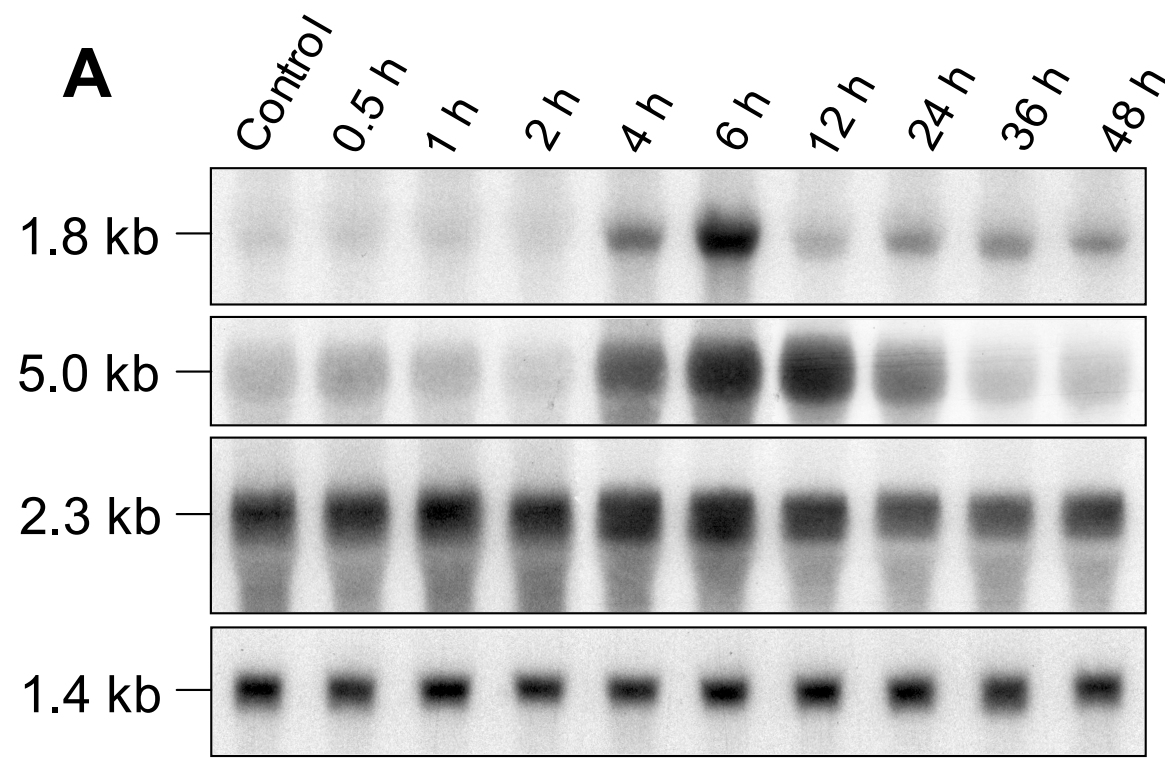

$\mathrm{HO}-1$

$\alpha 2-\mathrm{M}$

Albumin

GAPDH

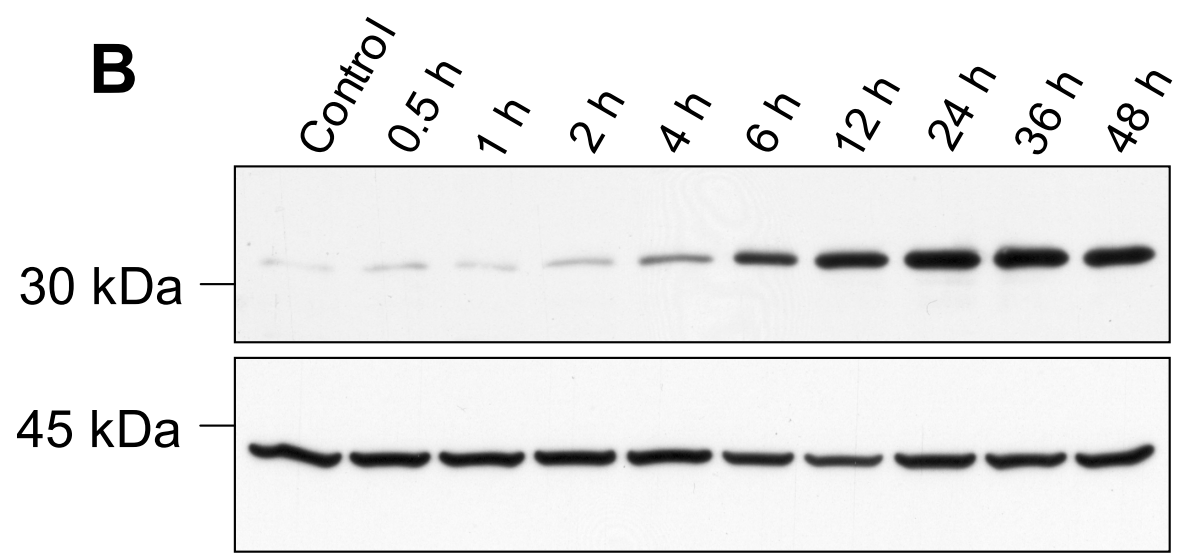

$\mathrm{HO}-1$

$\beta$-actin

Figure 11. Time course of hepatic HO-1 mRNA and protein expression after TO administration. An acute phase response was induced by TO injection in rats, afterwards liver specimens were removed at the indicated time points and homogenized for RNA and protein extraction as described in Methods. (A) Total RNA (10 $\mu \mathrm{g}$ ) from livers of control and TO-treated rats was subjected to Northern blot and sequentially hybridized with $\left[{ }^{32} \mathrm{P}\right]$-labeled cDNAs specific for HO-1, $\alpha 2$-macroglobulin ( $\left.\alpha 2-\mathrm{M}\right)$, albumin and GAPDH as an internal loading control. The sizes of the transcripts (in kilobases, kb) are indicated on the left. A representative of four independent experiments is shown. (B) The protein samples $(15 \mu \mathrm{g})$ from livers of control and TO-treated rats were immunoblotted and probed with a rabbit polyclonal anti-HO-1 antibody as described in Methods. Mouse monoclonal anti- $\beta$-actin antibody was used to control equal loading of protein samples. The positions of molecular weight standards (in kilodaltons, kDa) are indicated on the left. Data shown are representative of more than three independent experiments. 
The enhancement of HO-1 mRNA was followed by an induction of $\mathrm{HO}-1$ protein as shown by Western blot analysis. HO-1 protein levels started to increase after $4 \mathrm{~h}$ and remained elevated up to $48 \mathrm{~h}$ after TO administration (Figure 11B), indicating that in rat liver under inflammatory conditions, the life-time of the $\mathrm{HO}-1$ protein seems to be considerably longer than the life-time of the HO-1 mRNA. To control equal loading of proteins, the membranes were stripped and then probed with an anti- $\beta$-actin antibody.

Expression of HO-1 mRNA in extrahepatic rat tissues during a turpentine oil (TO)induced acute phase reaction

To determine whether $\mathrm{HO}-1$ induction is a liver-specific response to localized inflammation or it could also occur in other rat tissues under the given experimental conditions, Northern blot analysis of total RNA prepared from skeletal muscle, lung, heart, kidney, spleen, small and large intestine at various time points after injection of TO was performed using radiolabeled $\mathrm{HO}-1$ cDNA as a probe. A strong induction of HO-1 mRNA was observed in skeletal muscle at the site of injection where the acute phase response was initiated by local inflammation. As depicted on Figure 12, HO-1-specific transcripts appeared already after $2 \mathrm{~h}$, reached maximal levels by 4-6 $\mathrm{h}$ and slowly decreased up to 48 $\mathrm{h}$ after TO injection. It should be noted that HO-1 mRNA expression in injured muscle correlated with that in the liver (Figure 11A).

Figure 12 further illustrates that in the heart, kidney and large intestine, a slight induction of HO-1 mRNA was observed $6 \mathrm{~h}$ after TO injection, while in the lung, spleen and small intestine no changes in $\mathrm{HO}-1$ expression were detected. Relatively high basal levels of HO-1 gene expression were found in the spleen (Figure 12), which is consistent with published work (Braggins et al., 1986). It is likely a consequence of permanent spleen exposure to hemoglobin released from the disrupted senescent erythrocytes. 


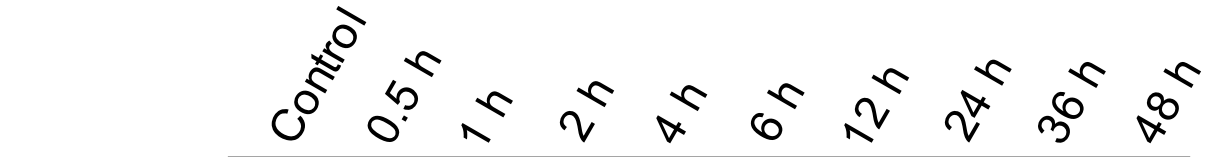
Injected

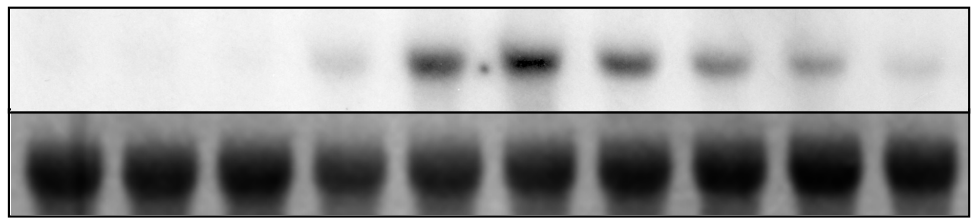

HO-1 muscle

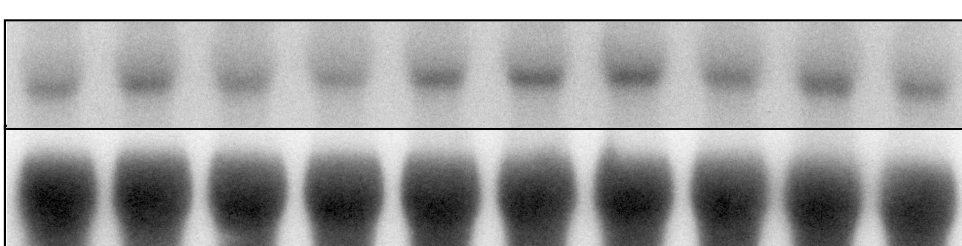

$28 S$

Lung

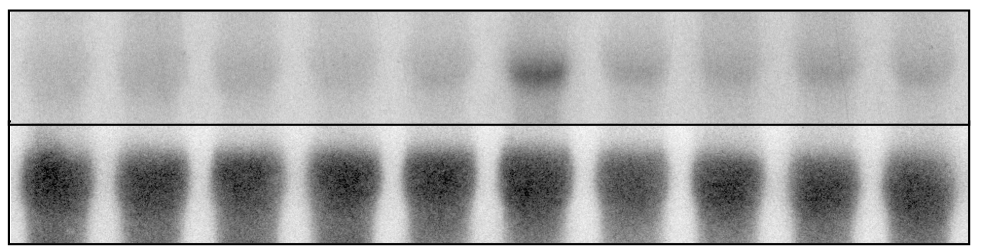

HO-1

$28 S$

Heart

HO-1

$28 S$

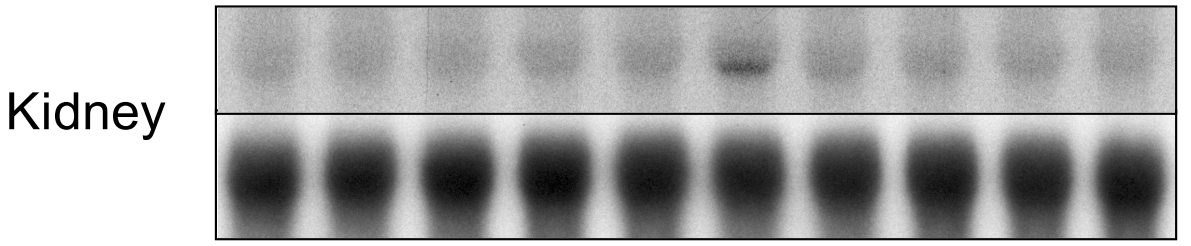

HO-1

$28 S$

Spleen

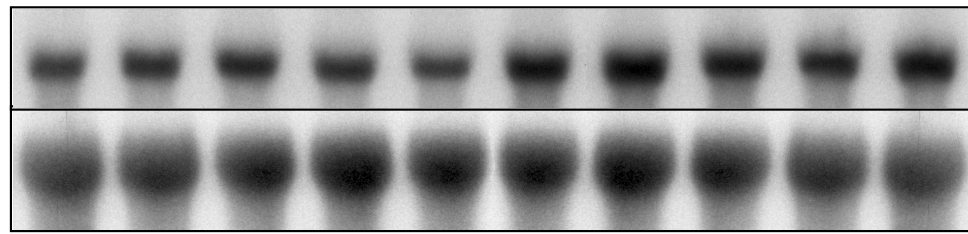

$\mathrm{HO}-1$

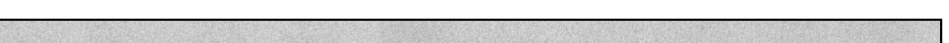

$28 S$

Small intestine

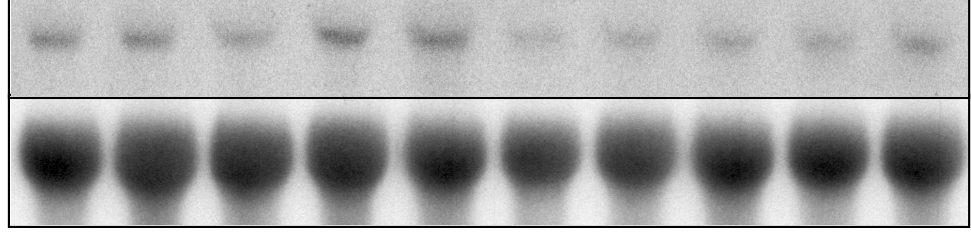

HO-1

$28 S$

Large intestine

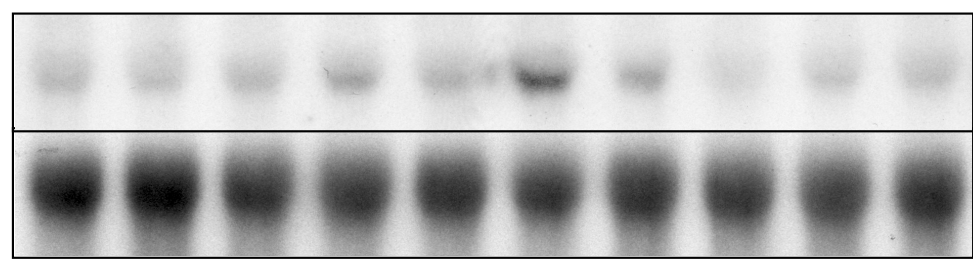

HO-1

$28 S$

Figure 12. Time course of HO-1 mRNA expression in extrahepatic rat tissues after TO administration. An acute phase response was induced by TO injection in rats, and total RNA from skeletal muscle, lung, heart, kidney, spleen, small and large intestine was extracted at the indicated time points as described in Methods. Total RNA (10 $\mu \mathrm{g})$ from these tissues was subjected to Northern blot and hybridized with $\left[{ }^{32} \mathrm{P}\right]$-labeled cDNA specific for HO-1. A 28S rRNA-specific oligonucleotide probe was used to control equal loading. Data shown are representative of two independent experiments. 


\subsubsection{Distribution of HO-1 within the liver and injured muscle during a turpentine oil (TO)-induced acute phase response (APR) in rats}

Since the HO-1 mRNA levels were found to be markedly elevated in the liver and injured muscle, it was of interest to determine the cell types responsible for $\mathrm{HO}-1$ up-regulation within these tissues during the TO-induced APR. For this purpose, histological and immunohistochemical analyses were carried out.

HO-1 distribution in the livers of untreated and turpentine oil (TO)-treated rats Hematoxylin/eosin staining did not reveal any morphological difference between the liver of untreated and liver of TO-treated rats, suggesting that the intramuscular turpentine oil injection used for the APR induction did not cause visible liver damage (Figure 13).

\section{Control}

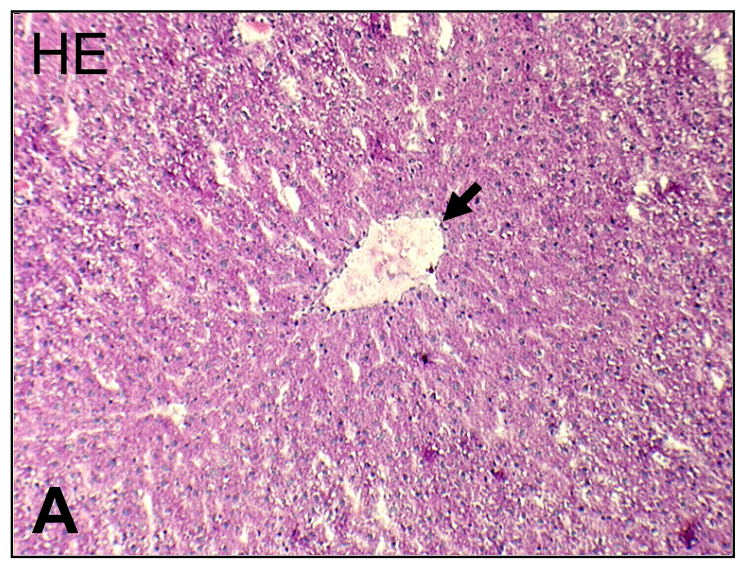

Turpentine oil

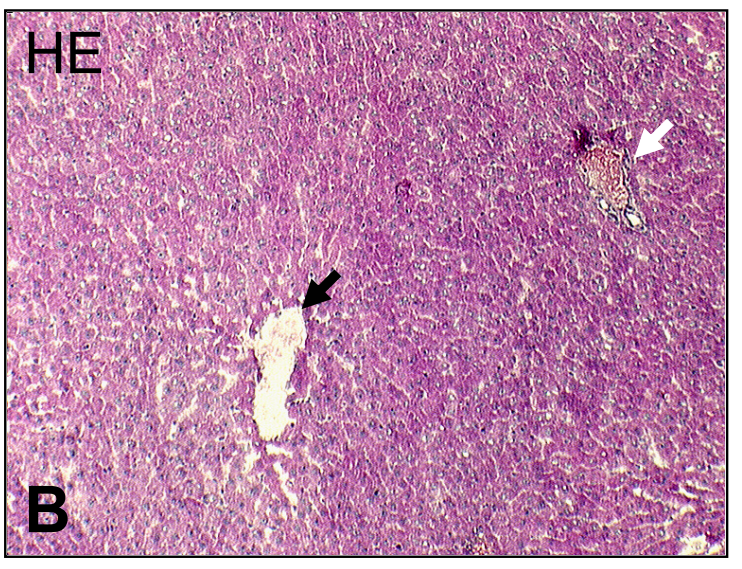

Figure 13. Histological analysis of the livers from control and TO-treated rats. Airdried cryostat sections of normal rat liver $(\mathbf{A})$ or liver excised from the rat $12 \mathrm{~h}$ after TO administration (B) were stained with hematoxylin and eosin (HE). Black arrows indicate central veins, white arrow - periportal field. Original magnification was 100-fold.

Cell type-specific expression of HO-1 in the livers obtained from control and TOtreated rats was assessed by immunohistochemical analysis of sequential cryostat sections. Under physiological conditions, the expression of $\mathrm{HO}-1$ immunoreactive protein was mainly attributed to Kupffer cells, as verified by application of the antibody against the rat ED2, a well-known specific marker of resident liver 
macrophages (Kupffer cells), whereas liver parenchymal cells were $\mathrm{HO}-1$ negative (Figure 14A, C, D).

\section{Control}
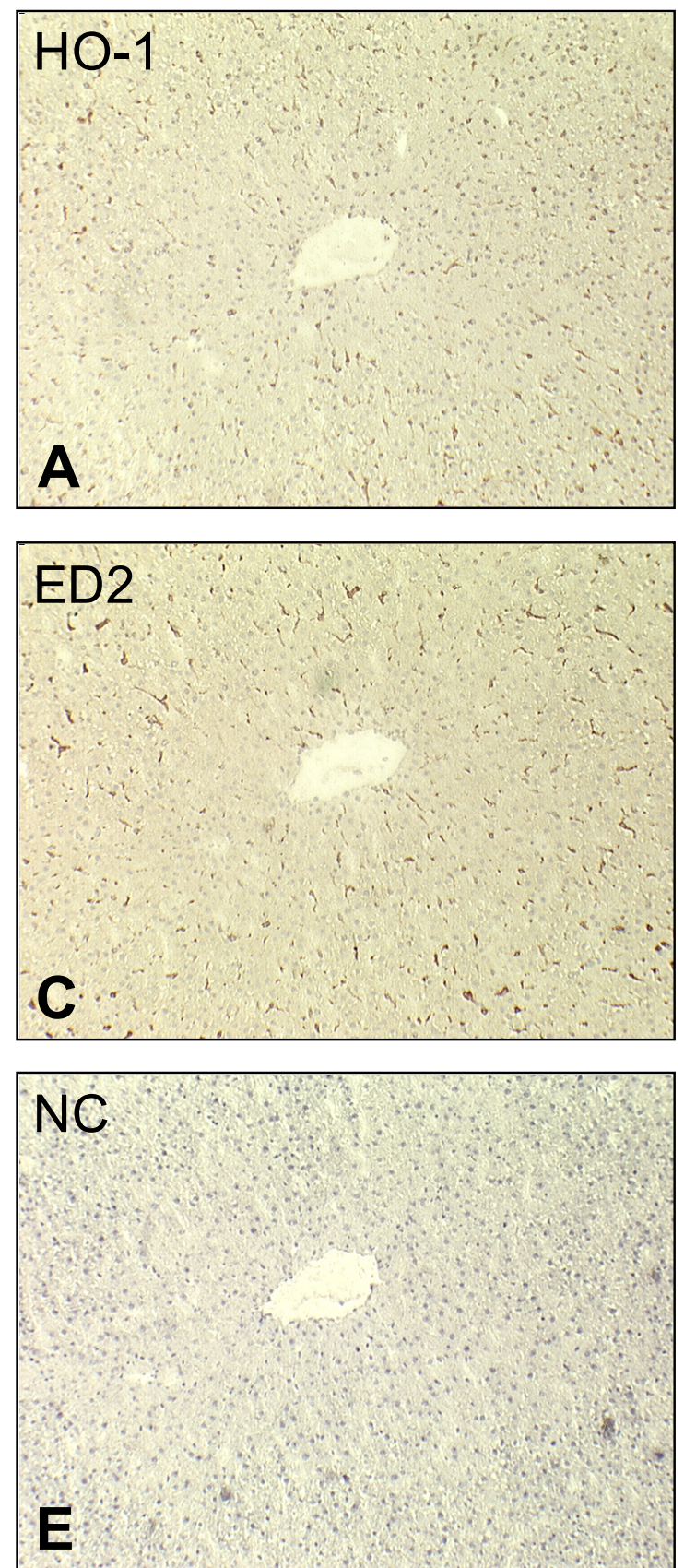

\section{Turpentine oil}
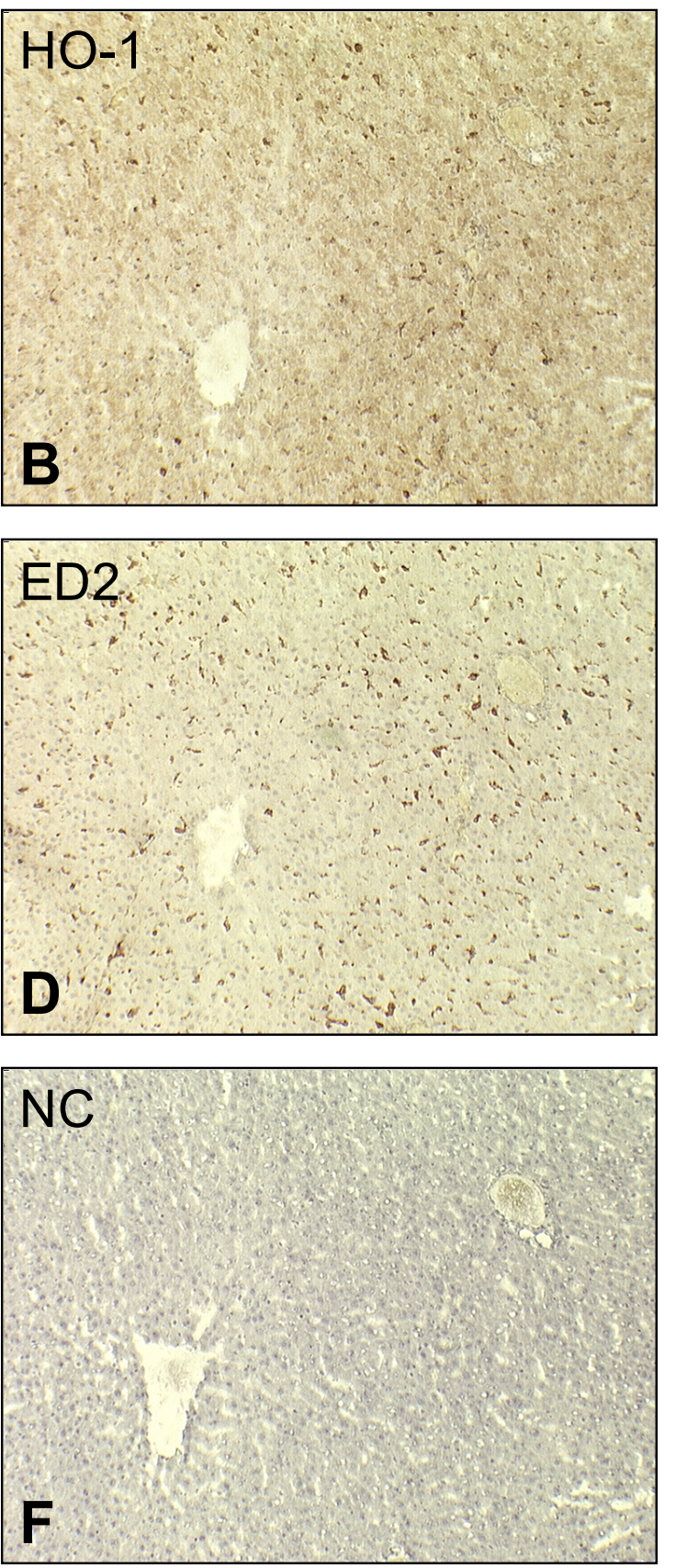

Figure 14. Immunohistochemical analysis of the livers from control and TO-treated rats. After blocking unspecific binding sites and endogenous peroxidase activity, sequential cryostat sections of control rat liver (A, C, E) or liver excised from the rat $12 \mathrm{~h}$ after TO administration (B, D, F) were stained with a monoclonal anti-rat $\mathrm{HO}-1$ antibody $(\mathbf{A}, \mathbf{B})$ or with the monoclonal antibody against rat ED2 (C, D) as described in Methods. Horseradish peroxidase-linked anti-mouse immunoglobulin was applied as a secondary antibody. The positive cells are brown colored. Nuclei are counterstained in blue. The panels $\mathbf{E}$ and $\mathbf{F}$ represent negative controls (NC) obtained by omitting the primary antibody. Original magnification was 100 -fold. 
However, during the TO-induced inflammatory response, a prominent induction of HO-1 immunoreactivity was observed in the liver parenchyma, whereas no significant increase in the intensity and number of the HO-1-positive Kupffer cells was visible (Figure 14B). The negative controls demonstrated a specificity of the immunohistological analysis performed (Figure 14E, F).

These data suggest that under control conditions, hepatic HO-1 expression is mainly attributed to Kupffer cells, whereas the dramatic increase in the HO-1 production observed on the mRNA and protein levels in the liver during the APR (Figure 11) is most likely caused by hepatocytes.

HO-1 distribution in injured muscle during a turpentine oil (TO)-induced acute phase reaction

As revealed by hematoxylin/eosin staining of the injured rat muscle ( $6 \mathrm{~h}$ after TO administration), a prominent infiltration of small irregularly shaped cells with large nuclei occurred at the site of inflammation (Figure 15B). The observed cells had the morphological features of leukocytes and were absent in the muscular tissue of control animals (Figure 15A).

\section{Control}

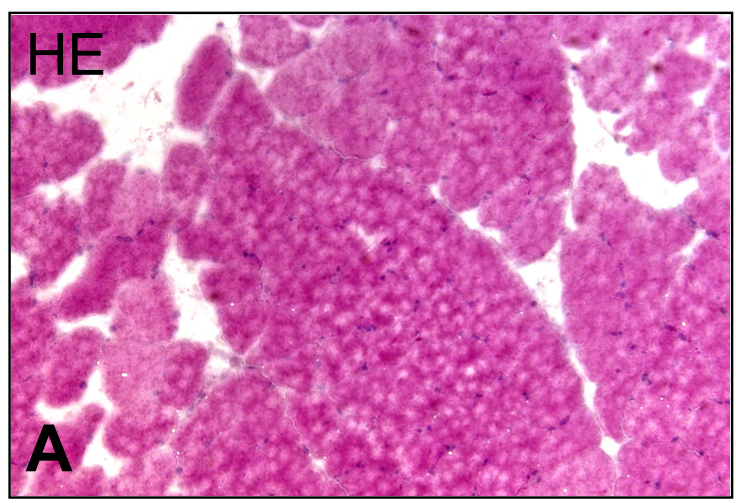

Turpentine oil

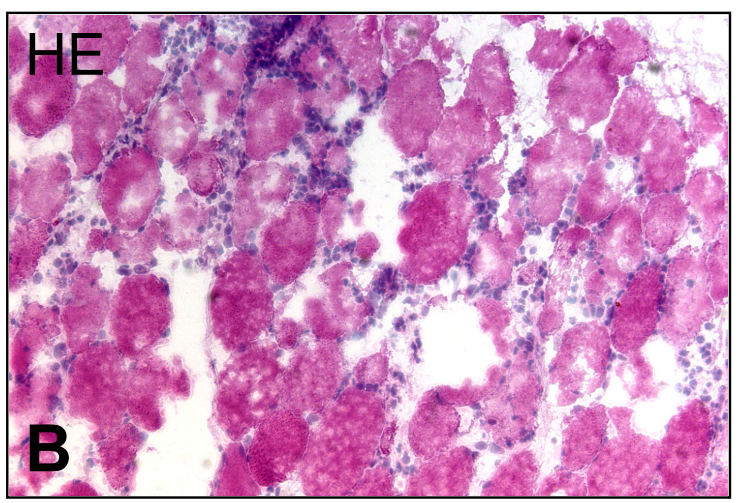

Figure 15. Histological analysis of normal and injured muscular tissue from rat hind limb. Air-dried cryostat sections of normal (A) or injured $(6 \mathrm{~h}$ after TO administration) rat skeletal muscle (B) were stained with hematoxylin and eosin (HE). Original magnification was 200 -fold.

Cell type-specific expression of $\mathrm{HO}-1$ in normal and injured muscle from rats was assessed by immunohistochemical analysis of sequential cryostat sections. In intact muscular tissue of control animals, HO-1 immunoreactive protein was only slightly detectable in some small, elongated, irregularly shaped cells, whereas 
muscle fibers were HO-1 negative (Figure 16A). However, the number of HO-1positive cells dramatically increased in the skeletal muscle under the inflammatory conditions (Figure 16B).

\section{Control}
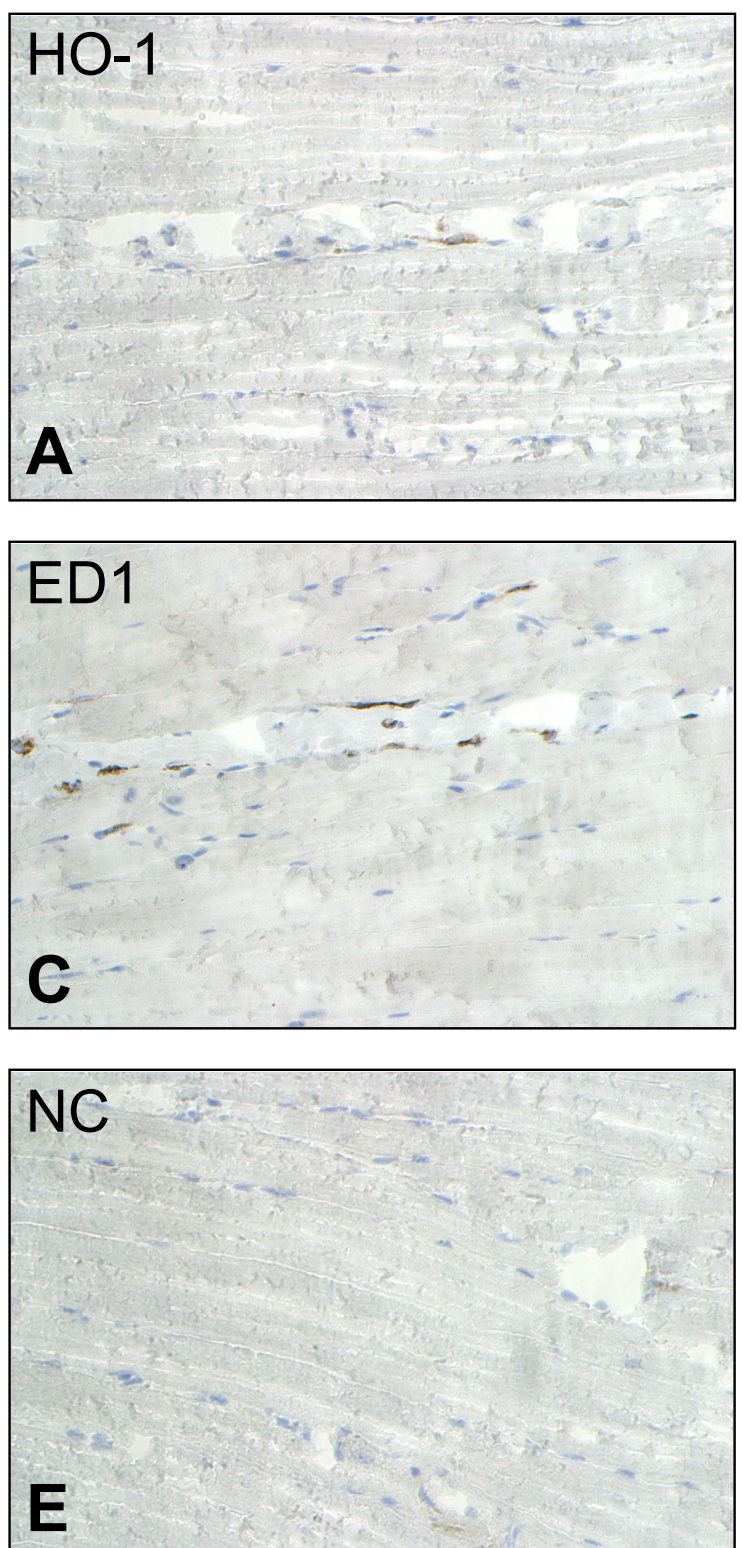

\section{Turpentine oil}
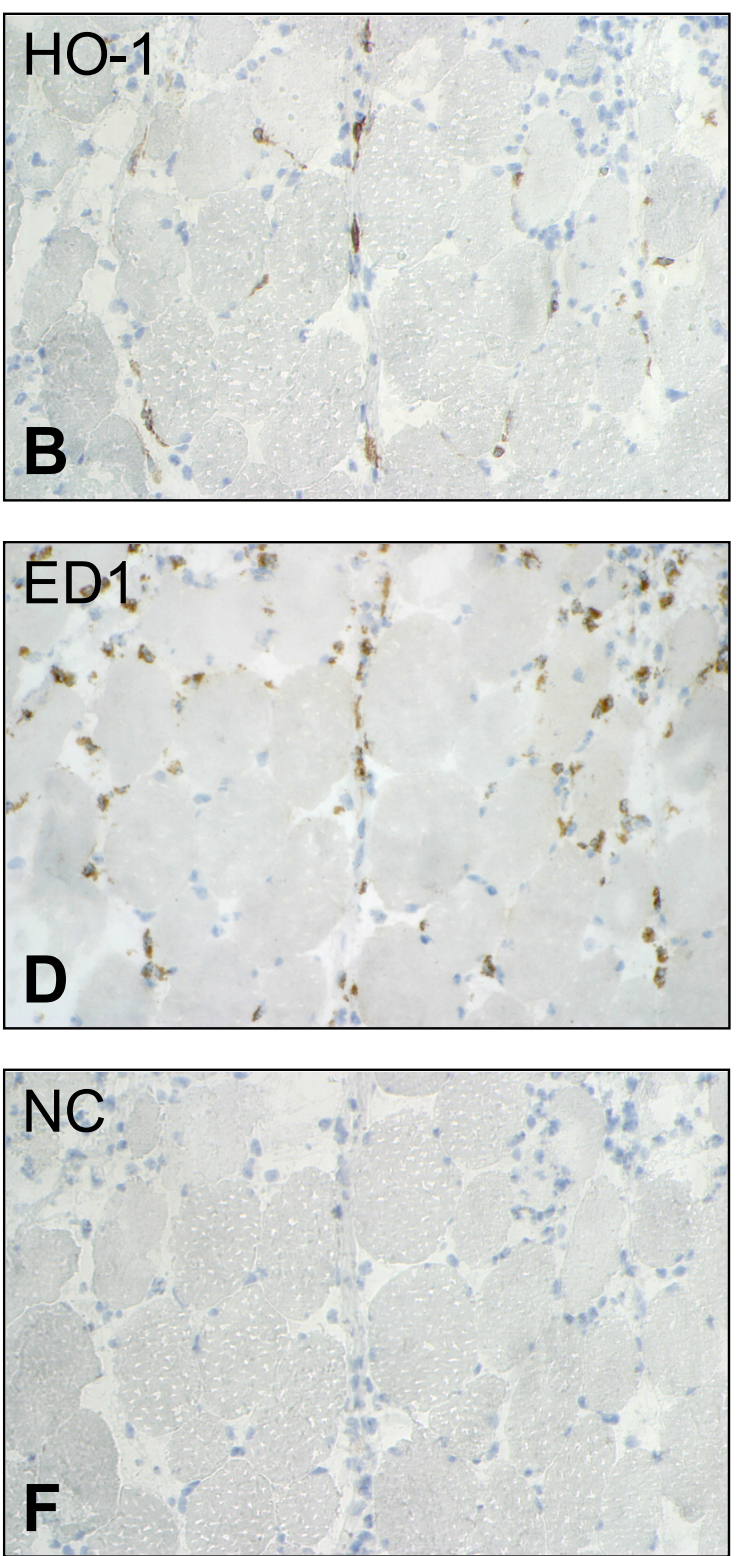

Figure 16. Immunohistochemical analysis of normal and injured muscular tissue from rat hind limb. After blocking unspecific binding sites and endogenous peroxidase activity, sequential cryostat sections of control (A, C, E) or injured (6 h after TO administration) rat muscle $(\mathbf{B}, \mathbf{D}, \mathbf{F})$ were stained with a monoclonal anti-rat HO-1 antibody (A, B) or with the monoclonal antibody against rat ED1 (C, D) as described in Methods. Horseradish peroxidase-conjugated anti-mouse immunoglobulin was applied as a secondary antibody. The positive cells are brown colored. Nuclei are counterstained in blue. The panels $\mathbf{E}$ and $\mathbf{F}$ represent negative controls obtained by omitting the primary antibody. Original magnification was 250 -fold. 
ED1, a specific marker of myeloid cells, is expressed predominantly on the lysosomal membrane by the majority of tissue macrophages and weakly by peripheral blood granulocytes. Application of the antibody against the rat ED1 using respective subsequent sections (Figure 16C, D) demonstrated colocalization of $\mathrm{HO}-1$ and ED1, suggesting that $\mathrm{HO}-1$ expression is attributed to activated monocytes (i.e. macrophages) recruited to muscle tissue during inflammation. The negative controls demonstrated a specificity of the immunostainings performed (Figure 16E, F).

\subsubsection{Assessment of IL-6 mRNA expression in various tissues and serum levels of IL-6 during a turpentine oil (TO)-induced acute phase response (APR) in rats}

Since IL-6 is known as a key cytokine released during TO-induced APR in rats (Luheshi et al., 1997), the assessment of IL-6 specific mRNA expression in various tissues and serum levels of IL-6 in rats after TO administration was carried out.

Expression of IL-6 mRNA occurred only in muscle during a turpentine oil (TO)induced acute phase reaction

In order to determine the source of IL-6 under the experimental conditions, Northern blot analysis of total RNA prepared from skeletal muscle, liver, lung, heart, kidney, spleen, small and large intestine at various time points after injection of TO was performed using radiolabeled IL-6 cDNA as a probe. Total cellular RNA isolated from rat Kupffer cells treated with LPS was processed in parallel and served as a positive control for IL-6-specific transcripts (Luckey et al., 2002). As depicted on Figure 17, 1.2 and 2.4 kb IL-6-specific transcripts were detectable only in injured skeletal muscle at 2 to $12 \mathrm{~h}$ after TO injection with maximal levels at 4-6 h. Other tissues from TO injected rats did not show any IL-6 positivity by Northern blot analysis (Figure 17), suggesting that only injured muscle is the source of IL-6 during the TO-induced acute phase response. 


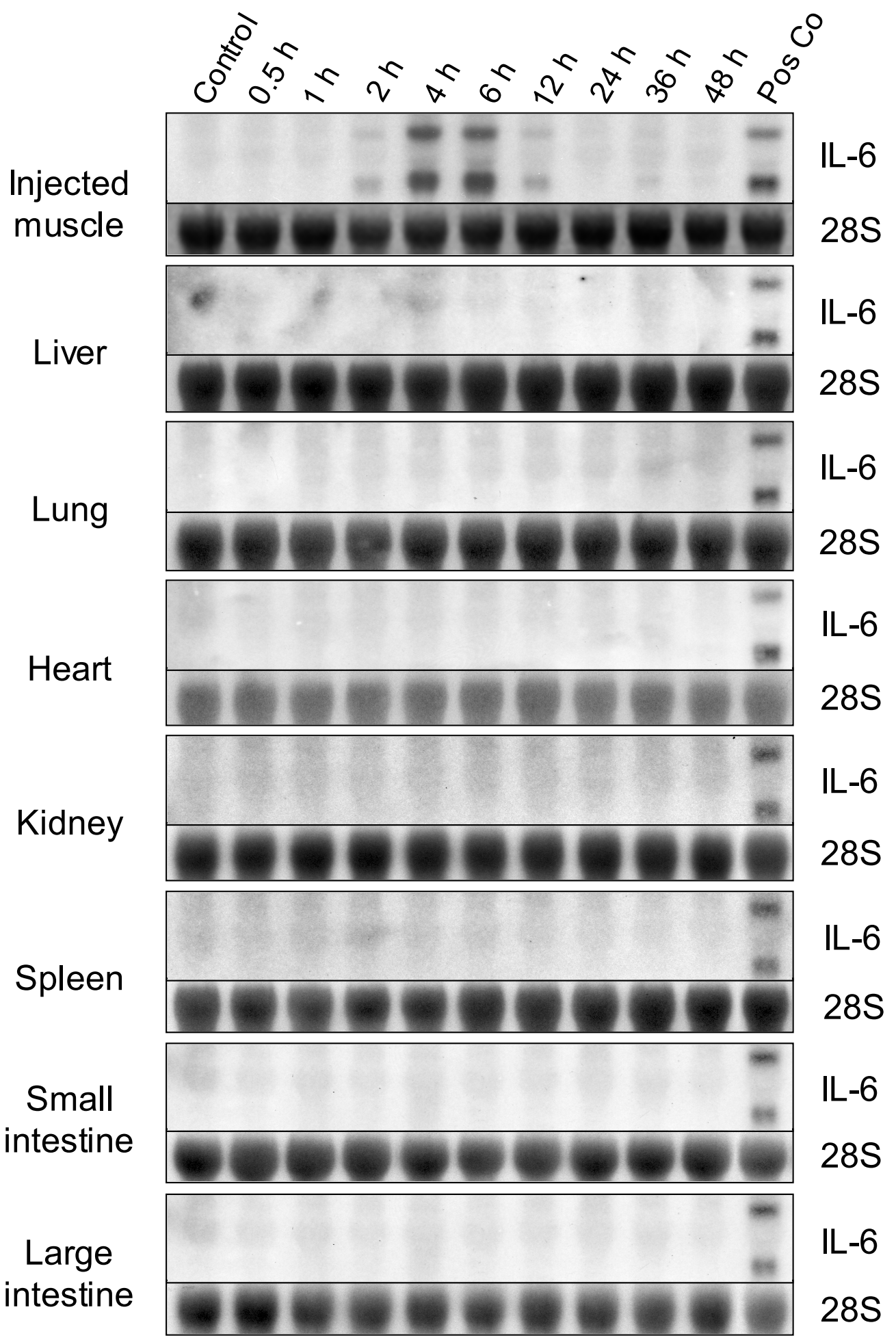

Figure 17. Time course of IL-6 mRNA expression in various rat tissues after TO administration. An acute phase response was induced by TO injection in rats, and RNA from skeletal muscle, liver, lung, heart, kidney, spleen, small and large intestine was extracted at the indicated time points as described in Methods. Total RNA (10 $\mu \mathrm{g})$ from these tissues was subjected to Northern blot analysis and hybridized with $\left[{ }^{32} \mathrm{P}\right]$-labeled cDNA specific for IL-6. 28S rRNA-specific oligonucleotide probe was used to control equal loading. Total cellular RNA $(10 \mu \mathrm{g})$ isolated from rat Kupffer cells treated with LPS $(500 \mathrm{ng} / \mathrm{ml})$ was processed in parallel and served as a positive control (Pos Co) for IL-6specific transcripts. Data shown are representative of two independent experiments. 
Serum IL-6 levels in rats during a turpentine oil (TO)-induced acute phase reaction To elucidate the possible relationship between hepatic HO-1 induction and IL-6specific mRNA expression in injured muscle, serum IL-6 levels in TO-treated rats were measured by rat IL-6-specific enzyme-linked immunosorbent assay (ELISA). Serum IL-6 concentrations were markedly elevated during the TO-induced APR reaching maximal values $6-12 \mathrm{~h}$ after injection up to $1725.785 \pm 310.985 \mathrm{pg} / \mathrm{ml}$ and $1277.913 \pm 383.983 \mathrm{pg} / \mathrm{ml}$, respectively. This corresponds to about 115 - 85 -fold increase compared to control levels (Figure 18).

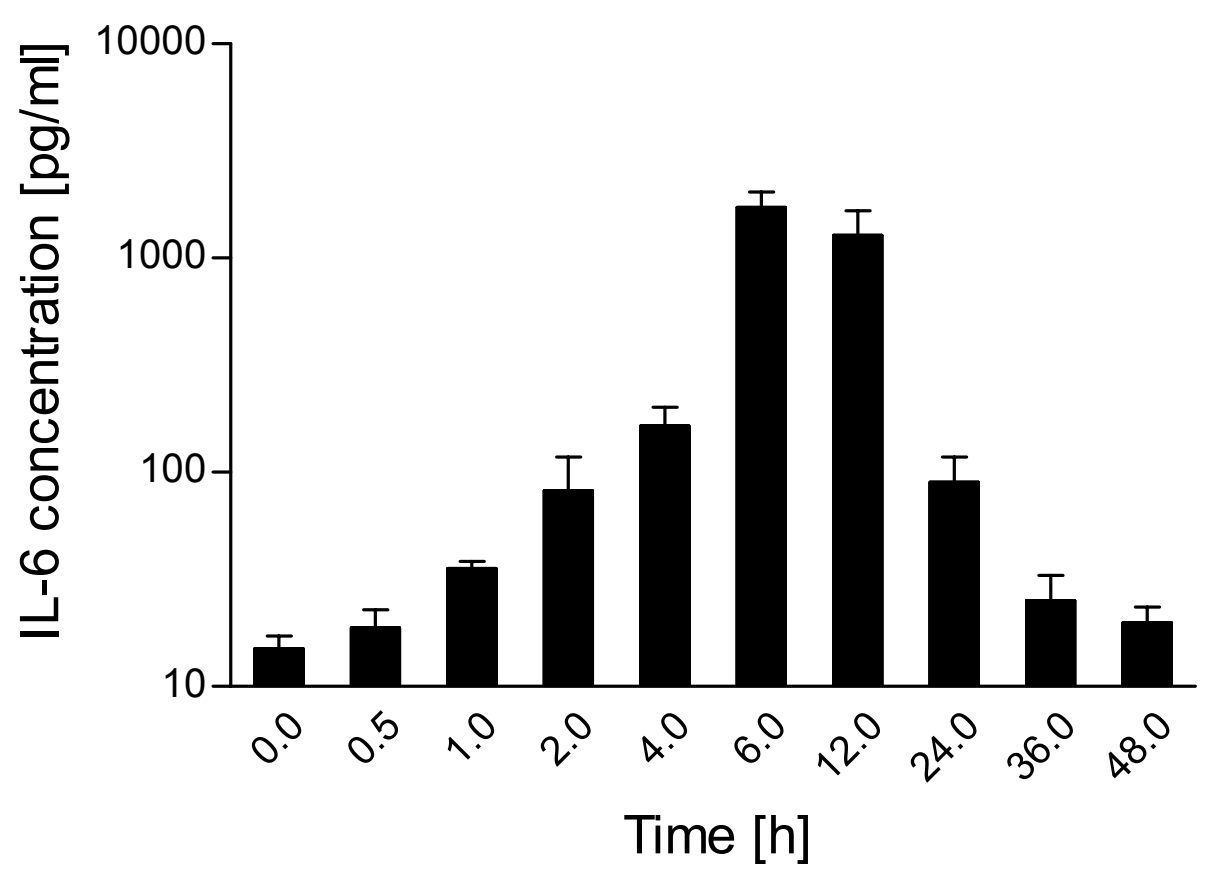

Figure 18. Serum IL-6 levels in rats after TO administration. An acute phase response was induced by TO injection in the rat and serum was collected at the indicated time points after injection as described in Methods. Serum IL-6 concentration was measured using a rat IL- 6 specific ELISA. The results are presented as means \pm SEM $(n=3)$.

After $12 \mathrm{~h}$, the IL-6 serum concentration in the rats under study considerably declined returning to control levels $48 \mathrm{~h}$ after TO injection. It should be noted that the serum IL-6 levels were already elevated $2 \mathrm{~h}$ after TO administration reaching more than a 5 -fold increase compared to the controls. The IL-6 serum levels from TO-treated rats are accompanied by IL-6 gene expression in injured muscle tissue, confirming that inflamed muscle seems to be the only source of IL- 6 in the model used. 


\subsection{Studies in vitro: HO-1 expression in primary cultures of rat hepatocytes treated with proinflammatory cytokines}

Hepatocytes were isolated from male Wistar rats by circulating perfusion with collagenase. The cultures were maintained at $37^{\circ} \mathrm{C}$ in a humid atmosphere containing $95 \%$ air/ $5 \% \mathrm{CO}_{2}$. Fetal calf serum (5\%) was present during the plating phase up to $4 \mathrm{~h}$, afterwards the cells were cultured under serum-free conditions and treated with various proinflammatory cytokines. After washing with PBS, the cells were frozen on the plates and kept at $-80^{\circ} \mathrm{C}$ until RNA or protein extraction. Northern blot hybridizations of total cellular RNA were performed with cDNAs specific for HO-1, a2-macroglobulin, albumin, GAPDH and with a 28S rRNAspecific oligonucleotide. Western blot analysis was carried out using antibodies against rat $\mathrm{HO}-1$ and $\beta$-actin. The transfection experiments with various $\mathrm{HO}-1$ promoter luciferase gene constructs were performed using the calcium phosphate precipitation method. HO-1 promoter controlled luciferase gene expression was assessed by detection of luciferase activity in cell lysate supernatants.

\subsubsection{Regulation of HO-1 mRNA expression in primary rat hepatocytes by proinflammatory cytokines}

It is known that under stress conditions, HO-1 expression can be induced to a different extent in all liver cell types (Suematsu and Ishimura, 2000). Liver parenchymal cells, the hepatocytes, represent the major cell population in the liver (about $80 \%$ of total cell number) being the main target of a multiple set of mediators involved in the APR. IL-6, IL-1 $\beta$ and TNF- $\alpha$ are the most potent inducers of acute phase protein synthesis in hepatocytes (Ramadori and Christ, 1999). Considering the above mentioned statements and the fact that induction of $\mathrm{HO}-1$ immunoreactive protein in the livers of TO-treated rats was attributed to the liver parenchymal cells (Figure 14B), the contribution of different cytokines to the HO-1 induction in vitro was evaluated using primary cultured rat hepatocytes.

Dose-dependent induction of HO-1 mRNA expression in primary rat hepatocytes by proinflammatory cytokines

Northern blot analysis of total cellular RNA isolated from primary rat hepatocytes cultured either in the absence (control) or in the presence of increasing 
concentrations $(0.1-100 \mathrm{ng} / \mathrm{ml})$ of IL-6, IL-1 $\beta$ or TNF- $\alpha$ for $24 \mathrm{~h}$, revealed an induction of $\mathrm{HO}-1-$ specific mRNA by all cytokines used in the study (Figure 19).
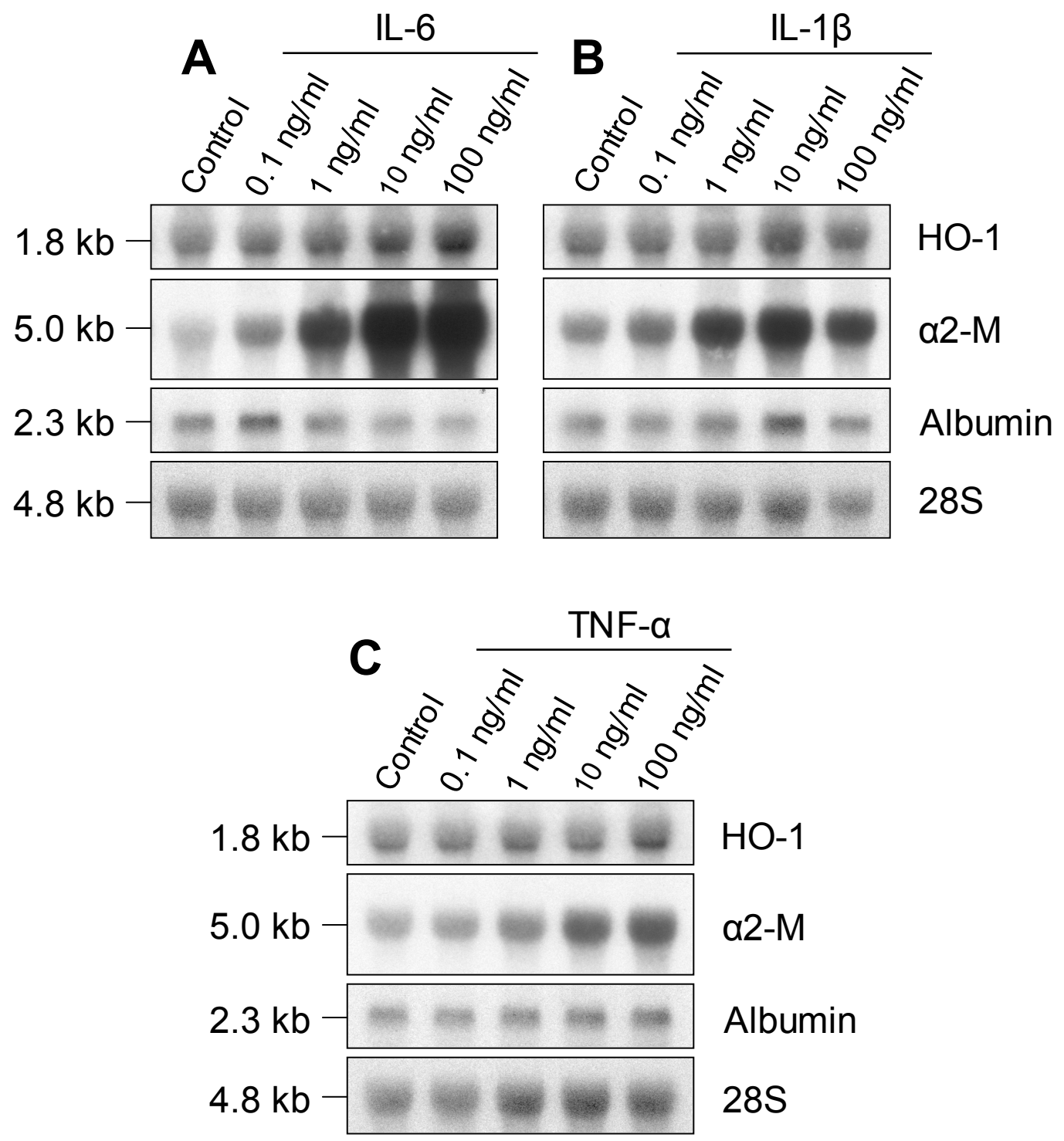

Figure 19. Dose-dependent induction of HO-1 mRNA expression by proinflammatory cytokines in primary rat hepatocytes. Rat hepatocytes were isolated, plated and cultured as described in Methods. After $18 \mathrm{~h}$ of cultivation under serum-free conditions, the medium was changed; the cells were incubated for $6 \mathrm{~h}$, and afterwards cultured in the absence (Control) or the presence of increasing concentrations of IL-6 (A), IL-1 $\beta$ (B) or TNF- $\alpha(\mathbf{C})$ for $24 \mathrm{~h}$. Total cytosolic RNA $(5 \mu \mathrm{g})$ from control and treated cells was subjected to Northern blot and sequentially hybridized with [ $\left.{ }^{32} \mathrm{P}\right]$-labeled cDNAs specific for HO-1, $\alpha 2-$ macroglobulin ( $\alpha 2-\mathrm{M})$, albumin and a $28 \mathrm{~S}$ rRNA specific oligonucleotide probe. The latter was used to control equal loading of RNA samples. The sizes of the transcripts (in $\mathrm{kb}$ ) are indicated on the left. Data shown are representative of three independent experiments

IL-6, however, led to the strongest induction in a dose-dependent manner (Figure 19A). This cytokine-induced HO-1 expression well correlated with a2- 
macroglobulin and albumin, positive and negative acute phase proteins, respectively. It should be noted that induction of a2-macroglobulin transcription was strongest in the presence of IL-6 (Figure 19A), moderate in the cells treated with IL-1 $\beta$ (Figure 19B), and the weakest induction was observed after treatment with TNF-a (Figure 19C), whereas albumin mRNA levels declined only after IL-6 treatment (Figure 19A) and were not affected by IL-1 $\beta$ or TNF- $\alpha$ (Figure 19B, C).

Time-dependent induction of HO-1 mRNA expression in primary rat hepatocytes by proinflammatory cytokines

In order to demonstrate the time-course of $\mathrm{HO}-1$ induction in vitro by various proinflammatory cytokines, Northern blot analysis of total cellular RNA isolated from primary rat hepatocytes cultured either in the absence (control $0 \mathrm{~h}, 6 \mathrm{~h}, 12 \mathrm{~h}$ ) or in the presence of IL-6, IL-1 $\beta$ or TNF- $\alpha$ for $10 \mathrm{~min}, 20 \mathrm{~min}, 30 \mathrm{~min}, 60 \mathrm{~min}, 3 \mathrm{~h}$, $6 \mathrm{~h}, 9 \mathrm{~h}$ and $12 \mathrm{~h}$ was performed using radiolabeled HO-1 cDNA as a probe.

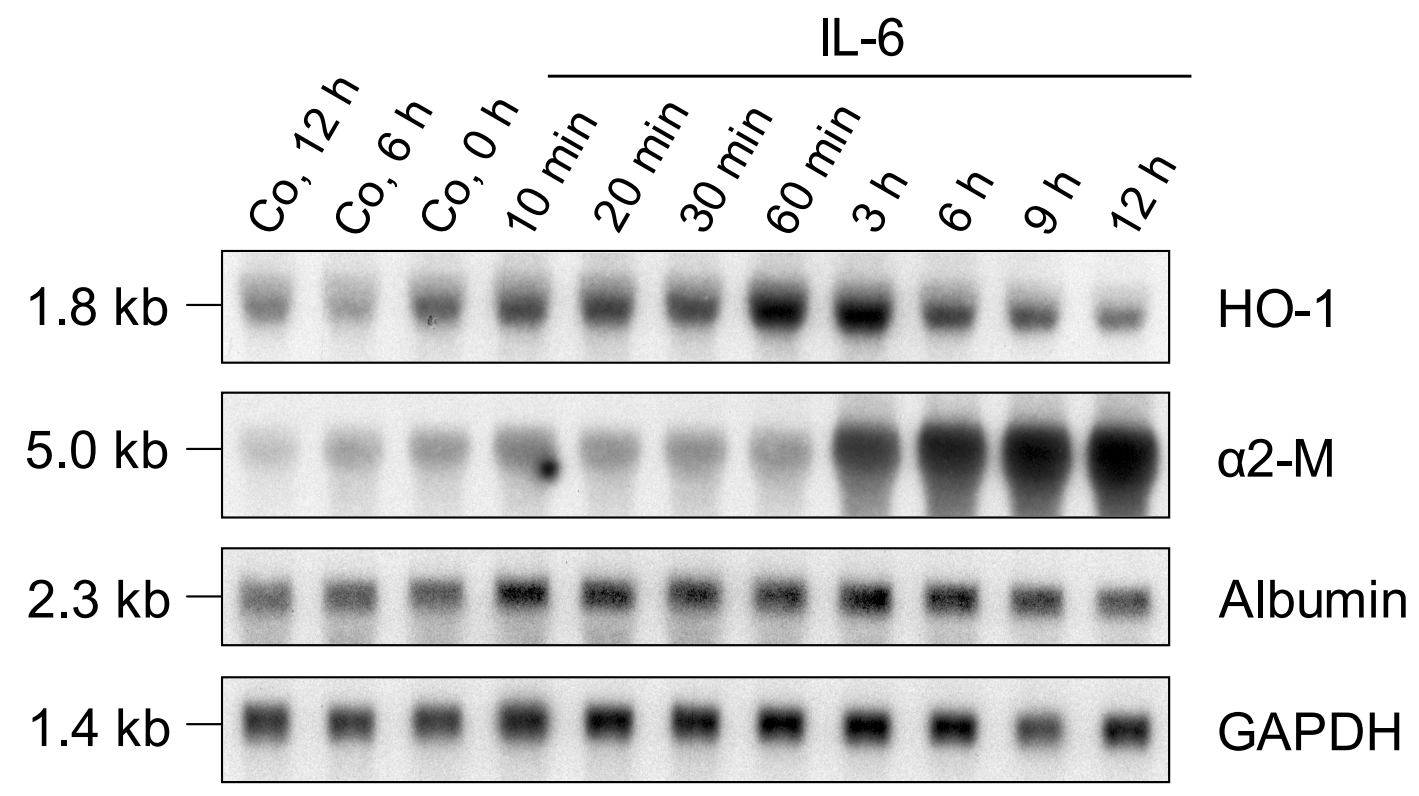

Figure 20. Time course of IL-6 induced HO-1 mRNA expression in primary rat hepatocytes. Rat hepatocytes were isolated, plated and cultured as described in Methods. After $18 \mathrm{~h}$ of cultivation under serum-free conditions, the medium was changed; the cells were incubated for $6 \mathrm{~h}$, and afterwards cultured in the absence (Co) or the presence of IL-6 $(500 \mathrm{ng} / \mathrm{ml})$ for the time indicated. Total cytosolic RNA $(5 \mu \mathrm{g})$ from control and treated cells was subjected to Northern blot and sequentially hybridized with $\left[{ }^{32} \mathrm{P}\right]$-labeled cDNAs specific for HO-1, $\alpha 2$-macroglobulin ( $\left.\alpha 2-\mathrm{M}\right)$, albumin and a $28 \mathrm{~S}$ rRNA specific oligonucleotide probe. The latter was used to control equal loading of RNA samples. The sizes of the transcripts (in $\mathrm{kb}$ ) are indicated on the left. Data shown are representative of three independent experiments. 
The strongest induction of HO-1 mRNA was observed 1-3 $\mathrm{h}$ after addition of IL-6 (Figure 20). Figure 20 further illustrates that the $\alpha 2$-macroglobulin mRNA upregulation started already $3 \mathrm{~h}$ after stimulation of the cells with IL-6. Down-regulation of albumin transcripts in the cells incubated with IL-6 occurred after $12 \mathrm{~h}$. In contrast to IL-6, HO-1 induction was significantly lower in $\mathrm{IL}-1 \beta$-stimulated rat hepatocytes (Figure 21) and negligible in TNF- $\alpha$-treated cells (Figure 22).

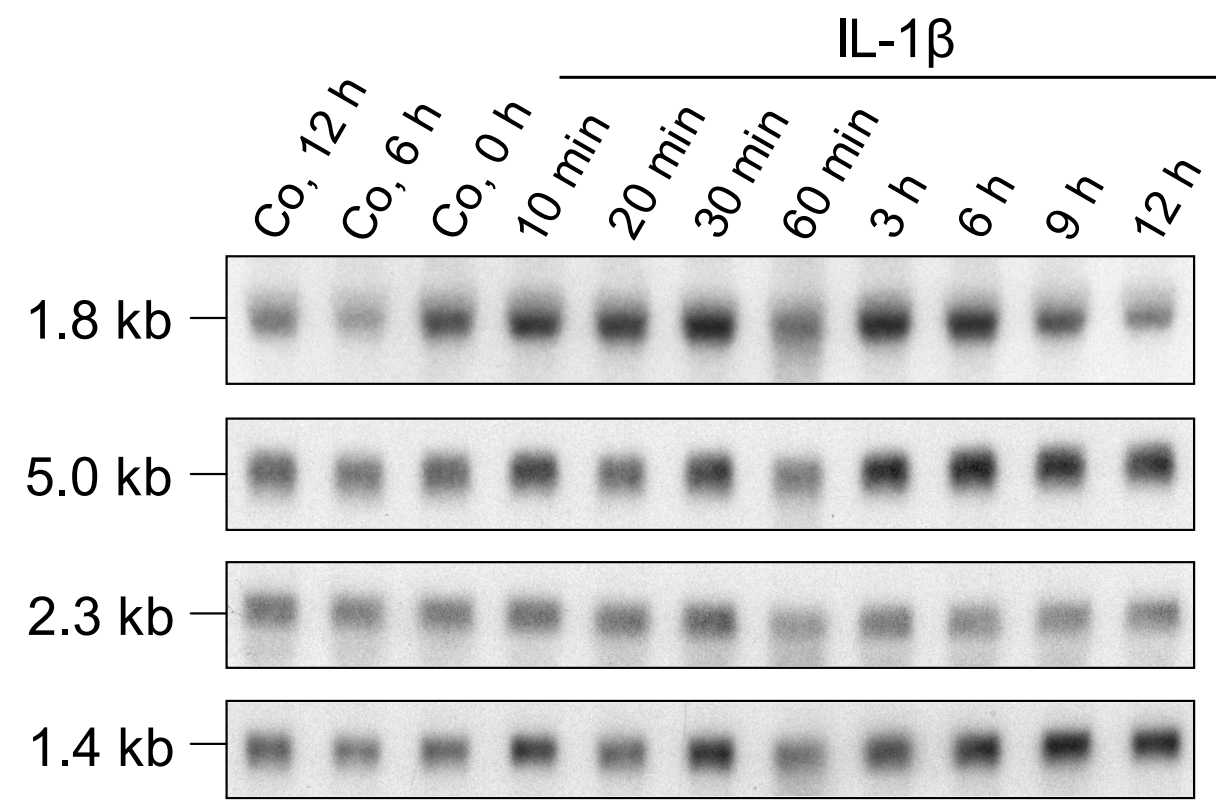

$\mathrm{HO}-1$ $\alpha 2-M$

Albumin GAPDH

Figure 21. Time course of IL-1 $\beta$ induced HO-1 mRNA expression in primary rat hepatocytes. Rat hepatocytes were isolated, plated and cultured as described in Methods. After $18 \mathrm{~h}$ of cultivation under serum-free conditions, the medium was changed; the cells were incubated for $6 \mathrm{~h}$, and afterwards cultured in the absence (Co) or the presence of IL-1 $13(500 \mathrm{ng} / \mathrm{ml})$ for the time indicated. Total cytosolic RNA $(5 \mu \mathrm{g})$ from control and treated cells was subjected to Northern blot and sequentially hybridized with $\left[{ }^{32} \mathrm{P}\right]$-labeled cDNAs specific for HO-1, $\alpha 2$-macroglobulin ( $\left.\alpha 2-\mathrm{M}\right)$, albumin and a $28 \mathrm{~S}$ rRNA specific oligonucleotide probe. The latter was used to control equal loading of RNA samples. The sizes of the transcripts (in kb) are indicated on the left. Data shown are representative of three independent experiments.

Hybridization with respective cDNAs did not show any relevant changes in the levels of $\alpha 2$-macroglobulin and albumin mRNA expression in primary rat hepatocytes after treatment with IL-1 $\beta$ or TNF- $\alpha$ (Figures 21,22 ).

Taken together, the present data from the studies of $\mathrm{HO}-1$ mRNA expression clearly demonstrate that among the proinflammatory cytokines used, IL-6 is the most potent inducer of $\mathrm{HO}-1$ mRNA expression. 


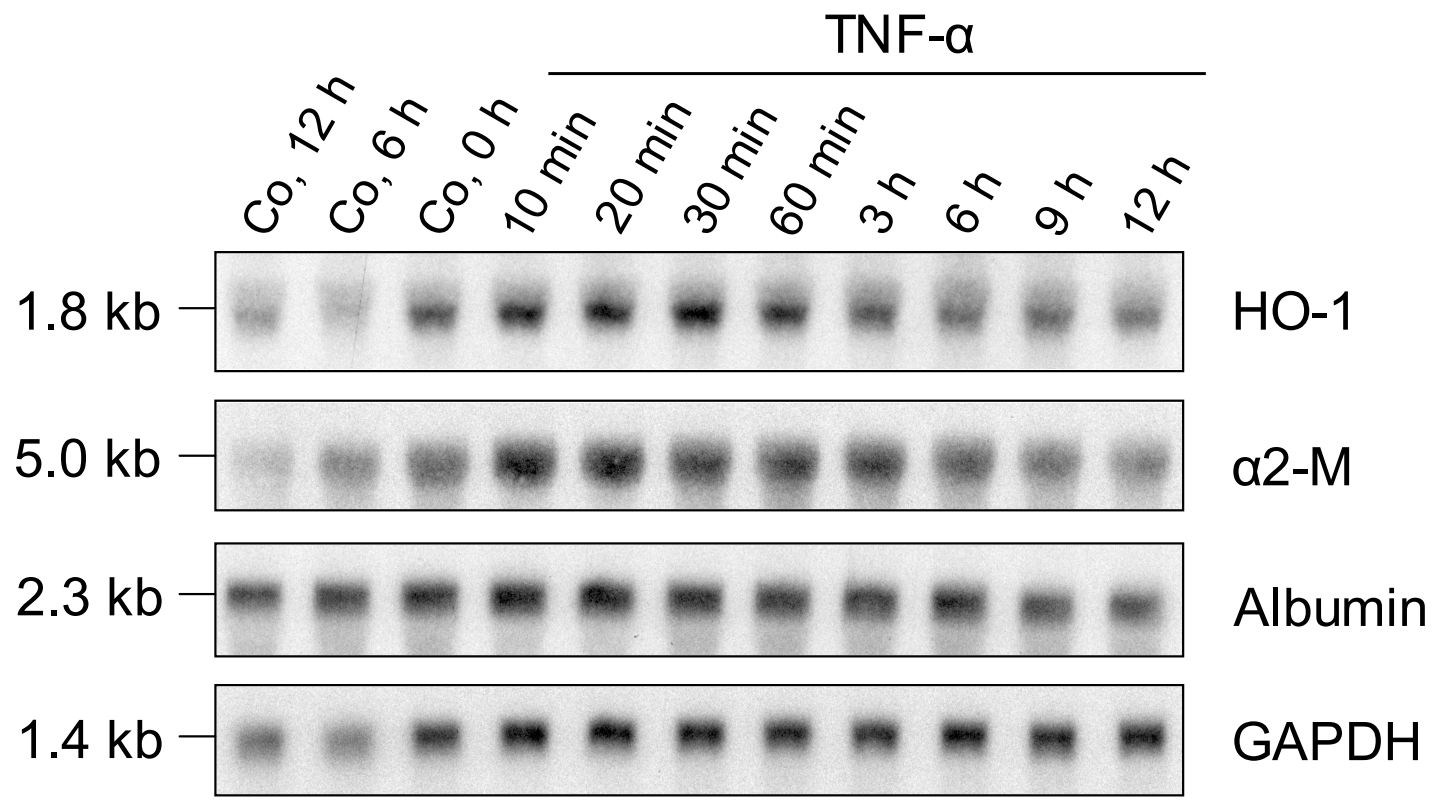

Figure 22. Time course of TNF- $\alpha$ induced HO-1 mRNA expression in primary rat hepatocytes. Rat hepatocytes were isolated, plated and cultured as described in Methods. After $18 \mathrm{~h}$ of cultivation under serum-free conditions, the medium was changed; the cells were incubated for $6 \mathrm{~h}$, and afterwards cultured in the absence (Co) or the presence of TNF- $\alpha(50 \mathrm{ng} / \mathrm{ml})$ for the time indicated. Total cytosolic RNA $(5 \mu \mathrm{g})$ from control and treated cells was subjected to Northern blot and sequentially hybridized with $\left[{ }^{32} \mathrm{P}\right]$-labeled cDNAs specific for $\mathrm{HO}-1$, $\alpha 2$-macroglobulin $(\alpha 2-\mathrm{M})$, albumin and a $28 \mathrm{~S}$ rRNA specific oligonucleotide probe. The latter was used to control equal loading of RNA samples. The sizes of the transcripts (in $\mathrm{kb}$ ) are indicated on the left. Data shown are representative of three independent experiments.

\subsubsection{Regulation of HO-1 mRNA and protein expression by IL-6 in primary rat hepatocytes}

The previous experiments in primary cultures of rat hepatocytes have shown that HO-1 mRNA levels were markedly up-regulated in a dose- and time-dependent manner after treatment with IL-6. To elucidate whether IL-6-dependent HO-1 induction at the mRNA level was accompanied by changes at the protein level of HO-1 production, a new set of experiments in cultured rat hepatocytes was performed. Control and IL-6-stimulated cells were subjected in parallel to RNA and protein extraction followed by Northern and Western blot analyses, respectively. The relative induction levels of $\mathrm{HO}-1$ mRNA and protein were assessed densitometrically and the values were plotted on the same graphs for better comparison. 

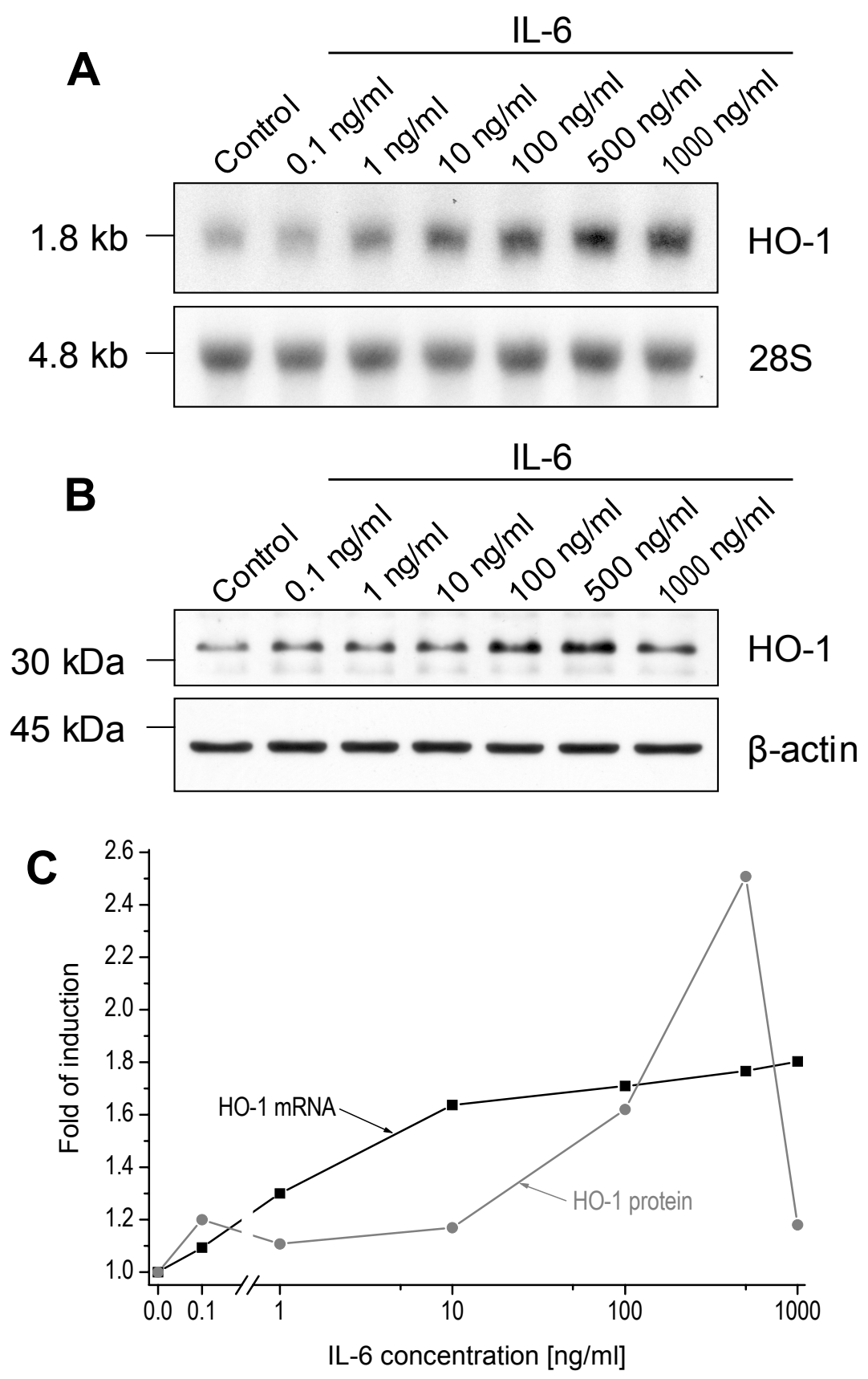

Figure 23. Dose-dependent induction of HO-1 mRNA and protein expression by IL6 in primary rat hepatocytes. Rat hepatocytes were isolated, plated and cultured as described in Methods. After $18 \mathrm{~h}$ of cultivation under serum-free conditions, the medium was changed; the cells were incubated for $6 \mathrm{~h}$, and afterwards cultured in the absence (Control) or the presence of increasing concentrations of IL-6 for $2 \mathrm{~h} \mathrm{(A)} \mathrm{and} 18 \mathrm{~h}$ (B). (A) Total cytosolic RNA (5 $\mu \mathrm{g}$ ) from control and treated cells was subjected to Northern blot and hybridized with [ $\left.{ }^{32} \mathrm{P}\right]$-labeled cDNA specific for HO-1. A $28 \mathrm{~S}$ rRNA-specific oligonucleotide probe was used to control equal loading of RNA samples. The sizes of the transcripts (in $\mathrm{kb}$ ) are indicated on the left. (B) The protein samples $(15 \mu \mathrm{g})$ from control and treated cells were immunoblotted and probed with a rabbit polyclonal antiHO-1 antibody as described in Methods. Mouse monoclonal anti- $\beta$-actin antibody was used to control equal loading of protein samples. The positions of molecular weight standards (in $\mathrm{kDa}$ ) are indicated on the left. (C) The graphs represent a densitometric quantification of HO-1 mRNA (-m-) and protein (-•-) expression normalized for $28 \mathrm{~S}$ rRNA or $\beta$-actin, respectively, and indicate fold of induction compared to control levels. 
Dose-dependent induction of HO-1 mRNA and protein expression by IL-6 in primary rat hepatocytes

To define the most effective doses of the cytokine, considering both the protein and mRNA levels of subsequent HO-1 induction, treatment of primary rat hepatocytes with a broader concentration range $(0.1-1000 \mathrm{ng} / \mathrm{ml})$ was performed (Figure 23). Since HO-1 mRNA has a short half-life of $3 \mathrm{~h}$ (Dennery, 2000) and in view of the fact that maximal HO-1 induction in primary hepatocytes occurred between 1 and $3 \mathrm{~h}$ after IL-6 stimulation (Figure 20), the cells were therefore incubated in the presence of different IL-6 concentrations for $2 \mathrm{~h}$ followed by subsequent RNA extraction and Northern blot hybridization. $\mathrm{HO}-1$ protein has a much longer (15-21 h) half-life (Dennery, 2000), and therefore rat hepatocytes were cultured either in the presence or absence of the indicated IL-6 concentrations for $18 \mathrm{~h}$ with subsequent protein extraction and Western blot analysis.

$\mathrm{HO}-1$-specific transcripts in primary rat hepatocytes were markedly elevated in a dose-dependent manner, reaching maximal levels at a concentration of $500 \mathrm{ng} / \mathrm{ml}$ IL-6. HO-1 mRNA induction was about 1.8-fold compared to the unstimulated control (Figure 23A, C). The protein levels of HO-1 in hepatocytes were also dosedependently increased after IL-6 treatment, reaching the maximum (about 2.5-fold compared to the control) at a concentration of $500 \mathrm{ng} / \mathrm{ml}$ (Figure 23B). It is notable that $\mathrm{HO}-1$ protein expression dramatically declined at the IL-6 dose of $1000 \mathrm{ng} / \mathrm{ml}$ (Figure 23C), which could be due to a toxic effect of the high non-physiological dose of the cytokine.

Thus, the IL-6 dose of $500 \mathrm{ng} / \mathrm{ml}$ was considered to be appropriate for the stimulation of rat primary hepatocytes in further experiments.

Time-dependent induction of HO-1 mRNA and protein expression by IL-6 in primary rat hepatocytes

Primary rat hepatocytes were cultured either in the presence or absence of 500 ng/ml IL- 6 for 0.5 h, 1 h, 2 h, 4 h, 6 h, 12 h, and 24 h. As revealed by Northern blot analysis, HO-1-specific mRNA was rapidly up-regulated already $1 \mathrm{~h}$ after treatment and reached an about 1.6-fold increase (the peak of up-regulation) compared to the respective control $2 \mathrm{~h}$ after treatment of primary rat hepatocytes with IL-6; thereupon the relative induction of the mRNA declined and remained at lower levels up to $24 \mathrm{~h}$ (Figure 24A, C). 

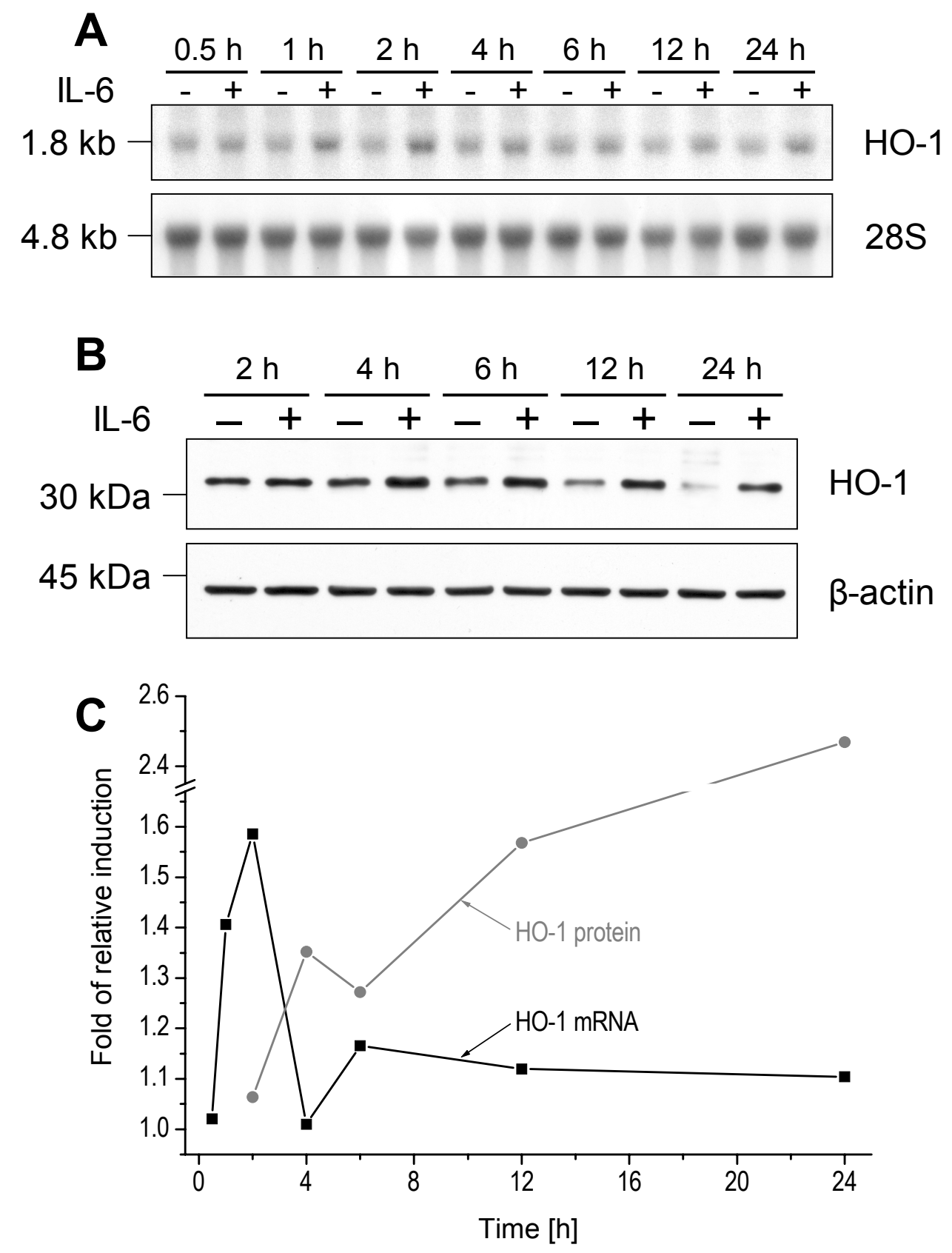

Figure 24. Time course of IL-6-induced HO-1 mRNA and protein expression in primary rat hepatocytes. Rat hepatocytes were isolated, plated and cultured as described in Methods. After $18 \mathrm{~h}$ of cultivation under serum-free conditions, the medium was changed; the cells were incubated for $6 \mathrm{~h}$, and afterwards cultured in the presence of $500 \mathrm{ng} / \mathrm{ml} \mathrm{IL}-6$ for the time indicated. The respective controls for each time point were processed in parallel. (A) Total cytosolic RNA (5 $\mu \mathrm{g})$ from control and treated cells was subjected to Northern blot and hybridized with [ $\left.{ }^{32} \mathrm{P}\right]$-labeled cDNA specific for HO-1. A 28S rRNA-specific oligonucleotide probe was used to control equal loading of RNA samples. The sizes of the transcripts (in $\mathrm{kb}$ ) are indicated on the left. (B) The protein samples $(15 \mu \mathrm{g})$ from control and treated cells were immunoblotted and probed with a rabbit polyclonal anti-HO- 1 antibody as described in Methods. Mouse monoclonal anti- $\beta$ actin antibody was used to control equal loading of protein samples. The positions of molecular weight standards (in $\mathrm{kDa}$ ) are indicated on the left. (C) The graphs represent a densitometric quantification of HO-1 mRNA (-m-) and protein (-๑-) expression and indicate fold of induction compared to the respective control levels. 
The induction of HO-1 mRNA was accompanied by an increase of $\mathrm{HO}-1$ protein (Figure 24B). The time-course of IL-6-dependent HO-1 protein induction in the cells under study appeared to be considerably different compared to that of $\mathrm{HO}-1$ mRNA. Being up-regulated $2 \mathrm{~h}$ after stimulation with IL-6, relative levels of $\mathrm{HO}-1$ protein remained elevated up to $24 \mathrm{~h}$, reaching the maximal 2.5-fold induction, while the mRNA levels of HO-1 were already decreased (Figure 24C). That is in line with the previous in vivo experiment perfomed to study time-dependency of $\mathrm{HO}-1$ induction at the mRNA and protein levels in rat liver after TO administration (Figure 11).

\subsubsection{Regulation of transfected HO-1 promoter luciferase gene constructs by IL-6 in primary rat hepatocytes}

To further investigate the regulatory role of IL-6 in the HO-1 gene expression, primary cultures of rat hepatocytes were transiently transfected with luciferase gene constructs driven by various rat $\mathrm{HO}-1$ promoter sequences and cultured in the presence or absence of IL-6.

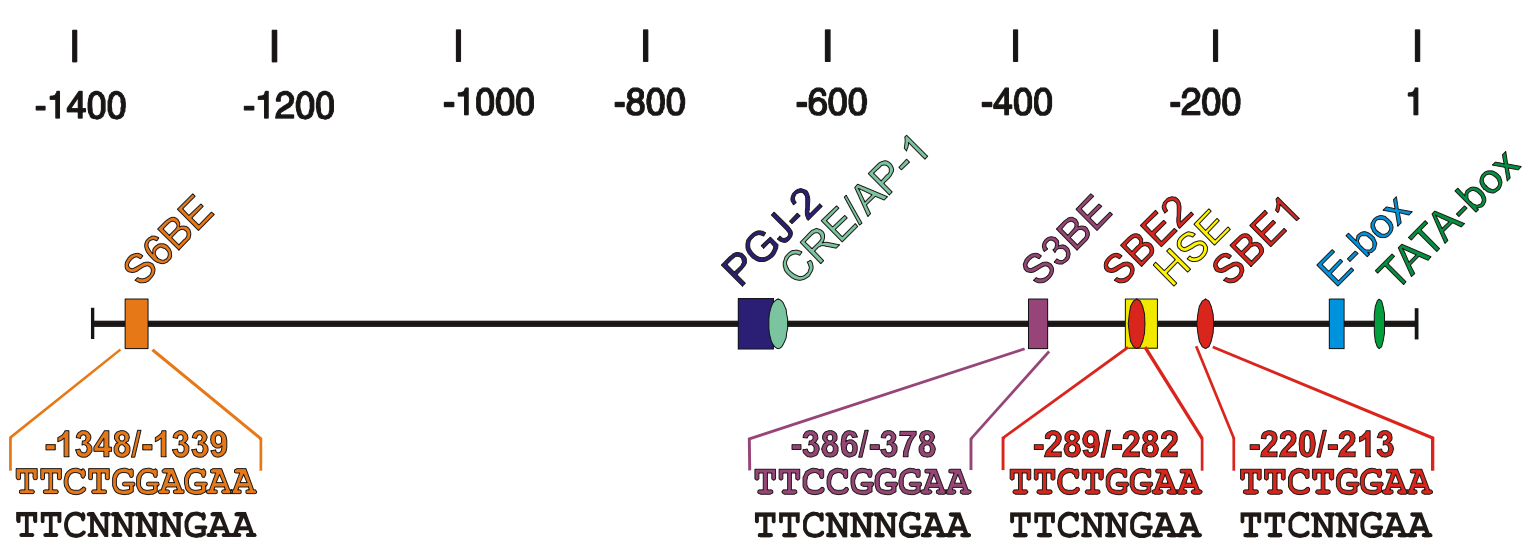

Figure 25. Localization of putative IL-6 response elements within the rat HO-1 gene promoter. The rat HO-1 gene promoter with the putative IL-6 response element is shown up to -1387 bp. TATA-box element; E-box, enhancer box element; HSE, heat shock response element; CRE/AP-1, CAMP response element / activator protein-1 binding site; PGJ-2, prostaglandin $\mathrm{J}_{2}$ response element; SBE1, signal transducers and activators of transcription (STAT) binding element 1; SBE2, STAT binding element 2; S3BE, STAT3like binding element; S6BE, STAT6-like binding element. Sequences of the putative STAT binding elements end their exact positions are indicated in colors. The consensuses matching the respective found sequences are shown underneath in black. The promoter length is indexed on top by negative numbers in bp, starting from the transcription initiation site. 


\section{Sequence analysis of the rat HO-1 promoter}

To determine the sequences that might be involved in the regulation of $\mathrm{HO}-1$ gene expression by IL-6 in rats, the rat HO-1 promoter sequence (Muller et al., 1987) was analyzed for similarities with the signal transducers and activators of transcription (STAT)-binding sites, well known IL-6 response elements (IL-6-RE) matching the general consensus $\operatorname{TTC}(\mathrm{N})_{2-4} \mathrm{GAA}$ (Seidel et al., 1995).

The sequence analysis revealed the presence of four putative binding sites for STAT transcription factors within the $1387 \mathrm{bp}$ of the rat HO-1 promoter (Figure 25). The first and the second identical sequences [STAT binding element (SBE) 1, -220/-213 and SBE2, -289/-282; 5'-TTCTGGAA-3'] completely match the IL-6-RE of the murine SAA3 gene (Hattori et al., 1990) which was later shown to be bound by STAT complexes (Seidel et al., 1995).

The third motif [STAT3-like binding element (S3BE), -386/-378, 5'-TTCCGGGAA3'] completely matches the known generalized STAT consensus sequence (Darnell, Jr., 1997; Lee et al., 2000).

The fourth found sequence [STAT6-like binding element (S6BE), -1348/-1339, 5'TTCTGGAGAA-3'] matches a general sequence [TTC $(\mathrm{N})_{4} \mathrm{GAA}$ ] bound by STAT6 (Darnell, Jr., 1997), which is involved in IL-4 signalling (Mikita et al., 1996).

Among these four putative STAT binding sites, S3BE is of potential interest. It has been shown that activated STAT3 complexes preferentially bind to TTCNNNGAA motifs that are present in the promoter regions of APP genes (Horvath et al., 1995; Heinrich et al., 1998; Lemmink et al., 2001). Moreover, since STAT3 was reported to be activated by IL- 6 in a murine model of TO-induced localized inflammation (Alonzi et al., 1998), an involvement of STAT3 in the regulation of HO-1 gene expression was further studied using an $\mathrm{HO}-1$ promoter reporter gene assay.

Furthermore, in addition to JAK/STAT pathway, MAPK activation is also involved in IL-6 signalling (Heinrich et al., 2003). Since an AP-1 binding site was shown to be functionally active in the MAPK-dependent induction of rat HO-1 by arsenite (Kietzmann et al., 2003), the role of the AP-1 binding site in IL-6-dependent HO-1 gene regulation was also investigated.

Induction of the rat HO-1 promoter controlled luciferase expression in primary rat hepatocytes by IL-6 treatment

To assess the transfection efficiency of primary rat hepatocytes, a reporter vector pcDNA3.1-GFP containing the GFP gene was used. The freshly isolated 
hepatocytes were transiently transfected with the plasmid pcDNA3.1-GFP using the calcium phosphate precipitation method.
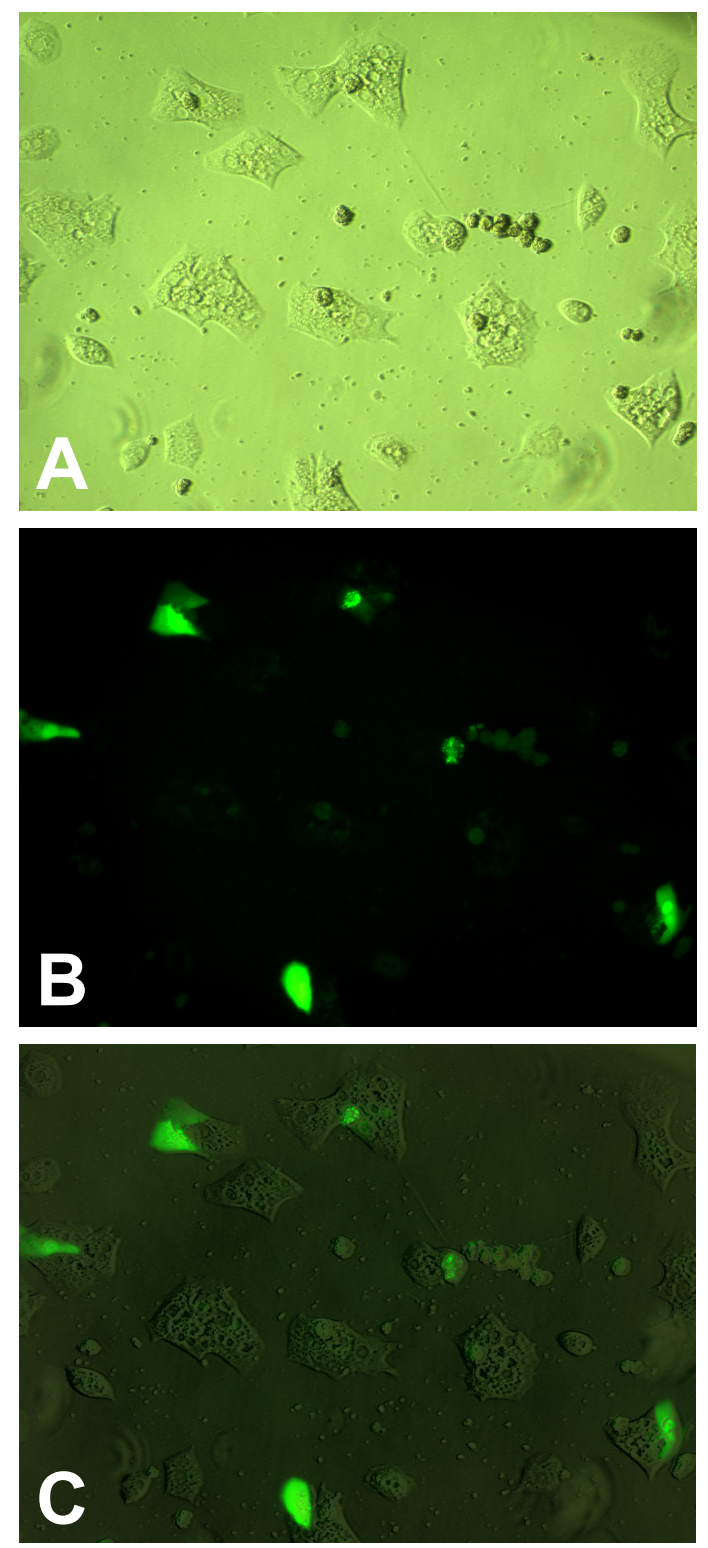

Figure 26. Verification of transfection efficiency in primary rat hepatocytes by fluorescent microscopy using a GFP-reporter. Freshly isolated rat hepatocytes were transiently transfected with the pcDNA3.1-GFP reporter vector containing the green fluorescent protein (GFP) gene using the calcium phosphate precipitation method. The cells were washed $5 \mathrm{~h}$ after transfection and incubated in serum-free medium for $24 \mathrm{~h}$ to allow GFP synthesis. Panel (A) represents the phase-contrast microscopy of the hepatocytes in culture; panel (B) demonstrates blue-light (470 nm filter)-stimulated GFP fluorescence in successfully transfected hepatocytes from the same view. Panel (C) represents image (B) merged with image $(\mathbf{A})$ to evaluate the transfection efficiency. 

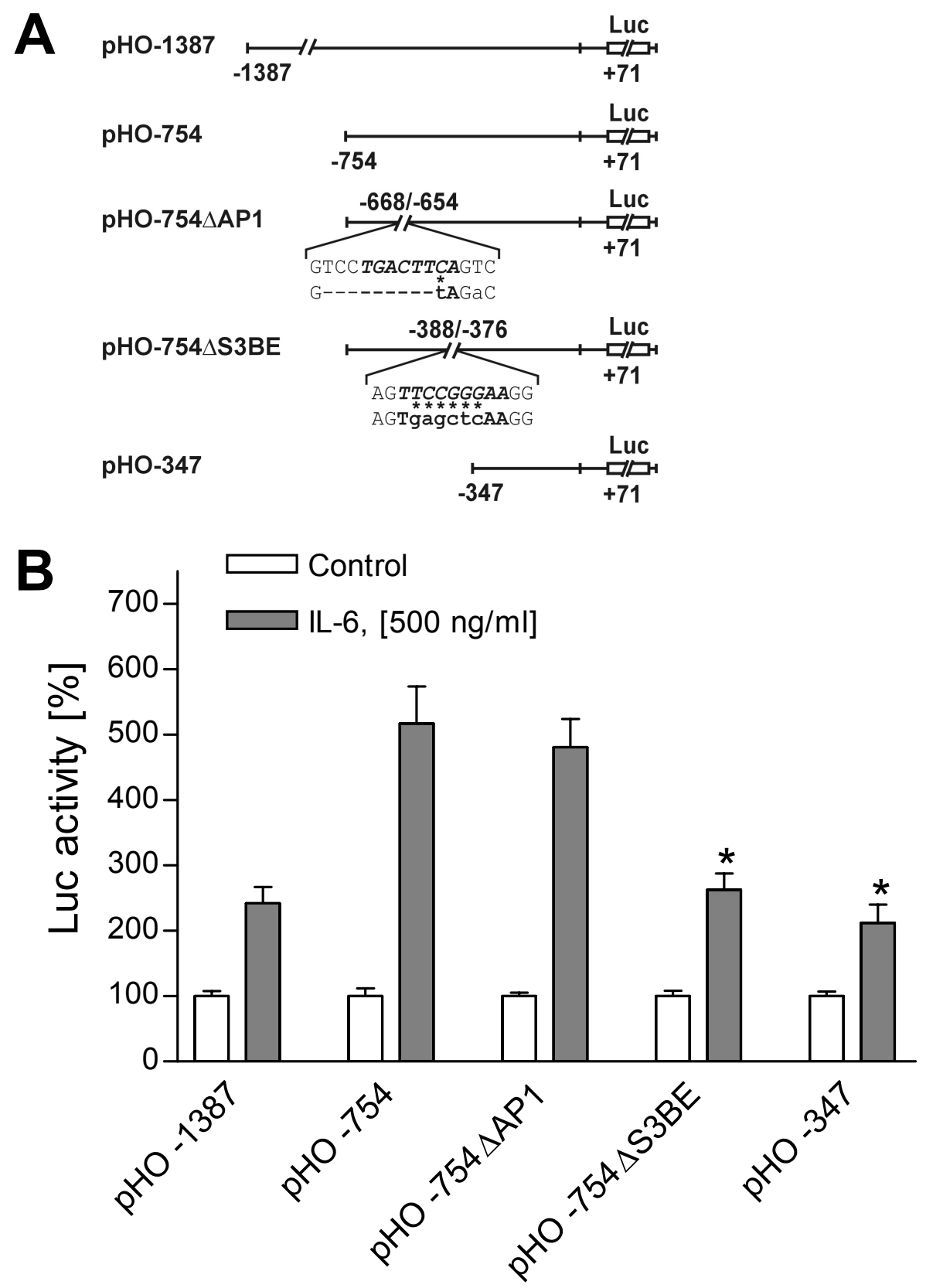

Figure 27. Induction of the rat HO-1 promoter controlled luciferase gene expression in primary rat hepatocytes treated with IL-6. (A) Freshly isolated rat hepatocytes were transiently transfected with luciferase (Luc) gene constructs driven by wild-type 1387,754 , and 347 bp of the rat HO-1 promoter (pHO-1387, pHO-754, and pHO-347) or the 754-bp promoter mutated at the CRE/AP-1 site (pHO-754 $\triangle$ AP1) or at the STAT3 site (pHO-754 $\triangle$ S3BE). In pHO-754 $\triangle \mathrm{AP} 1$ and pHO-754 $\triangle \mathrm{S} 3 \mathrm{BE}$, the wild-type HO-1 promoter sequence is shown on the upper strand, and the mutated sequence is shown on the lower strand: deleted bases are indicated by "-", mutated bases are shown in lowercase letters and indicated by asterisks. (B) The cells were washed $5 \mathrm{~h}$ after transfection and further cultured under serum-free conditions. After $18 \mathrm{~h}$ of cultivation under serum-free conditions, the medium was changed; the cells were incubated for $6 \mathrm{~h}$, and afterwards cultured in the absence (Control) or the presence of IL-6 $(500 \mathrm{ng} / \mathrm{ml})$ for $24 \mathrm{~h}$. In each experiment, the percentage of Luc activity was determined relative to the pHO-1387, pHO-754, pHO-347, pHO-754 $\triangle \mathrm{AP} 1$, or pHO-754 $\triangle \mathrm{S} 3 \mathrm{BE}$ controls, which were set equal to $100 \%$. The values represent means \pm SEM of three independent experiments. Statistics, Student's t-test for paired values: *, significant difference pHO$754 \Delta$ S3BE vs. pHO-754 and pHO-347 vs. pHO-754, $\mathrm{p}<0.05$. 
After $24 \mathrm{~h}$, the cells were monitored using phase-contrast and sequential fluorescent microscopy (Figure 26A, B). The transfection efficiency was evaluated from three independent experiments (10 randomly chosen views of each) using overlapped pictures obtained by phase-contrast and fluorescent microscopy from the same field of view (Figure 26C) and comprised about 30\%.

To examine the molecular mechanism of HO-1 gene regulation by IL-6, primary rat hepatocytes were transfected with constructs containing 1387, 754 and 347 bp of the wild-type rat HO-1 promoter in front of the luciferase (Luc) gene (pHO-1387, $\mathrm{pHO}-754$ and $\mathrm{pHO}-347$, respectively). The Luc expression from $\mathrm{pHO}-1387$ was up-regulated following IL-6 treatment to $242 \%$ (Figure 27). Surprisingly, when the cells were transfected with $\mathrm{pHO}-754$, the IL-6-dependent induction of Luc expression comprised $517 \%$, which was more than 2 times higher compared to $\mathrm{pHO}-1387$. This might imply the presence of negative regulatory elements in the upstream region between -754 and -1387 . Further, the Luc activity in pHO-347 transfected hepatocytes was induced only to $212 \%$ after IL-6 treatment, suggesting that the promoter region between -347 and -754 nucleotides is responsible for the IL-6-directed up-regulation of the rat $\mathrm{HO}-1$ gene.

To investigate the functional role of the potential STAT binding site S3BE in the regulation of $\mathrm{HO}-1$ gene expression by IL-6, primary rat hepatocytes were transfected with the construct pHO-754 $\triangle \mathrm{S} 3 \mathrm{BE}$, in which 6 out of $9 \mathrm{bp}$ of the motif were mutated. In rat primary hepatocytes transfected with $\mathrm{pHO}-754 \triangle \mathrm{S} 3 \mathrm{BE}$, the Luc activity increased only to about $262 \%$, which was close to pHO-347 and significantly lower compared to pHO-754 (Figure 27).

In order to examine the functional activity of the AP-1 binding site in IL-6 signalling, primary rat hepatocytes were transfected with the construct $\mathrm{pHO}-754 \triangle \mathrm{AP} 1$, in which the whole AP-1 binding sequence was deleted (Immenschuh et al., 1998). IL-6 treatment up-regulated Luc activity in pHO-754 $\triangle \mathrm{AP} 1$-transfected cells to $481 \%$ that was not significantly different from IL-6-dependent pHO-754 Luc induction (Figure 27).

Taken together, these results indicate that activation of the STAT pathway by IL-6 may induce the rat $\mathrm{HO}-1$ gene expression mainly through the S3BE sequence in the promoter of this gene, whereas the AP-1 binding site most likely is not involved in IL-6-dependent HO-1 induction. 


\section{Discussion}

The present study showed that during the acute phase reaction induced by turpentine oil injection in rats, $\mathrm{HO}-1$ expression is dramatically up-regulated in the liver, the major target organ of the inflammatory response, and in the injected muscle, the site of localized inflammation. In the other internal organs investigated, only moderate changes of $\mathrm{HO}-1$ expression under inflammatory conditions were observed. As revealed by immunohistochemical analysis, the induction of $\mathrm{HO}-1$ in the liver was attributed mainly to hepatocytes, whereas macrophages represented the major source of $\mathrm{HO}-1$ in the injured muscle. Interleukin- 6 mRNA expression was found exclusively in the inflamed muscle, but its plasma level profile correlated with HO-1 mRNA and protein induction in the liver, suggesting that this cytokine plays a role in $\mathrm{HO}-1$-induction. Experiments in vitro further supported this idea. Among the proinflammatory cytokines (IL-6, IL-1 $\beta$, and TNF- $\alpha$ ) used for the treatment of primary cultured rat hepatocytes, IL-6 was the most potent inducer of $\mathrm{HO}-1$ expression. Moreover, functional analysis of the rat $\mathrm{HO}-1$ promoter revealed the presence of an active IL-6-response element (STAT binding sequence) which is involved in IL-6-dependent $\mathrm{HO}-1$ gene regulation during the acute phase response.

\subsection{Regulation of HO-1 expression in turpentine oil (TO) model of the acute phase response (APR) in rats}

In the current study, TO injection in rats was used as a means to induce an APR and to investigate HO-1 regulation. The results indicate that HO-1 mRNA expression was dramatically increased in the liver by 4-6 $\mathrm{h}$ after TO administration with a peak at $6 \mathrm{~h}$ (Figure 11A). Previously, hepatic HO-1 mRNA expression in a TO model was studied by Lyoumi and colleagues (Lyoumi et al., 1998a; Lyoumi et al., 1999) along with an LPS-induced model of the APR. Using RT-PCR, they also have shown that in the liver, $\mathrm{HO}-1$ specific transcripts were maximally elevated $6 \mathrm{~h}$ after TO administration, however, no information was provided about the protein. In the present study, not only HO-1 mRNA expression but also $\mathrm{HO}-1$ protein levels were investigated. $\mathrm{HO}-1$ protein was markedly up-regulated after $6 \mathrm{~h}$ and reached a maximum $24 \mathrm{~h}$ after TO injection (Figure 11B). 
To find out whether the induction of $\mathrm{HO}-1$ during inflammation is a liver-specific cytokine-mediated direct consequence of the APR, in the current study, in addition to the liver, extrahepatic sites of HO-1 induction were investigated for the first time. Besides the liver, which is the main target organ for the APR, the most prominent HO-1 mRNA induction occurred in skeletal muscle, where the APR was initiated by TO injection (Figure 12). In the other internal organs investigated, only moderate changes in $\mathrm{HO}-1$ expression were observed (Figure 12).

It should be noted that in spite of the similarities in general signs and symptoms, different in vivo models of the APR are characterized by certain patterns of mediators and plasma proteins released in the course of inflammation (Fattori et al., 1994; Ramadori and Christ, 1999). For instance, an LPS model is characterized by rapid circulatory increase of the three major proinflammatory cytokines like IL-6, IL-1 $\beta$, and TNF- $\alpha$, causing systemic inflammation (Ulich et al., 1990; Ulich et al., 1991; Luster et al., 1994). The variety of mediators in this model makes difficult to define the role of individual cytokines in the induction of certain proteins, particularly, $\mathrm{HO}-1$ in the liver. The significant advantage of TO injection over the other models of the APR implicates the circulatory increase of only one major cytokine, IL-6, whereas no increase in plasma IL-1 $\beta$ or TNF- $\alpha$ bioactivity is detected (Luheshi et al., 1997). Therefore, to investigate the IL-6 expression in the TO-induced APR was another aim of the present study.

\subsection{Expression of IL- 6 after turpentine oil (TO) administration and its possible role in $\mathrm{HO}-1$ induction in the liver}

In agreement with previous observations of other groups (Luheshi et al., 1997; Tsujinaka et al., 1997; Lyoumi et al., 1998b), we demonstrated that serum IL-6 concentrations were extremely elevated after TO-injection (Figure 18). In order to find the source of IL-6 released during TO-induced APR, we studied IL-6 mRNA expression in various rat tissues. Our data have clearly demonstrated that during TO-induced APR, injured skeletal muscle was the only organ where induction of IL-6 expression was observed (Figure 17). Moreover, temporal expression of IL-6 in the muscle well correlated with circulatory IL-6 levels (Figure 18). Taking into consideration all these findings, we hypothesized that $\mathrm{HO}-1$ induction observed in the livers of TO-treated rats (Figure 11) might be mediated by IL-6 as it has been 
shown for other positive acute phase reactants, e. g., a2-macroglobulin in rats (Geiger et al., 1988).

Interleukin (IL)-6 has been shown to be a potent inducer of acute phase protein synthesis in vitro as well as in vivo (Geiger et al., 1988; Castell et al., 1989; Castell et al., 1990; Heinrich et al., 1990). The pivotal role of IL-6 as a major mediator of the acute phase response (APR) in the liver was unequivocally determined after generation of IL-6-difficient mice (Poli et al., 1994). It has been shown that in the absence of IL-6, mice are unable to develop a normal inflammatory response to localized tissue damage generated by turpentine oil injection (Fattori et al., 1994; Siewert et al., 2000). Moreover, it was also reported that IL-6, but not other members of its superfamily, is primarily in charge of the hepatic APR associated with TO-induced myositis (Kaibara et al., 1998).

Remarkably, IL-6 specific transcripts appeared in the skeletal muscle $2 \mathrm{~h}$ after TO injection (Figure 17), whereas induction of HO-1 mRNA expression in the liver was observed 4-6 $\mathrm{h}$ after TO administration (Figure 71A). It should be also noted that serum IL-6 levels were already elevated by $2 \mathrm{~h}$ after administration of TO (Figure 18). Taken together, these data suggest that induction of $\mathrm{HO}-1$ expression in the liver during APR is a consequence of the increased plasma levels of IL-6 that followed its expression at the site of inflammation. Moreover, expression profile of $\mathrm{HO}-1$ in the injected muscle (Figure 12) was similar to that of IL-6 (Figure 17). Thus, a possible relationship between up-regulation of these two genes could be the subject of further investigations.

Interestingly, the serum IL-6 levels were still high $12 \mathrm{~h}$ after TO injection (Figure 18), while HO-1 mRNA levels in the liver were already decreased (Figure 11A). This phenomenon might be explained by the known fact that IL-6 induces downregulation of its cognate receptor, IL-6R, in vitro (Hoffmann et al., 1994). Moreover, it has been demonstrated that IL-6R mRNA expression in the rat liver markedly decreased by 6-12 h after TO administration (Geisterfer et al., 1993). Therefore, it is likely that dramatic increase of IL-6 levels observed in TO-induced APR model subsequently leads to down-regulation of the IL-6R, thus abolishing the action of IL-6 in the liver when it is not required any more. It should also be noted that HO-1 mRNA has a short half-life of $3 \mathrm{~h}$, whereas the protein has a much longer half-life period of 15-21 h (Srivastava et al., 1993), which is in accordance with our data (Figure 11B). 


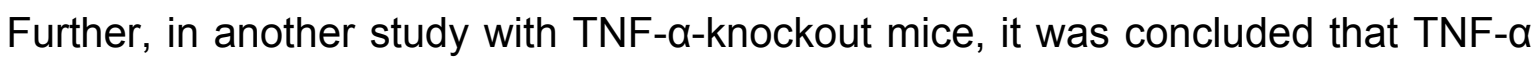
is a major candidate to trigger $\mathrm{HO}-1$ induction in response to LPS stimulation (Oguro et al., 2002). However, that study also contains indirect evidence for possible involvement of IL-6 in the LPS-dependent induction of HO-1 mRNA in the liver. They demonstrated that in TNF-a-deficient mice, which were unable to respond to LPS treatment with hepatic HO-1 induction, serum IL-6 levels were considerably lower compared to wild-type mice (Oguro et al., 2002).

Thus, IL-6 is most likely a principle inducer of hepatic HO-1 expression under inflammatory conditions, particularly in the TO-induced acute phase response model.

\subsection{Cell type specificity of HO-1 induction and its possible role in turpentine oil (TO)-induced acute phase response (APR)}

To elucidate which cell types are responsible for the TO-induced HO-1 expression in the injured muscle and in the liver, immunohistochemical analysis of these organs was performed. It has been demonstrated that within injured skeletal muscle, synthesis of HO-1 occurred mainly in the cells positive for ED1, a known marker of monocytes and macrophages, whereas muscle fibers were $\mathrm{HO}-1$ negative (Figure 16). These findings are consistent with data obtained by Kampfer and colleagues, who demonstrated that infiltrated macrophages are the major source of HO-1 at the wound site in the mouse excisional model of skin repair (Kampfer et al., 2001). Based on their in vitro data, the authors assumed involvement of $\mathrm{HO}-1$ in the regulation of macrophage-derived cytokine release (Kampfer et al., 2001). Indeed, numerous recent observations indicate a potential role of HO-1 in the down-regulation of proinflammatory cytokine expression at the site of inflammation in various model systems (Tamion et al., 2001; Tullius et al., 2002; Vicente et al., 2003; Ohta et al., 2003; Song et al., 2003a). It has been also shown, that HO-1 might provide an anti-inflammatory action in vivo through the down-modulation of cell adhesion molecules (Wagener et al., 2001; Soares et al., 2004), thus inhibiting leukocyte infiltration (Bussolati et al., 2004), and via promotion of non-inflammatory angiogenesis, facilitating tissue repair (Bussolati et al., 2004). Moreover, an increased leukocyte adhesion to the vessel wall and spontaneous perivascular infiltration of leukocytes in various tissues of $\mathrm{HO}-1$ deficient mice has been reported before (Poss and Tonegawa, 1997). 
Considering all these data and the results of the current study demonstrating that the levels of IL-6 mRNA in injured muscle were already declined, whereas HO-1 mRNA expression was still up-regulated (Figures 12 and 17), we can also speculate here about the role of $\mathrm{HO}-1$ in resolution of TO-induced localized inflammation and muscular tissue repair.

Although hepatic $\mathrm{HO}-1$ production under physiological and some pathological conditions is ascribed mainly to Kupffer cells, the resident liver tissue macrophages (Goda et al., 1998; Bauer et al., 1998; Kiemer et al., 2003; Song et al., 2003b), there is evidence that $\mathrm{HO}-1$ could be also up-regulated under certain conditions in hepatocytes, as has been shown in vivo by several groups (Bauer et al., 1998; Fernandez and Bonkovsky, 1999; Bauer et al., 2003; Mostert et al., 2003).

Immunohistochemical analysis of normal rat liver carried out in the present study revealed that expression of $\mathrm{HO}-1$ was attributed predominantly to Kupffer cells (Figure 14A, C), which is in compliance with the observations of other groups (Goda et al., 1998; Bauer et al., 1998). However, the dramatic induction of HO-1 immunoreactivity in the liver parenchyma after TO administration has been shown for the first time (Figure 14B). This suggests that during the inflammatory response to localized tissue injury, hepatocytes are the major source of increased $\mathrm{HO}-1$ mRNA and protein expression levels observed in the livers of TO-treated rats (Figure 11).

The data regarding muscle- and liver-specific $\mathrm{HO}-1$ induction in $\mathrm{TO}$ model of the APR might be of physiological importance, since the products of $\mathrm{HO}-1$ reaction have been shown to be involved in a wide variety of cytoprotective, particularly anti-inflammatory mechanisms. Carbon monoxide (CO) regulates blood vessel tone (Morita and Kourembanas, 1995), prevents platelet activation and aggregation (Brune and Ullrich, 1987), suppresses the pro-inflammatory cytokine production and promotes increased interleukin (IL)-10 expression by macrophages both in vitro and in vivo (Otterbein et al., 2000). Moreover, CO mediates the antiinflammatory effects of IL-10 (Lee and Chau, 2002). It was also reported that CO prevented apoptosis in several cell types, including endothelial cells, fibroblasts and hepatocytes (Otterbein et al., 2003). Biliverdin and its reduced product bilirubin both are potent antioxidants and may protect cells from oxidative injury by scavenging reactive oxygen species (Stocker et al., 1987). Biliverdin has also 
been shown to inhibit human complement in vitro (Nakagami et al., 1993). Bilirubin provided a protective effect on the transplanted liver grafts via inhibition of lipid peroxidation in hepatocytes (Kato et al., 2003). Although reduced iron $\left(\mathrm{Fe}^{2+}\right)$, released by $\mathrm{HO}-1$ from the core of the heme molecule, is a potent prooxidant, the potential catalysis of oxidative reactions by this compound is limited through its chelation by iron-sequestering protein ferritin as well as via its active removal from the cell by the specific Fe-ATPase pump (Ferris et al., 1999). Both these mechanisms are potentiated by increased intracellular pool of free iron following increased HO-1 expression (Eisenstein et al., 1991; Baranano et al., 2000) and could protect the cells from apoptosis (Ferris et al., 1999; Yang et al., 2002).

Despite a number of data accumulated, the precise role of $\mathrm{HO}-1$ in the APR remains to be fully defined. For instance, it has been shown that in re-oxygenated rat peritoneal macrophages, CO promoted inflammation through cGMP-dependent pathway, stimulating IL-6 and TNF- $\alpha$ synthesis (Tamion et al., 1999). On the other hand, $\mathrm{CO}$ was shown to mediate anti-inflammatory effects of $\mathrm{HO}-1$ via MAPK activation both in vitro, in macrophage cell line, and in vivo, in LPS-induced mouse APR model (Otterbein et al., 2000). Therefore, considering these studies and based on our data concerning the HO-1 and IL-6 induction in the injured muscle and liver, we could speculate that HO-1 has a regulatory function in the APR, promoting the induction of pro-inflammatory cytokine synthesis in macrophages to trigger the defense reaction of the organism and "switching off" the APR afterwards (down-regulation of pro-inflammatory and induction of anti-inflammatory cytokines) to avoid unfavorable consequences of chronic inflammation. At the same time under inflammatory conditions, HO-1 protects hepatocytes which could become damaged due to a number of toxic metabolites.

\subsection{Cytokine-dependent regulation of $\mathrm{HO}-1$ in cultured hepatocytes}

In vitro studies of primary rat hepatocytes treated with proinflammatory cytokines (Figures 19, 20, 21, 22) further confirmed the statement that IL-6 is a major regulator of acute phase protein synthesis in hepatocytes (Castell et al., 1989; Castell et al., 1990; Ramadori and Christ, 1999). Indeed, the most prominent induction of $\alpha 2$-macroglobulin transcript levels and the down-regulation of albumin 
mRNA expression occurred in primary rat hepatocytes treated with IL-6 in both time- and dose-dependent experiments (Figures 19A and 20), whereas other proinflammatory cytokines (IL-1 $\beta$ and TNF- $\alpha$ ) had significantly lower effects on the regulation of these acute phase proteins (Figures 19B, C, 21, 22). These observations are consistent with early data reported by Andus and co-workers. They demonstrated that in primary rat hepatocytes treated with human recombinant proinflammatory cytokines, IL-6 was 27 times more potent inducer of

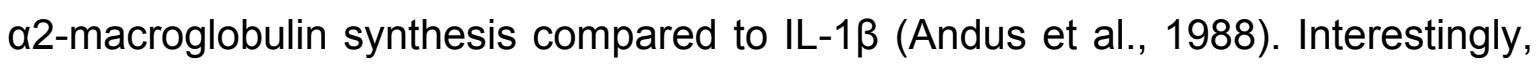
in primary rat hepatocytes, HO-1 mRNA expression was also induced by IL-6 to a higher extent compared to other cytokines used (Figures 19A and 20).

In addition to our data obtained in primary rat hepatocytes, there is also early evidence that $\mathrm{HO}-1$ is a positive acute phase reactant in a human liver-derived cell line (Mitani et al., 1992). They showed that HO-1 mRNA was time- and dosedependently accumulated in Hep3B cells after IL-6 treatment; this accumulation of $\mathrm{HO}$ was essentially abolished by simultaneous treatment of the cells with actinomycin D, suggesting that the induction occurs at the transcriptional level (Mitani et al., 1992). In our study, in addition to mRNA, protein levels of IL-6induced $\mathrm{HO}-1$ expression in primary rat hepatocytes were analyzed (Figures 23B and 24B). Remarkably, HO-1 mRNA expression was up-regulated within a whole range of IL-6 concentrations used in the dose-dependent experiment, whereas $\mathrm{HO}-1$ protein levels were significantly declined at the high doses of IL-6, which could be explained by the toxic effect of IL-6 at the high concentration (Figure 23C). Time-course of $\mathrm{HO}-1$ mRNA expression in primary rat hepatocytes treated with IL-6 was considerably different from that of $\mathrm{HO}-1$ protein (Figure 24C). Being rapidly elevated $2 \mathrm{~h}$ after IL-6 application, the mRNA levels of $\mathrm{HO}-1$ were already declined $4 \mathrm{~h}$ post IL-6 treatment, whereas the relative levels of $\mathrm{HO}-1$ protein remained elevated at all time points assayed (Figure 24C). This shift between the kinetics of HO-1 mRNA and protein synthesis may be explained by the different half-lives of $\mathrm{HO}-1$ transcripts $(3 \mathrm{~h})$ and protein $(15-21 \mathrm{~h})$, which correlates well with our in vivo data (Figure 11). In this regard, it should be noted that use of primary cell cultures has an advantage over the cell lines, since they are more close to the in vivo conditions. Thus, the regulation of $\mathrm{HO}-1$ by different proinflammatory cytokines can vary depending on the cell type examined. For instance, in nontransformed human endothelial cells, HO-1 was significantly induced by TNF- $\alpha$ 
and IL-1a, but not by IL-6 (Terry et al., 1998), whereas in human umbilical vein endothelial cells (HUVEC cell line), treatment with TNF- $\alpha$ and LPS did not significantly induce HO-1 expression (Kronke et al., 2003).

Thus, based on our in vitro data, the induction of HO-1 mRNA and protein levels might be considered as an event associated with the APR and supports the role of $\mathrm{HO}-1$ as an intracellular positive acute phase protein in vivo.

\subsection{Molecular mechanisms of HO-1 regulation under inflammatory conditions}

The sequences of $\mathrm{HO}-1$ gene 5'-flanking regions from four animal species (human, mouse, rat, and chicken) are known to date (Choi and Alam, 1996; Elbirt and Bonkovsky, 1999). Among them, the rat HO-1 gene promoter region is poorly investigated. Only four functional response elements of the rat $\mathrm{HO}-1$ promoter have been characterized (Figure 2).

The JAK/STAT pathway was found to be the major signalling pathway induced by the principle mediator of the APR, IL-6, which signals via the activation of Janus kinases (JAKs) and transcription factors of the STAT family (Heinrich et al., 1998). Since we have shown that IL-6 up-regulates HO-1 mRNA and protein expression in primary rat hepatocytes (Figures 23 and 24), it was of interest to analyse the known sequence of the rat HO-1 promoter for the presence of putative STATbinding sites (Figure 25). As early as in 1992, Mitani and colleagues discovered in the human HO-1 promoter the motif 5'-TTCTGGGAC-3' (nucleotide residues -373 to -365), sharing a significant homology with the consensus sequence found in many acute phase protein genes (Mitani et al., 1992). This consensus $\left[T T C(N)_{3} G A A\right]$ was later referred to as STAT binding site (Heinrich et al., 1998). This putative STAT binding site in the $5^{\prime}$-flanking region of human $\mathrm{HO}-1$ was shown to be functional, as revealed by electrophoretic mobility shift assay (EMSA) using specific oligonucleotides (Mitani et al., 1992).

Among the putative STAT binding sites found by analysis of the rat $\mathrm{HO}-1$ promoter, S3BE (STAT3-like binding element, -386/-378, 5'-TTCCGGGAA-3') that completely matches the known generalized STAT consensus sequence (Darnell, Jr., 1997; Lee et al., 2000) was considered as the most promising candidate to bind activated STAT3 (Figure 25). In turn, the pivotal role of STAT3 in transduction of the IL-6 signal was demonstrated using IL-6-deficient mice (Alonzi et al., 1998). 
Furthermore, the sequence and position of S3BE in the rat $\mathrm{HO}-1$ promoter is much similar to that of IL-6 response element reported by Mitani and colleagues in the promoter region of the human HO-1 gene (Mitani et al., 1992).

The functional role of the potential STAT binding site S3BE in the regulation of the rat HO-1 gene expression by IL-6 has been clearly demonstrated in the current study by means of a luciferase (Luc) reporter gene assay (Figure 27). The induction of the Luc activity measured after IL-6 treatment in primary rat hepatocytes transfected with S3BE-mutated ( $\mathrm{pHO}-754 \triangle \mathrm{S} 3 \mathrm{BE}$ ) or S3BE-deleted (pHO-347) HO-1 promoter luciferase gene constructs was almost 2 times less potent compared to that in the hepatocytes transfected with the wild-type (pHO754) rat HO-1 promoter construct (Figure 27).

In addition, functional analysis of the mouse $\mathrm{HO}-1$ gene $5^{\prime}$-flanking region has identified a sequence motif, $5^{\prime}$-TTCCGGGAA-3', that conforms to the consensus IL-6-response element [TTC $\left.(\mathrm{N})_{3} \mathrm{GAA}\right]$, i. e. STAT binding site. Interestingly, transcriptional activation of the mouse $\mathrm{HO}-1$ gene by IL-6 required cooperation between the $5^{\prime}$-distal enhancer with an AP-1 binding site and the proximal promoter enclosing the STAT binding site (Choi and Alam, 1996; Lee et al., 2000). However, in the present study, the induction of the Luc activity measured after IL-6 treatment in primary rat hepatocytes transfected with the construct pHO-754 $\triangle \mathrm{AP} 1$, where the whole AP-1 binding sequence was deleted (Immenschuh et al., 1998), was not significantly different from that in the hepatocytes transfected with the wild-type pHO-754 construct (Figure 27). This suggests that cooperation between AP-1 and S3BE is not important for the IL-6-dependent induction of HO-1 gene in rats.

It should be noted that IL-6-dependent induction of Luc expression from pHO$754 \triangle \mathrm{S} 3 \mathrm{BE}$ as well as pHO-347 was not completely abolished compared to the wild-type pHO-754 construct (Figure 27), indicating the potential role of SBE1 and/or SBE2 putative STAT binding sequences in IL-6-mediated HO-1 gene regulation (Figure 25). Indeed, these two identical motifs (TTCTGGAA, -289/-282 and $-220 /-213$ ) completely match the IL-6-response element of the murine SAA3 gene (Hattori et al., 1990) which, as was shown later, is bound by STAT complexes (Seidel et al., 1995). Therefore, it is of interest to further investigate the roles of these two putative STAT binding sites in the regulation of rat HO-1 gene by IL-6. 
Notably, following IL-6 treatment of primary rat hepatocytes, the Luc expression in the pHO-1387-transfected cells was up-regulated to a considerably lesser extent compared to the cells transfected with pHO-754 (Figure 27). This might be explained by the presence of negative regulatory elements in the upstream region between -754 and -1387 . Indeed, the promoter analysis of the rat HO-1 gene revealed the presence of several putative glucocorticoid response elements (GREs) in this region (data not shown). Moreover, negative regulation of rat HO-1 gene by glucocorticoids was reported (Cantoni et al., 1991) and functional GRE in the human HO-1 promoter was identified (Lavrovsky et al., 1996; Deramaudt et al., 1999). Since the pituitary-adrenal axis is activated during the acute phase response (Ramadori and Christ, 1999), further investigations are required to elucidate the role of the putative GREs in the HO-1 gene regulation under inflammatory conditions. The lower Luc expression from pHO-1387 compared to pHO-754 might be also due to the presence of the putative STAT6 binding element (S6BE) in the longer HO-1 promoter construct (Figure 25), which may be involved in IL-4 signalling (Mikita et al., 1996). IL-4, in turn, was demonstrated to exert anti-inflammatory function by the inhibition of acute phase protein production in vitro (Loyer et al., 1993).

In summary, the results presented here clearly indicate that activation of the STAT pathway by IL- 6 induces the rat HO-1 gene expression mainly through the S3BE sequence in the promoter of this gene.

\subsection{Conclusions and future directions}

The present study has demonstrated that during turpentine oil-induced localized inflammation in rats, the expression of HO-1 was strongly up-regulated in injured muscle, the initiating site of the acute phase reaction, and in the liver, the major source of serum acute phase proteins. In injured muscle, the induction of HO-1 was attributed to macrophages, whereas in the liver, hepatocytes were the major source of the elevated $\mathrm{HO}-1$ levels during the acute phase response.

Studies in primary rat hepatocytes further underlined the pivotal role of IL-6 in the induction of HO-1 expression under inflammatory conditions. Sequence analysis of the rat $\mathrm{HO}-1$ promoter revealed the presence of several putative binding sites for transcription factors of the STAT-family, the major transducers of IL-6 signalling. Furthermore, the functional analysis of the rat HO-1 promoter by means of 
luciferase reporter gene assay identified one of the putative STAT binding sites, S3BE, as an active element of the IL-6-dependent HO-1 gene regulation.

Taken together, these data indicate that $\mathrm{HO}-1$ might be referred to as an intracellular positive acute phase protein that seems to play an important role in cytoprotection of hepatocytes via the products released in the heme breakdown reaction. Bilirubin is a potent antioxidant and could protect the cells against oxidative stress, carbon monoxide provides a vasodilatory effect improving hepatic microcirculation, and free iron induces synthesis of ferritin, an iron-sequestering protein with a potent protective function. Moreover, at the site of turpentine oil injection, up-regulation of $\mathrm{HO}-1$ in macrophages could participate in the resolution of inflammation.

The work presented here could be the basis for the future investigations of the HO-1 gene regulation under inflammatory conditions. A functional analysis of two other putative STAT binding sites, SBE1 and SBE2, found in the rat HO-1 promoter sequence might be performed. Furthermore, the certain transcription factors from the STAT family (STAT1, STAT3, STAT5 homo- or heterodimers) that may bind to the found sequences, thus mediating IL-6-dependent HO-1 gene induction in rats, can be identified. Since IL-4 that signals via STAT6 is known to down-regulate expression of acute phase proteins, it might be of interest to investigate the involvement of S6BE, a putative binding site for STAT6, in the rat HO-1 gene regulation. The potential negative regulatory role of putative GREs found in the rat HO-1 promoter could be also elucidated.

Furthermore, to provide unequivocal evidence that induction of $\mathrm{HO}-1$ in vivo occurs as a response to IL- 6 produced at the site of inflammation, studies in IL-6 knockout mice could be carried out. The use of IL-6-receptor antagonists, neutralizing antibodies or recombinant IL-6 injection might be other approaches to further study IL-6-dependent HO-1 induction in vivo. 


\section{References}

1. Alam J., Cai J., and Smith A. Isolation and characterization of the mouse heme oxygenase-1 gene. Distal 5' sequences are required for induction by heme or heavy metals. J.Biol.Chem. 269: 1001-1009, 1994.

2. Alcaraz M.J., Fernandez P., and Guillen M.I. Anti-inflammatory actions of the heme oxygenase-1 pathway. Curr.Pharm.Des. 9: 2541-2551, 2003.

3. Alonzi T., Fattori E., Cappelletti M., Ciliberto G., and Poli V. Impaired Stat3 activation following localized inflammatory stimulus in IL-6-deficient mice. Cytokine. 10: 13-18, 1998.

4. Andus T., Geiger T., Klapproth J., Kunz D., Heisig M., Castell J., and Heinrich P.C. Regulation of alpha 2-macroglobulin gene expression by interleukin-6 (BSF-2/HSF). Tokai J.Exp.Clin.Med. 13: 265-276, 1988.

5. Balla G., Jacob H.S., Balla J., Rosenberg M., Nath K., Apple F., Eaton J.W., and Vercellotti G.M. Ferritin: a cytoprotective antioxidant strategem of endothelium. J.Biol.Chem. 267: 18148-18153, 1992.

6. Baranano D.E., Wolosker H., Bae B.I., Barrow R.K., Snyder S.H., and Ferris C.D. A mammalian iron ATPase induced by iron. J.Biol.Chem. 275: 1516615173, 2000.

7. Barbu V. and Dautry F. Northern blot normalization with a $28 \mathrm{~S}$ rRNA oligonucleotide probe. Nucleic Acids Res. 17: 7115- 1989.

8. Bauer I., Rensing H., Florax A., Ulrich C., Pistorius G., Redl H., and Bauer M. Expression pattern and regulation of heme oxygenase-1/heat shock protein 32 in human liver cells. Shock. 20: 116-122, 2003.

9. Bauer I., Wanner G.A., Rensing H., Alte C., Miescher E.A., Wolf B., Pannen B.H., Clemens M.G., and Bauer M. Expression pattern of heme oxygenase isoenzymes 1 and 2 in normal and stress-exposed rat liver. Hepatology. 27: 829-838, 1998.

10. Bauer M. and Bauer I. Heme oxygenase-1: redox regulation and role in the hepatic response to oxidative stress. Antioxid.Redox.Signal. 4: 749-758, 2002.

11. Braggins P.E., Trakshel G.M., Kutty R.K., and Maines M.D. Characterization of two heme oxygenase isoforms in rat spleen: comparison with the hematininduced and constitutive isoforms of the liver. Biochem.Biophys.Res. Commun. 141: 528-533, 1986.

12. Brune B. and Ullrich V. Inhibition of platelet aggregation by carbon monoxide is mediated by activation of guanylate cyclase. Mol.Pharmacol. 32: 497-504, 1987.

13. Bussolati B., Ahmed A., Pemberton H., Landis R.C., Di C.F., Haskard D.O., and Mason J.C. Bifunctional role for VEGF-induced heme oxygenase-1 in vivo: induction of angiogenesis and inhibition of leukocytic infiltration. Blood. 103: 761-766, 2004. 
14. Camhi S.L., Alam J., Otterbein L., Sylvester S.L., and Choi A.M. Induction of heme oxygenase-1 gene expression by lipopolysaccharide is mediated by AP-1 activation. Am.J.Respir.Cell Mol.Biol. 13: 387-398, 1995.

15. Cantoni L., Rossi C., Rizzardini M., Gadina M., and Ghezzi P. Interleukin-1 and tumour necrosis factor induce hepatic haem oxygenase. Feedback regulation by glucocorticoids. Biochem.J. 279 ( Pt 3): 891-894, 1991.

16. Castell J.V., Gomez-Lechon M.J., David M., Andus T., Geiger T., Trullenque R., Fabra R., and Heinrich P.C. Interleukin-6 is the major regulator of acute phase protein synthesis in adult human hepatocytes. FEBS Lett. 242: 237239, 1989.

17. Castell J.V., Gomez-Lechon M.J., David M., Fabra R., Trullenque R., and Heinrich P.C. Acute-phase response of human hepatocytes: regulation of acute-phase protein synthesis by interleukin-6. Hepatology. 12: 1179-1186, 1990.

18. Chalfie M., Tu Y., Euskirchen G., Ward W.W., and Prasher D.C. Green fluorescent protein as a marker for gene expression. Science. 263: 802-805, 1994.

19. Chirgwin J.M., Przybyla A.E., MacDonald R.J., and Rutter W.J. Isolation of biologically active ribonucleic acid from sources enriched in ribonuclease. Biochemistry. 18: 5294-5299, 1979.

20. Choi A.M. and Alam J. Heme oxygenase-1: function, regulation, and implication of a novel stress-inducible protein in oxidant-induced lung injury. Am.J.Respir.Cell Mol.Biol. 15: 9-19, 1996.

21. Christodoulides N., Durante W., Kroll M.H., and Schafer A.I. Vascular smooth muscle cell heme oxygenases generate guanylyl cyclase-stimulatory carbon monoxide. Circulation. 91: 2306-2309, 1995.

22. Cruse I. and Maines M.D. Evidence suggesting that the two forms of heme oxygenase are products of different genes. J.Biol.Chem. 263: 3348-3353, 1988.

23. Darnell J.E., Jr. STATs and gene regulation. Science. 277: 1630-1635, 1997.

24. Decker K. Biologically active products of stimulated liver macrophages (Kupffer cells). Eur.J.Biochem. 192: 245-261, 1990.

25. Dennery P.A. Regulation and role of heme oxygenase in oxidative injury. Curr.Top.Cell Regul. 36: 181-199, 2000.

26. Deramaudt T.B., da Silva J.L., Remy P., Kappas A., and Abraham N.G. Negative regulation of human heme oxygenase in microvessel endothelial cells by dexamethasone. Proc.Soc.Exp.Biol.Med. 222: 185-193, 1999.

27. Dore S., Takahashi M., Ferris C.D., Zakhary R., Hester L.D., Guastella D., and Snyder S.H. Bilirubin, formed by activation of heme oxygenase-2, protects neurons against oxidative stress injury. Proc.Natl.Acad.Sci.U.S.A. 96: 24452450, 1999. 
28. Eisenstein R.S., Garcia-Mayol D., Pettingell W., and Munro H.N. Regulation of ferritin and heme oxygenase synthesis in rat fibroblasts by different forms of iron. Proc.Natl.Acad.Sci.U.S.A. 88: 688-692, 1991.

29. Eisenstein R.S. and Munro H.N. Translational regulation of ferritin synthesis by iron. Enzyme. 44: 42-58, 1990.

30. Elbirt K.K. and Bonkovsky H.L. Heme oxygenase: recent advances in understanding its regulation and role. Proc.Assoc.Am.Physicians. 111: 438447, 1999.

31. Fattori E., Cappelletti M., Costa P., Sellitto C., Cantoni L., Carelli M., Faggioni R., Fantuzzi G., Ghezzi P., and Poli V. Defective inflammatory response in interleukin 6-deficient mice. J.Exp.Med. 180: 1243-1250, 1994.

32. Feder L.S., Todaro J.A., and Laskin D.L. Characterization of interleukin-1 and interleukin-6 production by hepatic endothelial cells and macrophages. J.Leukoc.Biol. 53: 126-132, 1993.

33. Feinberg A.P. and Vogelstein B. A technique for radiolabeling DNA restriction endonuclease fragments to high specific activity. Anal.Biochem. 132: 6-13, 1983.

34. Fernandez M. and Bonkovsky H.L. Increased heme oxygenase-1 gene expression in liver cells and splanchnic organs from portal hypertensive rats. Hepatology. 29: 1672-1679, 1999.

35. Ferris C.D., Jaffrey S.R., Sawa A., Takahashi M., Brady S.D., Barrow R.K., Tysoe S.A., Wolosker H., Baranano D.E., Dore S., Poss K.D., and Snyder S.H. Haem oxygenase-1 prevents cell death by regulating cellular iron. Nat.Cell Biol. 1: 152-157, 1999.

36. Fey G.H. and Fuller G.M. Regulation of acute phase gene expression by inflammatory mediators. Mol.Biol.Med. 4: 323-338, 1987.

37. Fort P., Marty L., Piechaczyk M., el S.S., Dani C., Jeanteur P., and Blanchard J.M. Various rat adult tissues express only one major mRNA species from the glyceraldehyde-3-phosphate-dehydrogenase multigenic family. Nucleic Acids Res. 13: 1431-1442, 1985.

38. Gehring M.R., Shiels B.R., Northemann W., de Bruijn M.H., Kan C.C., Chain A.C., Noonan D.J., and Fey G.H. Sequence of rat liver alpha 2macroglobulin and acute phase control of its messenger RNA. J.Biol.Chem. 262: 446-454, 1987.

39. Geiger T., Andus T., Klapproth J., Hirano T., Kishimoto T., and Heinrich P.C. Induction of rat acute-phase proteins by interleukin 6 in vivo. Eur.J.Immunol. 18: 717-721, 1988.

40. Geisterfer M., Richards C., Baumann M., Fey G., Gywnne D., and Gauldie J. Regulation of IL-6 and the hepatic IL-6 receptor in acute inflammation in vivo. Cytokine. 5: 1-7, 1993.

41. Goda N., Suzuki K., Naito M., Takeoka S., Tsuchida E., Ishimura Y., Tamatani T., and Suematsu M. Distribution of heme oxygenase isoforms in rat liver. Topographic basis for carbon monoxide-mediated microvascular relaxation. J.Clin.Invest. 101: 604-612, 1998. 
42. Graham F.L. and van der Eb A.J. A new technique for the assay of infectivity of human adenovirus 5 DNA. Virology. 52: 456-467, 1973.

43. Gunshin H., Mackenzie B., Berger U.V., Gunshin Y., Romero M.F., Boron W.F., Nussberger S., Gollan J.L., and Hediger M.A. Cloning and characterization of a mammalian proton-coupled metal-ion transporter. Nature. 388: 482-488, 1997.

44. Hartsfield C.L. Cross talk between carbon monoxide and nitric oxide. Antioxid.Redox.Signal. 4: 301-307, 2002.

45. Hattori M., Abraham L.J., Northemann W., and Fey G.H. Acute-phase reaction induces a specific complex between hepatic nuclear proteins and the interleukin 6 response element of the rat alpha 2-macroglobulin gene. Proc.Natl.Acad.Sci.U.S.A. 87: 2364-2368, 1990.

46. Heinrich P.C., Behrmann I., Haan S., Hermanns H.M., Muller-Newen G., and Schaper F. Principles of interleukin (IL)-6-type cytokine signalling and its regulation. Biochem.J. 374: 1-20, 2003.

47. Heinrich P.C., Behrmann I., Muller-Newen G., Schaper F., and Graeve L. Interleukin-6-type cytokine signalling through the gp130/Jak/STAT pathway. Biochem.J. 334 ( Pt 2): 297-314, 1998.

48. Heinrich P.C., Castell J.V., and Andus T. Interleukin-6 and the acute phase response. Biochem.J. 265: 621-636, 1990.

49. Hentze M.W. and Kuhn L.C. Molecular control of vertebrate iron metabolism: mRNA-based regulatory circuits operated by iron, nitric oxide, and oxidative stress. Proc.NatI.Acad.Sci.U.S.A. 93: 8175-8182, 1996.

50. Hoffmann R., Henninger H.P., Schulze-Specking A., and Decker K. Regulation of interleukin-6 receptor expression in rat Kupffer cells: modulation by cytokines, dexamethasone and prostaglandin E2. J.Hepatol. 21: 543-550, 1994.

51. Horvath C.M., Wen Z., and Darnell J.E., Jr. A STAT protein domain that determines DNA sequence recognition suggests a novel DNA-binding domain. Genes Dev. 9: 984-994, 1995.

52. Immenschuh S., Hinke V., OhImann A., Gifhorn-Katz S., Katz N., Jungermann K., and Kietzmann T. Transcriptional activation of the haem oxygenase-1 gene by cGMP via a cAMP response element/activator protein-1 element in primary cultures of rat hepatocytes. Biochem.J. 334 ( Pt 1): 141-146, 1998.

53. Immenschuh S. and Ramadori G. Gene regulation of heme oxygenase-1 as a therapeutic target. Biochem.Pharmacol. 60: 1121-1128, 2000.

54. Immenschuh S., Tan M., and Ramadori G. Nitric oxide mediates the lipopolysaccharide dependent upregulation of the heme oxygenase-1 gene expression in cultured rat Kupffer cells. J.Hepatol. 30: 61-69, 1999.

55. Inouye S. and Tsuji F.I. Aequorea green fluorescent protein. Expression of the gene and fluorescence characteristics of the recombinant protein. FEBS Lett. 341: 277-280, 1994. 
56. Kaibara A., Espat N.J., Auffenberg T., Abouhamze A.S., Martin D., Kalra S., and Moldawer L.L. Interleukin 6, but not ciliary neurotrophic factor or leukaemia inhibitory factor, is responsible for the acute phase response to turpentineinduced myositis. Cytokine. 10: 452-456, 1998.

57. Kampfer H., Kolb N., Manderscheid M., Wetzler C., Pfeilschifter J., and Frank S. Macrophage-derived heme-oxygenase-1: expression, regulation, and possible functions in skin repair. Mol.Med. 7: 488-498, 2001.

58. Kato Y., Shimazu M., Kondo M., Uchida K., Kumamoto Y., Wakabayashi G., Kitajima M., and Suematsu M. Bilirubin rinse: A simple protectant against the rat liver graft injury mimicking heme oxygenase-1 preconditioning. Hepatology. 38: 364-373, 2003.

59. Katz J., Golden S., and Wals P.A. Glycogen synthesis by rat hepatocytes. Biochem.J. 180: 389-402, 1979.

60. Kelly R.B., Cozzarelli N.R., Deutscher M.P., Lehman I.R., and Kornberg A. Enzymatic synthesis of deoxyribonucleic acid. XXXII. Replication of duplex deoxyribonucleic acid by polymerase at a single strand break. J.Biol.Chem. 245: 39-45, 1970.

61. Kiemer A.K., Gerwig T., Gerbes A.L., Meissner H., Bilzer M., and Vollmar A.M. Kupffer-cell specific induction of heme oxygenase 1 (hsp32) by the atrial natriuretic peptide--role of cGMP. J.Hepatol. 38: 490-498, 2003.

62. Kietzmann T., Samoylenko A., and Immenschuh S. Transcriptional regulation of heme oxygenase-1 gene expression by MAP kinases of the JNK and p38 pathways in primary cultures of rat hepatocytes. J.Biol.Chem. 278: 1792717936, 2003.

63. Kioussis D., Eiferman F., van de R.P., Gorin M.B., Ingram R.S., and Tilghman S.M. The evolution of alpha-fetoprotein and albumin. II. The structures of the alpha-fetoprotein and albumin genes in the mouse. J.Biol.Chem. 256: 19601967, 1981.

64. Knittel T., Fellmer P., Neubauer K., Kawakami M., Grundmann A., and Ramadori G. The complement-activating protease P100 is expressed by hepatocytes and is induced by IL-6 in vitro and during the acute phase reaction in vivo. Lab Invest. 77: 221-230, 1997.

65. Knook D.L. and Sleyster E.C. Separation of Kupffer and endothelial cells of the rat liver by centrifugal elutriation. Exp.Cell Res. 99: 444-449, 1976.

66. Koizumi T., Odani N., Okuyama T., Ichikawa A., and Negishi M. Identification of a cis-regulatory element for delta 12-prostaglandin J2-induced expression of the rat heme oxygenase gene. J.Biol.Chem. 270: 21779-21784, 1995.

67. Kolesnick R. and Golde D.W. The sphingomyelin pathway in tumor necrosis factor and interleukin-1 signaling. Cell. 77: 325-328, 1994.

68. Kronke G., Bochkov V.N., Huber J., Gruber F., Bluml S., Furnkranz A., Kadl A., Binder B.R., and Leitinger N. Oxidized phospholipids induce expression of human heme oxygenase-1 involving activation of cAMP-responsive elementbinding protein. J.Biol.Chem. 278: 51006-51014, 2003. 
69. Laemmli U.K. Cleavage of structural proteins during the assembly of the head of bacteriophage T4. Nature. 227: 680-685, 1970.

70. Lavrovsky Y., Drummond G.S., and Abraham N.G. Downregulation of the human heme oxygenase gene by glucocorticoids and identification of $56 \mathrm{~b}$ regulatory elements. Biochem.Biophys.Res.Commun. 218: 759-765, 1996.

71. Lee P.J., Camhi S.L., Chin B.Y., Alam J., and Choi A.M. AP-1 and STAT mediate hyperoxia-induced gene transcription of heme oxygenase-1. Am.J.Physiol Lung Cell Mol.Physiol. 279: L175-L182, 2000.

72. Lee T.S. and Chau L.Y. Heme oxygenase-1 mediates the anti-inflammatory effect of interleukin-10 in mice. Nat.Med. 8: 240-246, 2002.

73. Lemmink H.H., Tuyt L., Knol G., Krikke E., and Vellenga E. Identification of LILSTAT in monocytic leukemia cells and monocytes after stimulation with interleukin-6 or interferon gamma. Blood. 98: 3849-3852, 2001.

74. Loyer P., Ilyin G., Abdel R.Z., Banchereau J., Dezier J.F., Campion J.P., Guguen-Guillouzo C., and Guillouzo A. Interleukin 4 inhibits the production of some acute-phase proteins by human hepatocytes in primary culture. FEBS Lett. 336: 215-220, 1993.

75. Luckey S.W., Taylor M., Sampey B.P., Scheinman R.I., and Petersen D.R. 4hydroxynonenal decreases interleukin-6 expression and protein production in primary rat Kupffer cells by inhibiting nuclear factor-kappaB activation. J.Pharmacol.Exp.Ther. 302: 296-303, 2002.

76. Luheshi G.N., Stefferl A., Turnbull A.V., Dascombe M.J., Brouwer S., Hopkins S.J., and Rothwell N.J. Febrile response to tissue inflammation involves both peripheral and brain IL-1 and TNF-alpha in the rat. Am.J.Physiol. 272: R862-R868, 1997.

77. Luster M.I., Germolec D.R., Yoshida T., Kayama F., and Thompson M. Endotoxin-induced cytokine gene expression and excretion in the liver. Hepatology. 19: 480-488, 1994.

78. Lyoumi S., Puy H., Tamion F., Bogard C., Leplingard A., Scotte M., Vranckx R., Gauthier F., Hiron M., Daveau M., Nordmann Y., Deybach J.C., and Lebreton J.P. Heme and acute inflammation role in vivo of heme in the hepatic expression of positive acute-phase reactants in rats. Eur.J.Biochem. 261: 190-196, 1999.

79. Lyoumi S., Puy H., Tamion F., Scotte M., Daveau M., Nordmann Y., Lebreton J.P., and Deybach J.C. Nitric oxide synthase inhibition and the induction of cytochrome P-450 affect heme oxygenase-1 messenger RNA expression after partial hepatectomy and acute inflammation in rats. Crit Care Med. 26: 1683-1689, 1998a.

80. Lyoumi S., Tamion F., Petit J., Dechelotte P., Dauguet C., Scotte M., Hiron M., Leplingard A., Salier J.P., Daveau M., and Lebreton J.P. Induction and modulation of acute-phase response by protein malnutrition in rats: comparative effect of systemic and localized inflammation on interleukin-6 and acute-phase protein synthesis. J.Nutr. 128: 166-174, 1998b.

81. Maines M.D. The heme oxygenase system: a regulator of second messenger gases. Annu.Rev.Pharmacol.Toxicol. 37: 517-554, 1997. 
82. Maines M.D., Mayer R.D., Ewing J.F., and McCoubrey W.K., Jr. Induction of kidney heme oxygenase-1 (HSP32) mRNA and protein by ischemia/reperfusion: possible role of heme as both promotor of tissue damage and regulator of HSP32. J.Pharmacol.Exp.Ther. 264: 457-462, 1993.

83. Maines M.D., Trakshel G.M., and Kutty R.K. Characterization of two constitutive forms of rat liver microsomal heme oxygenase. Only one molecular species of the enzyme is inducible. J.Biol.Chem. 261: 411-419, 1986.

84. McCoubrey W.K., Jr., Huang T.J., and Maines M.D. Heme oxygenase-2 is a hemoprotein and binds heme through heme regulatory motifs that are not involved in heme catalysis. J.Biol.Chem. 272: 12568-12574, 1997a.

85. McCoubrey W.K., Jr., Huang T.J., and Maines M.D. Isolation and characterization of a cDNA from the rat brain that encodes hemoprotein heme oxygenase-3. Eur.J.Biochem. 247: 725-732, $1997 \mathrm{~b}$.

86. McCoubrey W.K., Jr. and Maines M.D. The structure, organization and differential expression of the gene encoding rat heme oxygenase-2. Gene. 139: 155$161,1994$.

87. Mikita T., Campbell D., Wu P., Williamson K., and Schindler U. Requirements for interleukin-4-induced gene expression and functional characterization of Stat6. Mol.Cell Biol. 16: 5811-5820, 1996.

88. Mitani K., Fujita H., Kappas A., and Sassa S. Heme oxygenase is a positive acutephase reactant in human Hep3B hepatoma cells. Blood. 79: 1255-1259, 1992.

89. Morin J.G. and Hastings J.W. Energy transfer in a bioluminescent system. J.Cell Physiol. 77: 313-318, 1971.

90. Morita T. and Kourembanas S. Endothelial cell expression of vasoconstrictors and growth factors is regulated by smooth muscle cell-derived carbon monoxide. J.Clin.Invest. 96: 2676-2682, 1995.

91. Moshage H. Cytokines and the hepatic acute phase response. J.Pathol. 181: 257266, 1997.

92. Mostert V., Hill K.E., Ferris C.D., and Burk R.F. Selective induction of liver parenchymal cell heme oxygenase-1 in selenium-deficient rats. Biol.Chem. 384: 681-687, 2003.

93. Motterlini R., Green C.J., and Foresti R. Regulation of heme oxygenase-1 by redox signals involving nitric oxide. Antioxid.Redox.Signal. 4: 615-624, 2002.

94. Muller R.M., Taguchi H., and Shibahara S. Nucleotide sequence and organization of the rat heme oxygenase gene. J.Biol.Chem. 262: 6795-6802, 1987.

95. Nakagami T., Toyomura K., Kinoshita T., and Morisawa S. A beneficial role of bile pigments as an endogenous tissue protector: anti-complement effects of biliverdin and conjugated bilirubin. Biochim.Biophys.Acta. 1158: 189-193, 1993. 
96. Neuzil J. and Stocker R. Free and albumin-bound bilirubin are efficient coantioxidants for alpha-tocopherol, inhibiting plasma and low density lipoprotein lipid peroxidation. J.Biol.Chem. 269: 16712-16719, 1994.

97. Northemann W., Braciak T.A., Hattori M., Lee F., and Fey G.H. Structure of the rat interleukin 6 gene and its expression in macrophage-derived cells. J.Biol.Chem. 264: 16072-16082, 1989.

98. Oguro T., Takahashi Y., Ashino T., Takaki A., Shioda S., Horai R., Asano M., Sekikawa K., Iwakura Y., and Yoshida T. Involvement of tumor necrosis factor alpha, rather than interleukin-1alpha/beta or nitric oxides in the heme oxygenase-1 gene expression by lipopolysaccharide in the mouse liver. FEBS Lett. 516: 63-66, 2002.

99. Ohta K., Kikuchi T., Arai S., Yoshida N., Sato A., and Yoshimura N. Protective role of heme oxygenase-1 against endotoxin-induced uveitis in rats. Exp. Eye Res. 77: 665-673, 2003.

100. Okinaga S. and Shibahara S. Identification of a nuclear protein that constitutively recognizes the sequence containing a heat-shock element. Its binding properties and possible function modulating heat-shock induction of the rat heme oxygenase gene. Eur.J.Biochem. 212: 167-175, 1993.

101. Otterbein L.E., Bach F.H., Alam J., Soares M., Tao L.H., Wysk M., Davis R.J., Flavell R.A., and Choi A.M. Carbon monoxide has anti-inflammatory effects involving the mitogen-activated protein kinase pathway. Nat.Med. 6: 422-428, 2000.

102. Otterbein L.E. and Choi A.M. Heme oxygenase: colors of defense against cellular stress. Am.J.Physiol Lung Cell Mol.Physiol. 279: L1029-L1037, 2000.

103. Otterbein L.E., Soares M.P., Yamashita K., and Bach F.H. Heme oxygenase-1: unleashing the protective properties of heme. Trends Immunol. 24: 449-455, 2003.

104. Perregaux D.G. and Gabel C.A. Post-translational processing of murine IL-1: evidence that ATP-induced release of IL-1 alpha and IL-1 beta occurs via a similar mechanism. J.Immunol. 160: 2469-2477, 1998.

105. Pillar T.M. and Seitz H.J. Oxidative stress response induced in rat primary hepatocyte monolayers by mechanical removal of adherent cells. Cell Tissue Res. 295: 363-367, 1999.

106. Poli V., Balena R., Fattori E., Markatos A., Yamamoto M., Tanaka H., Ciliberto G., Rodan G.A., and Costantini F. Interleukin-6 deficient mice are protected from bone loss caused by estrogen depletion. EMBO J. 13: 1189-1196, 1994.

107. Poss K.D. and Tonegawa S. Heme oxygenase 1 is required for mammalian iron reutilization. Proc.Natl.Acad.Sci.U.S.A. 94: 10919-10924, 1997.

108. Prasher D.C., Eckenrode V.K., Ward W.W., Prendergast F.G., and Cormier M.J. Primary structure of the Aequorea victoria green-fluorescent protein. Gene. 111: 229-233, 1992.

109. Ramadori G. and Armbrust T. Cytokines in the liver. Eur.J.Gastroenterol.Hepatol. 13: 777-784, 2001. 
110. Ramadori G. and Christ B. Cytokines and the hepatic acute-phase response. Semin.Liver Dis. 19: 141-155, 1999.

111. Rizzardini M., Carelli M., Cabello Porras M.R., and Cantoni L. Mechanisms of endotoxin-induced haem oxygenase mRNA accumulation in mouse liver: synergism by glutathione depletion and protection by $\mathrm{N}$-acetylcysteine. Biochem.J. 304 ( Pt 2): 477-483, 1994.

112. Rizzardini M., Zappone M., Villa P., Gnocchi P., Sironi M., Diomede L., Meazza C., Monshouwer M., and Cantoni L. Kupffer cell depletion partially prevents hepatic heme oxygenase 1 messenger RNA accumulation in systemic inflammation in mice: role of interleukin 1beta. Hepatology. 27: 703-710, 1998.

113. Rowell D.L., Eckmann L., Dwinell M.B., Carpenter S.P., Raucy J.L., Yang S.K., and Kagnoff M.F. Human hepatocytes express an array of proinflammatory cytokines after agonist stimulation or bacterial invasion. Am.J.Physiol. 273: G322-G332, 1997.

114. Ryter S.W. and Choi A.M. Heme oxygenase-1: molecular mechanisms of gene expression in oxygen-related stress. Antioxid.Redox.Signal. 4: 625-632, 2002.

115. Ryter S.W. and Tyrrell R.M. The heme synthesis and degradation pathways: role in oxidant sensitivity. Heme oxygenase has both pro- and antioxidant properties. Free Radic.Biol.Med. 28: 289-309, 2000.

116. Schreiber G., Aldred A.R., Thomas T., Birch H.E., Dickson P.W., Tu G.F., Heinrich P.C., Northemann W., Howlett G.J., de Jong F.A., and . Levels of messenger ribonucleic acids for plasma proteins in rat liver during acute experimental inflammation. Inflammation. 10: 59-66, 1986.

117. Seglen P.O. Preparation of rat liver cells. 3. Enzymatic requirements for tissue dispersion. Exp.Cell Res. 82: 391-398, 1973.

118. Seidel H.M., Milocco L.H., Lamb P., Darnell J.E., Jr., Stein R.B., and Rosen J. Spacing of palindromic half sites as a determinant of selective STAT (signal transducers and activators of transcription) DNA binding and transcriptional activity. Proc.Natl.Acad.Sci.U.S.A. 92: 3041-3045, 1995.

119. Shibahara S., Muller R., Taguchi H., and Yoshida T. Cloning and expression of cDNA for rat heme oxygenase. Proc.Natl.Acad.Sci.U.S.A. 82: 7865-7869, 1985.

120. Shibahara S., Yoshizawa M., Suzuki H., Takeda K., Meguro K., and Endo K. Functional analysis of cDNAs for two types of human heme oxygenase and evidence for their separate regulation. J.Biochem.(Tokyo). 113: 214-218, 1993.

121. Siewert E., Bort R., Kluge R., Heinrich P.C., Castell J., and Jover R. Hepatic cytochrome P450 down-regulation during aseptic inflammation in the mouse is interleukin 6 dependent. Hepatology. 32: 49-55, 2000.

122. Smith P.K., Krohn R.I., Hermanson G.T., Mallia A.K., Gartner F.H., Provenzano M.D., Fujimoto E.K., Goeke N.M., Olson B.J., and Klenk D.C. Measurement of protein using bicinchoninic acid. Anal.Biochem. 150: 76-85, 1985. 
123. Soares M.P., Seldon M.P., Gregoire I.P., Vassilevskaia T., Berberat P.O., Yu J., Tsui T.Y., and Bach F.H. Heme oxygenase-1 modulates the expression of adhesion molecules associated with endothelial cell activation. J.Immunol. 172: 3553-3563, 2004.

124. Song R., Kubo M., Morse D., Zhou Z., Zhang X., Dauber J.H., Fabisiak J., Alber S.M., Watkins S.C., Zuckerbraun B.S., Otterbein L.E., Ning W., Oury T.D., Lee P.J., McCurry K.R., and Choi A.M. Carbon monoxide induces cytoprotection in rat orthotopic lung transplantation via anti-inflammatory and anti-apoptotic effects. Am.J.Pathol. 163: 231-242, 2003a.

125. Song Y., Shi Y., Ao L.H., Harken A.H., and Meng X.Z. TLR4 mediates LPSinduced HO-1 expression in mouse liver: role of TNF-alpha and IL-1beta. World J.Gastroenterol. 9: 1799-1803, 2003b.

126. Srivastava K.K., Cable E.E., Donohue S.E., and Bonkovsky H.L. Molecular basis for heme-dependent induction of heme oxygenase in primary cultures of chick embryo hepatocytes. Demonstration of acquired refractoriness to heme. Eur.J.Biochem. 213: 909-917, 1993.

127. Stocker R., Yamamoto Y., McDonagh A.F., Glazer A.N., and Ames B.N. Bilirubin is an antioxidant of possible physiological importance. Science. 235: 10431046, 1987.

128. Streetz K.L., Wustefeld T., Klein C., Manns M.P., and Trautwein C. Mediators of inflammation and acute phase response in the liver. Cell Mol.Biol.(Noisy.-legrand). 47: 661-673, 2001.

129. Suematsu M. and Ishimura Y. The heme oxygenase-carbon monoxide system: a regulator of hepatobiliary function. Hepatology. 31: 3-6, 2000.

130. Tamion F., Richard V., Bonmarchand G., Leroy J., Lebreton J.P., and Thuillez C. Induction of heme-oxygenase-1 prevents the systemic responses to hemorrhagic shock. Am.J.Respir.Crit Care Med. 164: 1933-1938, 2001.

131. Tamion F., Richard V., Lyoumi S., Hiron M., Bonmarchand G., Leroy J., Daveau M., Thuillez C., and Lebreton J.P. Induction of haem oxygenase contributes to the synthesis of pro-inflammatory cytokines in re-oxygenated rat macrophages: role of cGMP. Cytokine. 11: 326-333, 1999.

132. Taylor J.L., Carraway M.S., and Piantadosi C.A. Lung-specific induction of heme oxygenase-1 and hyperoxic lung injury. Am.J.Physiol. 274: L582-L590, 1998.

133. Tenhunen R., Marver H.S., and Schmid R. The enzymatic conversion of heme to bilirubin by microsomal heme oxygenase. Proc.Natl.Acad.Sci.U.S.A. 61: 748755, 1968.

134. Tenhunen R., Marver H.S., and Schmid R. Microsomal heme oxygenase. Characterization of the enzyme. J.Biol.Chem. 244: 6388-6394, 1969.

135. Tenhunen R., Marver H.S., and Schmid R. The enzymatic catabolism of hemoglobin: stimulation of microsomal heme oxygenase by hemin. J.Lab Clin.Med. 75: 410-421, 1970.

136. Terry C.M., Clikeman J.A., Hoidal J.R., and Callahan K.S. Effect of tumor necrosis factor-alpha and interleukin-1 alpha on heme oxygenase-1 expression in human endothelial cells. Am.J.Physiol. 274: H883-H891, 1998. 
137. Towbin H., Staehelin T., and Gordon J. Electrophoretic transfer of proteins from polyacrylamide gels to nitrocellulose sheets: procedure and some applications. Proc.Natl.Acad.Sci.U.S.A. 76: 4350-4354, 1979.

138. Tsujinaka T., Kishibuchi M., Yano M., Morimoto T., Ebisui C., Fujita J., Ogawa A., Shiozaki H., Kominami E., and Monden M. Involvement of interleukin-6 in activation of lysosomal cathepsin and atrophy of muscle fibers induced by intramuscular injection of turpentine oil in mice. J.Biochem.(Tokyo). 122: 595600, 1997.

139. Tullius S.G., Nieminen-Kelha M., Buelow R., Reutzel-Selke A., Martins P.N., Pratschke J., Bachmann U., Lehmann M., Southard D., lyer S., Schmidbauer G., Sawitzki B., Reinke P., Neuhaus P., and Volk H.D. Inhibition of ischemia/reperfusion injury and chronic graft deterioration by a single-donor treatment with cobalt-protoporphyrin for the induction of heme oxygenase-1. Transplantation. 74: 591-598, 2002.

140. Ulich T.R., Guo K.Z., Irwin B., Remick D.G., and Davatelis G.N. Endotoxininduced cytokine gene expression in vivo. II. Regulation of tumor necrosis factor and interleukin-1 alpha/beta expression and suppression. Am.J.Pathol. 137: 1173-1185, 1990.

141. Ulich T.R., Guo K.Z., Remick D., del C.J., and Yin S.M. Endotoxin-induced cytokine gene expression in vivo. III. IL-6 mRNA and serum protein expression and the in vivo hematologic effects of IL-6. J.Immunol. 146: 23162323, 1991.

142. Verma A., Hirsch D.J., Glatt C.E., Ronnett G.V., and Snyder S.H. Carbon monoxide: a putative neural messenger. Science. 259: 381-384, 1993.

143. Vicente A.M., Guillen M.I., Habib A., and Alcaraz M.J. Beneficial effects of heme oxygenase-1 up-regulation in the development of experimental inflammation induced by zymosan. J.Pharmacol.Exp.Ther. 307: 1030-1037, 2003.

144. Wagener F.A., Eggert A., Boerman O.C., Oyen W.J., Verhofstad A., Abraham N.G., Adema G., van K.Y., de W.T., and Figdor C.G. Heme is a potent inducer of inflammation in mice and is counteracted by heme oxygenase. Blood. 98: 1802-1811, 2001.

145. Wagner C.T., Durante W., Christodoulides N., Hellums J.D., and Schafer A.I. Hemodynamic forces induce the expression of heme oxygenase in cultured vascular smooth muscle cells. J.Clin.Invest. 100: 589-596, 1997.

146. Wang R., Wang Z., and Wu L. Carbon monoxide-induced vasorelaxation and the underlying mechanisms. Br.J.Pharmacol. 121: 927-934, 1997.

147. Wang S. and Hazelrigg T. Implications for bcd mRNA localization from spatial distribution of exu protein in Drosophila oogenesis. Nature. 369: 400-403, 1994.

148. Wilks A. Heme oxygenase: evolution, structure, and mechanism. Antioxid.Redox.Signal. 4: 603-614, 2002.

149. Wunder C. and Potter R.F. The heme oxygenase system: its role in liver inflammation. Curr.Drug Targets.Cardiovasc.Haematol.Disord. 3: 199-208, 2003. 
150. Yang D.C., Jiang X., Elliott R.L., and Head J.F. Antisense ferritin oligonucleotides inhibit growth and induce apoptosis in human breast carcinoma cells. Anticancer Res. 22: 1513-1524, 2002.

151. Yoshida T. and Kikuchi G. Purification and properties of heme oxygenase from rat liver microsomes. J.Biol.Chem. 254: 4487-4491, 1979.

152. Zucker S.D., Goessling W., and Hoppin A.G. Unconjugated bilirubin exhibits spontaneous diffusion through model lipid bilayers and native hepatocyte membranes. J.Biol.Chem. 274: 10852-10862, 1999. 


\section{Acknowledgements}

I want to express gratitude to Professor Giuliano Ramadori for the opportunity he gave me to work in this department and for his encouragement to perform this study. I deeply appreciate the time he spent supervising and teaching me.

I am thankful to Professor Rüdiger Hardeland for reviewing my $\mathrm{PhD}$ thesis and to Professor Kurt von Figura for being my coreviewer.

I am thankful to Professor Gerhard Burckhardt, a leader of GRK 335, for giving me the opportunity to be a scholar in the frame of GRK "Clinical, Cellular and Molecular Biology of Internal Organs", and for his help in every respect.

I am grateful to Dr. Thomas Kietzmann and Dr. Anatoly Samoylenko for their help and cooperation. I appreciate their helpful advices and the time they spent discussing our results.

My sincere thanks to Dr. Jozsef Dudas for his cooperation, practical advices and answering all my questions. I am thankful to Ruslan Novosyadlyy for his contribution to my project and cooperativeness.

I want to give my special thanks to Renate Klages for help in organizing of my work and for her constant wholehearted support in every respect.

I am very thankful to Dr. Silke Cameron for proof-read and corrections of the manuscript.

I am thankful to Missis Zachmann for help with isolation of hepatocytes and to Anke Herbst for teaching me laboratory techniques.

I thank Buba, Abdul, Velasco and all other colleagues, with whom I worked day by day in the department, for the creation of scientific working atmosphere.

My very special thanks to Dasha for her support in all respects. 


\section{Curriculum Vitae}

\begin{tabular}{|c|c|}
\hline Name & Kyrylo Tron \\
\hline Date of birth & 26.07.1977 \\
\hline Place of birth & Zhytomyr, Ukraine \\
\hline Citizenship & Ukraine \\
\hline \multirow[t]{2}{*}{$1984-1994$} & School education \\
\hline & Kiev, Ukraine \\
\hline \multirow[t]{4}{*}{$1995-2000$} & University Study \\
\hline & Biological faculty \\
\hline & Kiev National Taras Shevchenco University \\
\hline & Kiev, Ukraine \\
\hline \multirow[t]{3}{*}{1999} & Bachelor diploma with honors \\
\hline & $\begin{array}{l}\text { Degree: Bachelor of Science in biology, teacher of } \\
\text { biology }\end{array}$ \\
\hline & $\begin{array}{l}\text { Defense of Bachelor scientific project "The comparative } \\
\text { characteristic of the methods of human } \\
\text { microplasminogen purification" }\end{array}$ \\
\hline \multirow[t]{3}{*}{2000} & Master diploma with honors \\
\hline & $\begin{array}{l}\text { Degree: Master of Science in biology, biochemistry, } \\
\text { University teacher of biology }\end{array}$ \\
\hline & $\begin{array}{l}\text { Defense of Master scientific project "Isolation and study } \\
\text { of tyrosine protein kinases from rat splenocytes under } \\
\text { irradiation" }\end{array}$ \\
\hline \multirow[t]{4}{*}{$2000-2001$} & PhD Student \\
\hline & Department of biochemistry \\
\hline & Kiev National Taras Shevchenco University \\
\hline & Kiev, Ukraine \\
\hline $\begin{array}{l}\text { March } 2001 \text { - May } \\
2004\end{array}$ & $\begin{array}{l}\text { Experimental work for the present dissertation in } \\
\text { Department of Gastroenterology and Endocrinology of } \\
\text { Georg-August University Clinic (Göttingen) in the frame of } \\
\text { GRK } 335 \text { "Clinical, Cellular and Molecular Biology of } \\
\text { Internal Organs" }\end{array}$ \\
\hline
\end{tabular}

